LBNL/PUB-3277

\title{
TH_PULSE:
}

\section{Program for Calculating Infiltration of Episodic Liquid Fingers in Superheated Rock Fractures}

\author{
Theory, User's Manual, \\ and Sample Applications
}

Jens T. Birkholzer

Earth Sciences Division

Ernest Orlando Lawrence Berkeley National Laboratory

University of California

Berkeley, CA 94720

June 2002

This work was supported by the Director, Office of Civilian Radioactive Waste Management, U.S. Department of Energy, through Memorandum Purchase Order EA9013MC5X between Bechtel SAIC Company, LLC and the Ernest Orlando Lawrence Berkeley National Laboratory (Berkeley Lab). The support is provided to Berkeley Lab through the U.S. Department of Energy Contract No. DE-AC03-76SF00098. 
- II -

INTENTIONALLY LEFT BLANK. 


\title{
TH_PULSE:
}

\section{Program for Calculating Infiltration of Episodic Liquid Fingers in Superheated Rock Fractures}

\begin{abstract}
This report describes the code TH_PULSE developed at the Ernest Orlando Lawrence Berkeley National Laboratory (Berkeley Lab). The code handles gravity-driven flow of episodic infiltration events entering above-boiling rock-temperature regions. Such temperature conditions are expected, for example, after emplacement of heat-generating nuclear waste in underground repositories. Complex fluid-flow and heat-transfer phenomena occur, as the infiltrating water is subject to vigorous boiling from the hot rock. A new efficient semi-analytical method is presented herein that simulates such phenomena. It is assumed that flow forms in localized preferential flow paths (referred to as "fingers").

The first section of this report gives the conceptual and mathematical background for the solution scheme. The second section is a user's manual for TH_PULSE, providing all information required to run the code, including a detailed description of the input and output files. In the third section, the new solution scheme is applied to several test cases. Sample simulations are performed for conditions representative of the potential nuclear waste repository at Yucca Mountain, Nevada. A brief summary is given in Section 4.
\end{abstract}


INTENTIONALLY LEFT BLANK. 
\begin{tabular}{l|l} 
ABSTRACT & I
\end{tabular}

1 TH_PULSE: Motivation, Theory, and Conceptual Model 1

1.1 Motivation 1

1.2 Conceptual and Mathematical Model 3

1.2.1 Analytical Solution for the Semi-Infinite Matrix Conduction Problem 5

1.2.2 Fitting-Function Solution for the Semi-Infinite Matrix Conduction $\begin{array}{ll}\text { Problem } & 6\end{array}$

1.2.3 Analytical Solution for the Finite Matrix Conduction Problem 7

1.2.4 Finger Flow Velocity Representation 7

$\begin{array}{lll}1.3 & \text { Semi-Analytical Solution Scheme } & 10\end{array}$

2 User's Manual for TH_PULSE 13

$2.1 \quad$ Main Features $\quad 13$

2.2 Compiling and Running the Code 14

2.3 Input File Structure $\quad 14$

$\begin{array}{lll}2.4 & \text { Simulation Section } & 17\end{array}$

$\begin{array}{lll}2.4 .1 & \text { Array Allocation } & 17\end{array}$

2.4.2 Initial Setting of Hardwired Properties 18

2.4.3 Reading Input File INP 18

2.4.4 Calculation of Thermal and Flow Properties 18

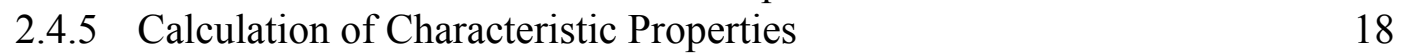

$\begin{array}{lll}2.4 .6 & \text { Discretization } & 20\end{array}$

2.4.7 Time-Marching Simulation 20

2.4.8 Postprocessing and Output of Results 21

$\begin{array}{lll}2.5 & \text { Output File Structure } & 22\end{array}$

$3 \quad$ Sample Problems $\quad 28$

$\begin{array}{lll}3.1 & \text { Introduction } & 28\end{array}$

3.2 Short-Term Finger Flow $\quad 28$

3.3 Long-Term Finger Flow 38

3.4 Code Verification $\quad \mathbf{4 2}$

3.4.1 Short-Term Verification $\quad 42$

3.4.2 Long-Term Verification 44

4 Summary 45

$\begin{array}{ll}\text { Nomenclature } & 46\end{array}$

$\begin{array}{ll}\text { Acknowledgment } & 47\end{array}$

$\begin{array}{ll}\text { References } & 47\end{array}$

Appendix A: Phillip's Analytical Solution $\quad \mathbf{5 0}$

Appendix B: Listing for Code TH_PULSE V1.0 52 
List of Figures:

Figure 1: Schematic illustration of conceptual model of infiltration in unsaturated fractured rock surrounding heat-generating nuclear waste packages in emplacement tunnels (drifts)

Figure 2: Conceptual model for liquid finger flow in a vertical fracture with heat conduction from the adjacent matrix rock

Figure 3: Different concepts for change of flow velocity as a function of mass flow rate

Figure 4: Schematic illustration of the time-marching algorithm proposed for the flow of finite submasses $M_{j}$ introduced into superheated rock

Figure 5: Examples of vertical rock temperature distributions incorporated in TH_PULSE 13

Figure 6: Schematic illustration of the sample cases 29

Figure 7: $\quad$ Penetration distance versus time for infiltration event Case 1 32

Figure 8: Penetration distance versus time for infiltration event Case 2 33

Figure 9: Maximum possible penetration versus pulse duration for infiltration event Case 1

Figure 10: Profiles of mass flow for infiltration event Case 1, at $t=60 \mathrm{~s}, 120 \mathrm{~s}$, and $150 \mathrm{~s}$

Figure 11: Profiles of mass flow for infiltration event Case 2, at $t=3 \mathrm{~s}, 9 \mathrm{~s}$, and $18 \mathrm{~s}$

Figure 12: Breakthrough of mass flow for infiltration event Case 1, at $z=0.5 \mathrm{~m}, 1 \mathrm{~m}$, and $2 \mathrm{~m}$

Figure 13: Breakthrough of mass flow for infiltration event Case 2, at $z=0.5 \mathrm{~m}, 1 \mathrm{~m}$, and $2 \mathrm{~m}$

Figure 14: Cumulative mass collected at location $z$, compared to total injected mass (in \%)

Figure 15: Penetration distance versus time for long-term simulation. Two rock boundary conditions are chosen: infinite boundary $(I R O C K=2)$ and finite boundary at $0.1 \mathrm{~m}(\operatorname{IROCK}=3)$.

Figure 16: Profiles of dimensionless mass flow for infiltration event Case 1 at $t=90 \mathrm{~s}$ and infiltration event Case 2 at $t=18 \mathrm{~s}$. The initial rock temperature is uniform. Results compare new solution scheme with TOUGH2 simulation, using three different vertical discretization lengths.

Figure 17: Penetration distance versus time, for continuous infiltration. Results compare TH_PULSE results with analytical solution for asymptotic long-term behavior. 
List of Tables:

2.3.1 INP - Input File for TH_PULSE

2.3.2 Sample Data Set INP for Case 1

2.5.1 Sample Screen Dump for Case 1

2.5.2 Sample Output File FRONT.TEC for Case 1

2.5.3 Sample Output File TOTMASS.TEC for Case 1

2.5.4 Sample Output File PROFILE.TEC for Case 1

2.5.5 Sample Output File BREAK.TEC for Case 1

3.2.1 Sample Data Set INP for Case 2

$\begin{array}{lll}\text { 3.2.2 } & \text { Sample Screen Dump for Case 2 } & 31\end{array}$

3.3.1 Sample Data Set INP for Long-Term Finger Flow with Infinite Boundary 38

3.3.2 Sample Screen Dump for Long-Term Finger Flow with Infinite Boundary 39

3.3.3 Sample Screen Dump for Long-Term Finger Flow with Finite Boundary 
- VIII -

INTENTIONALLY LEFT BLANK. 


\section{TH_PULSE: Motivation, Theory, and Conceptual Model}

\subsection{Motivation}

Heat released from high-level nuclear waste packages in a partially saturated environment can have a major impact on moisture distribution and migration. At Yucca Mountain, Nevada, the potential repository horizon is located in thick, partially saturated tuff formations that contain more than $80 \%$ liquid water in the pore space. As formation temperatures approach and exceed the boiling point at prevailing pressures, pore water vaporizes and a hot dry-out region develops in the vicinity of the waste emplacement tunnels. Since liquid water infiltrating down towards the repository will be subject to strong vaporization, the superheated rock zone forming above the repository may significantly reduce the possibility of water contacting the waste packages [Ramspott, 1991; Nitao et al., 1992; Wilder, 1993; Buscheck and Nitao, 1993]. The amount of infiltrating water that can reach the emplacement tunnels has significant implications for the integrity of the waste canisters and the subsequent release of contaminants.

The thermally driven flow processes to be expected at Yucca Mountain have been analyzed in a combined program of field, laboratory, and theoretical studies. There is a long record of mathematical modeling studies devoted to the prediction of the future thermal-hydrological conditions in the unsaturated environment [Nitao et al., 1992; Pruess and Tsang, 1993, 1994; Pruess et al., 1984, 1985, 1988, 1990a, b; Tsang and Pruess, 1987, 1989]. Typically, these studies have demonstrated that a large, superheated dry rock region will form for several thousand years at Yucca Mountain, and that during this period, infiltrating liquid water is not expected to contact waste packages. These findings have been supported by measured data - and associated numerical modeling work - collected from in situ heater experiments, such as the Single Heater Test and the Drift Scale Test, in which conditions around the heat sources are typically "hot and dry", and significant amount of seepage into drifts is not observed [Tsang and Birkholzer, 1999; Birkholzer and Tsang, 2000].

However, there is concern that the exclusion of liquid water from the hot rocks may not be absolute [Pruess and Tsang, 1994]. The amount of water that can be generated by vaporizationcondensation processes is potentially very large. Condensate will form a halo of elevated liquid saturation just outside the dry-out region, and thus provide a localized source of continuous or episodic water flow. Although the above modeling studies are capable of predicting the relevant physical processes (such as the significant vaporization-condensation cycles), they typically involve some sort of volume averaging and homogenization of heterogeneous formation properties. As a result, the model results tend to underestimate the probability of preferential localized pathways that may carry liquid water at flow rates much larger than average infiltration. Also, since spatially uniform flow in fractures is assumed, they overestimate vaporization effects, caused by the much larger cross-sectional area between the flowing liquid and the adjacent hot rock, compared to preferential-flow-path models [Pruess, 1997].

In recent years, a number of laboratory, field, and theoretical studies have been performed to analyze localized preferential flow paths in unsaturated sub-boiling fractures [e.g., Glass, 1993; Nicholl et al., 1994; Glass and Nicholl, 1996; Pruess, 1998; Su et al., 1999]. It was consistently observed that liquid flow forms in narrow fingers under mainly gravitational forces, and that fingering flow often occurred in intermittent rivulets, induced by gravitational instability. Kneafsey and Pruess [1998] reported similar findings in a laboratory experiment performed for 
above-boiling conditions, analyzing heat-driven two-phase flow in artificial fracture replicas. $\mathrm{Ho}$ and Wilson [1998] proposed a conceptual model for unsaturated infiltration at Yucca Mountain that assumes discrete ribbon-type vertical flow paths (weeps) of given spacing and episodicity.

The above considerations suggest that the probability of infiltrating water reaching emplacement tunnels at above-boiling conditions must be estimated using a preferential-flowpath model. In 1996, Phillips presented an analytical solution for the penetration of a liquid finger in superheated rock. Though the simple conceptual model proposed by Phillips is very useful for understanding basic phenomena, his analytical solution was derived using a heatbalance assumption that makes the solution applicable only at large time scales, ones that exceed the time periods relevant for flow of episodic infiltration events. The objective of this report is to provide a fast and simple tool for calculating gravity-driven finger flow in superheated rock, to study mechanisms controlling the infiltration of episodic and continuous flow events at aboveboiling conditions. A new semi-analytical time-marching algorithm is presented that tracks the movement of water pulses while considering mass losses resulting from water vaporization. The underlying conceptual model is similar to that proposed in Phillips [1996]; however, the new solution scheme is valid both for early and late time periods. Mainly for illustration purposes, the new method is applied to a variety of test cases somewhat typical for the future conditions at Yucca Mountain during the heating phase of the repository.

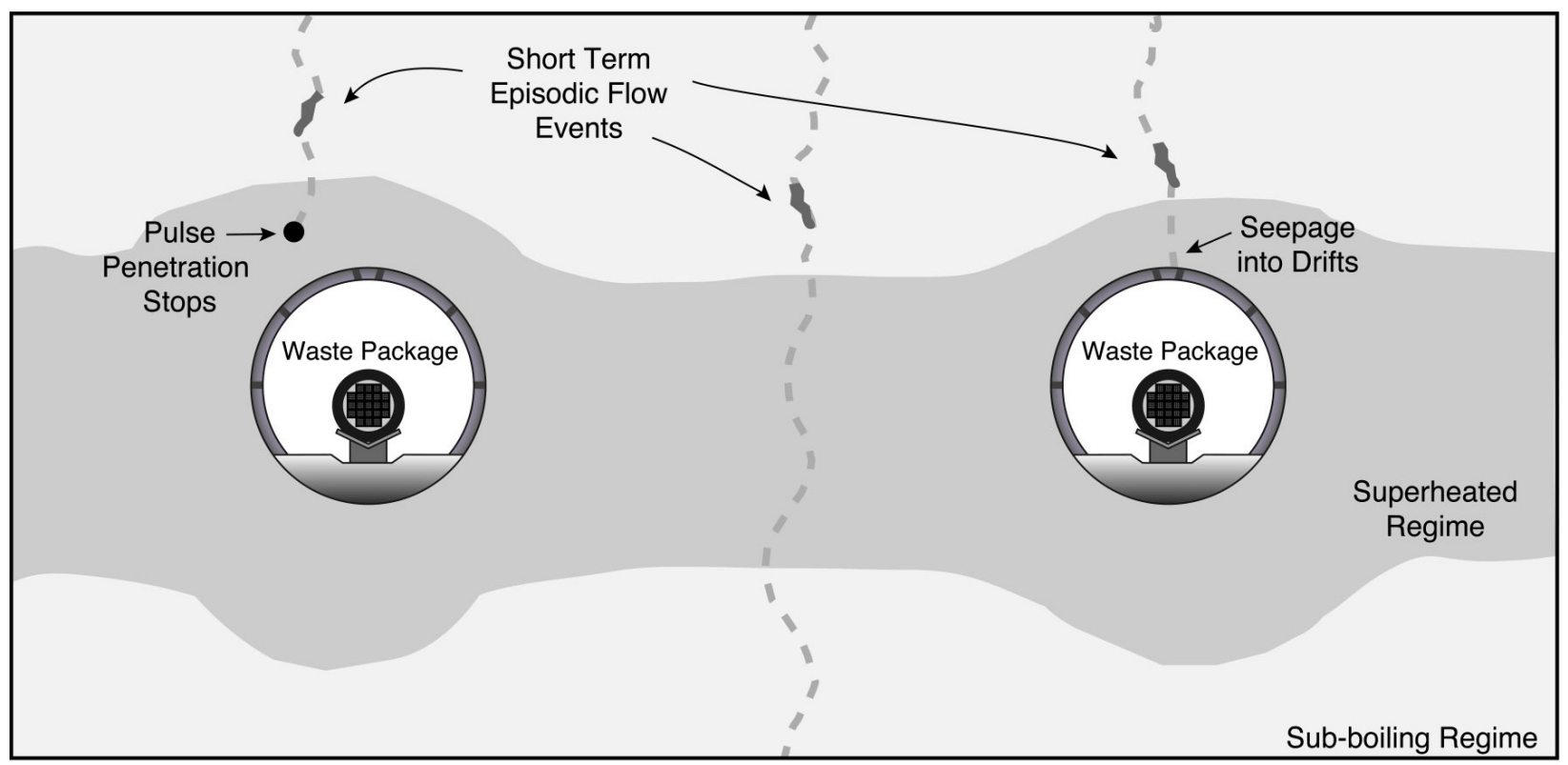

Figure 1: Schematic illustration of conceptual model of infiltration in unsaturated fractured rock surrounding heat-generating nuclear waste packages in emplacement tunnels (drifts)

Figure 1 illustrates the relevant processes studied: it is assumed that episodic infiltration events are induced by gravitational instabilities somewhere in the condensation zone above the repository. Finger-type fast flow is directed towards the superheated region around the waste emplacement tunnels, hereafter referred to as "drifts." Depending on magnitude and duration of flow, and temperature and pressure conditions, some liquid pulses will completely vaporize, whereas others may penetrate significantly into the superheated region and eventually reach the 
waste canisters. Thus, for given episodic flow events, it is important to estimate the maximum penetration distance of the liquid finger, the decrease of mass flow resulting from boiling, and possibility that part of the liquid may escape vaporization and eventually reach the emplacement drifts. The code TH_PULSE presented in this report allows for such analysis.

\subsection{Conceptual and Mathematical Model}

The processes described above are represented using a simple conceptual model as depicted in Figure 2, showing a typical situation close to a representative waste emplacement drift. A superheated region of rock has developed around the drift, extending to a distance $L$ above the drift crown. As the ambient rock water has long been boiled off, fractures and rock are dry. The temperature field is assumed to be uniform in the lateral $x$-direction and a function of location in the vertical $z$-direction $\left(T_{R I}=f(z)\right)$.

Above the superheated rock, a sub-boiling region is established that may hold substantial amounts of water, both from ambient saturation of matrix pore volume and condensation of vapor caused by heating. Liquid infiltration events of constant mass flow rate $m_{P}$ with a given pulse duration $t_{P}$ can form somewhere in this sub-boiling region. Note that these pulses may be either episodic with finite $t_{P}$ or continuous with infinite $t_{P}$. The water moves downward under gravity in a single vertical fracture of uniform aperture $(2 b)$. Within the fracture plane, a fingering flow with uniform ribbon or "finger" width $w$ is assumed. Lateral spreading of the ribbon is not considered, and flow is strictly one-dimensional. Typically, the ribbon width is much larger than the fracture aperture.

In the sub-boiling region, the liquid finger infiltrating down toward the superheated region is assumed to be in thermal equilibrium with the surrounding rock. By heat conduction from the rock, the water is heated up to almost boiling temperature when the boiling-point isotherm is approached. Because the rock matrix has very low permeability, the only relevant contribution to heat transport in the matrix comes from conduction. Imbibition of the infiltrating water into the rock is neglected. Thus, in the sub-boiling region, the mass flow rate $m_{P}$ of the flow event is uniform in space and has a constant duration $t_{P}$.

At time $t=0$, the liquid finger penetrates past the boiling-point isotherm and enters the superheated region. The assumption is that water has already reached boiling temperature $T_{P}$ at time $t=0$ and remains at $T_{P}$ for all times $t>0$. As the liquid finger travels down the fracture in the superheated region, part of the water vaporizes as a result of the thermal energy provided by

the surrounding hot rock faces. It is assumed that the energy resistance at the contact between the fracture and the rock is negligible. Therefore, the rock surface instantaneously cools to boiling temperature, and a steep temperature gradient is established in the surrounding matrix as soon as the liquid front in the fractures reaches the considered position. With time, the thermal perturbation penetrates further into the rock, the thermal gradient decreases, and heat flow from the matrix to the fracture is reduced. Heat conduction in the matrix is very slow compared to the vertical movement of the liquid pulse. Consequently, the lateral gradient in the rock is much larger than the vertical gradient, and the conductive heat flow within the matrix and from the matrix to the fracture is assumed to be strictly lateral, perpendicular to the fracture plane. 


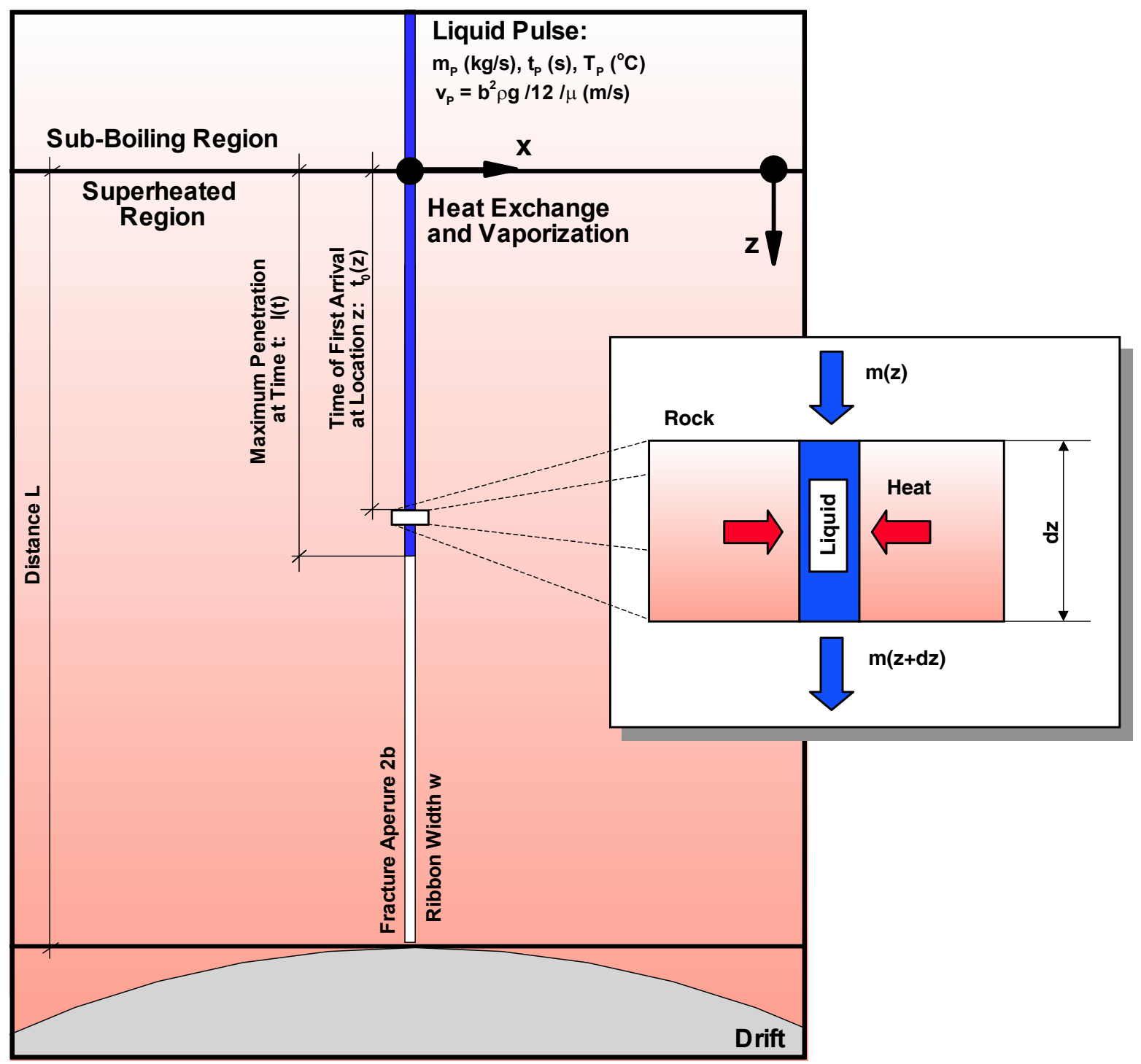

Figure 2: Conceptual model for liquid finger flow in a vertical fracture with heat conduction from the adjacent matrix rock

The maximum penetration of a given liquid pulse into the superheated region depends on the different time and length scales involved as well as on the relative intensity of mass flow in the fracture and heat flow in the rock. Considering the above assumptions and neglecting advection and diffusion of heat within the liquid ribbon (i.e., constant liquid temperature $T_{P}$ ), we can formulate a simple energy balance equation:

$$
h \frac{\partial m(z, t)}{\partial z}=-\left.2 w k_{m} \frac{\partial T_{R}(x, z, t)}{\partial x}\right|_{x=0},
$$

where $h$ is specific enthalpy of vaporization, $m$ is mass flow rate, $w$ is finger width, $k_{m}$ is rock thermal conductivity, and $T_{R}$ at is rock temperature. The left side of Equation (1) gives the energy required to vaporize a fraction of the liquid mass flow in the fracture, while the right side of Equation (1) denotes the energy supplied from the rock by conduction, calculated from the 
temperature gradient at the rock-fracture interface. The coordinate $z$ denotes the distance down the fracture below the undisturbed position of the boiling-point isotherm. The liquid front enters the superheated region at $t=0$. At location $z=0$ and within time period $0<t \leq t_{P}, m(0, t)=m_{P}$.

The lateral temperature distribution in the rock is governed by the one-dimensional heat conduction equation

$$
\frac{\partial T_{R}(x, t)}{\partial t}=\kappa \frac{\partial^{2} T_{R}(x, t)}{\partial x^{2}}
$$

where $\kappa$ is rock thermal diffusivity. The boundary conditions are as follows:

$$
\begin{array}{ll}
T_{R}(0, t)=T_{R I}, & \text { for } z>l(t) \\
T_{R}(0, t)=T_{P}, & \text { for } z \leq l(t) \\
T_{R}(\infty, t)=T_{R I}, & \text { for all } t .
\end{array}
$$

Here, $l(t)$ is the infiltration distance of the liquid front at time $t$. As long as the front has not arrived at location $z$, the rock temperature $T_{R}$ at the fracture-rock interface (i.e., at $x=0$ ) remains undisturbed and equal to the initial rock temperature $T_{R I}$. However, as soon as the liquid pulse moves to the considered location, $T_{R}(0, t)$ instantaneously decreases to the liquid pulse temperature $T_{P}$. At $x=\infty$, far away from the fracture, the rock matrix temperature remains unchanged from its initial value $T_{R I}$. This latter boundary condition can be relaxed, however, and instead, a constant temperature boundary condition could be assumed at a finite distance $d$ into the rock:

$$
T_{R}(d, t)=T_{R I}, \quad \text { for } z \leq l(t)
$$

\subsubsection{Analytical Solution for the Semi-Infinite Matrix Conduction Problem}

An analytical solution is readily available for the matrix conduction problem as given in Equation (2) with the boundary conditions (3), (4), and (5) [e.g., Carslaw and Jaeger, 1959, pp. $58 \mathrm{ff}]$. Let $t_{0}(z)$ be the time measured from initial infiltration across $z=0$ until the arrival of the tip of the liquid finger at location $z$. Then, the lateral rock-temperature distribution at location $z$ and time $t$ is given as

$$
T_{R}(x, z, t)=T_{P}+\left(T_{R I}-T_{P}\right) \operatorname{erf}\left(\frac{x}{2 \sqrt{\kappa\left(t-t_{0}(z)\right)}}\right), \quad \text { for } z \leq l(t), t>t_{0}(z)
$$

while the temperature gradient at $x=0$ becomes

$$
\left.\frac{\partial T_{R}}{\partial x}(z, t)\right|_{x=0}=\frac{T_{R I}-T_{P}}{\sqrt{\pi \kappa\left(t-t_{0}(z)\right)}} .
$$

Inserting Equation (8) into Equation (1) and performing slight rearrangements results in

$$
\frac{\partial m(z, t)}{\partial z}=-\frac{2 w k_{m}}{h} \frac{T_{R I}-T_{P}}{\sqrt{\pi \kappa\left(t-t_{0}(z)\right)}} .
$$


This equation is valid as long as the thermal perturbation in the rock is nearly uniform across the width of the liquid finger. Since thermal perturbation grows with $(\kappa t)^{1 / 2}$, the maximum time period $t_{m}$ associated with uniform thermal perturbation is of order

$$
t_{m}=\frac{w^{2}}{\kappa} .
$$

For $t>t_{m}$, the nearly one-dimensional heat flow perpendicular to the fracture-rock interface transforms to a more circular spreading of heat, and Equation (9) can no longer be applied. However, in most cases of practical concern, $t_{m}$ is much larger than the time scale of interest.

Equation (9) gives the change of mass flow rate, caused by the vaporization of water, as a function of time and space. Despite its simplicity, this equation is very hard to solve analytically. One reason is that $m(z, t)$ depends on the front arrival time $t_{0}(z)$, which is unknown prior to solving the equation. Here it is important to realize that the velocity of water flowing in the liquid ribbon is very different from the apparent velocity of the movement of the tip of the liquid finger, since the front penetration slows down significantly as more and more water vaporizes. Therefore, $t_{0}(z)$ cannot be estimated from the flow velocity of the liquid ribbon water. Another complicating factor is that the initial rock temperature $T_{R I}$ can be any given function of vertical coordinate $z$. We therefore use a semi-analytical solution scheme for Equation (9) that is explained in Section 1.3.

\subsubsection{Fitting-Function Solution for the Semi-Infinite Matrix Conduction Problem}

As an alternative to the above exact solution, model users can choose to approximate the rock temperature distribution utilizing a simple trial function, as proposed in Vinsome and Westerveld [1980]. This method has been shown to give good accuracy for heat exchange between reservoir fluids and confining beds [e.g., Pruess et al., 1999]. In TH_PULSE, the method was included mainly to allow direct comparison with TOUGH2 simulation runs, where the same heat exchange approach can be utilized. Default choice, however, should be the exact analytical solution of Section 1.2.1, because it eliminates trial-function errors. Note that the method of Vinsome and Westerveld [1980] allows for time-varying temperature boundary conditions at the fracture-rock interface, in contrast to the above analytical solution. Thus the fitting-function solution would be the method of choice for a possible future extension of TH_PULSE to account for cyclic heating and cooling phases.

Vinsome and Westerveld [1980] proposed to represent the lateral temperature profile in a semi-infinite rock block as follows

$$
T_{R}(x, z, t)=T_{P}+\left(T_{R I}-T_{P}+p x+q x^{2}\right) \exp \left(\frac{-2 x}{\sqrt{\kappa\left(t-t_{0}(z)\right)}}\right) . \quad \text { for } \mathrm{z} \leq 1(\mathrm{t}), \mathrm{t}>\mathrm{t}_{0}(\mathrm{z})
$$

Here, $p$ and $q$ are fitting coefficients that are different for each location and time step. They are determined concurrently with the time-marching algorithm from the physical constraints of (1) continuity of heat flux across the rock-fracture interface at $x=0$ and (2) energy conservation for the semi-infinite rock. After determination of $p$ and $q$, the heat flux at the interface is readily derived, and the change of mass flow rate as a result of water vaporization is given as: 


$$
\frac{\partial m(z, t)}{\partial z}=-\frac{4 w k_{m}}{h}\left(\frac{T_{R I}-T_{P}}{\sqrt{\kappa\left(t-t_{0}(z)\right)}}-p\right) .
$$

This resulting equation for mass flow rate is solved utilizing the semi-analytical time-marching scheme proposed in Section 1.3. Note that the maximum time period for application of Equation (12) is $t_{m}$, given in Equation (10).

\subsubsection{Analytical Solution for the Finite Matrix Conduction Problem}

For a finite-sized matrix, a fixed rock-temperature boundary condition is set at a finite distance $d$ from the fracture-rock interface (Eq. (6)). An analytical solution can be derived for this case as well; however, the resulting equations are slightly more complicated and involve numerical integration. For the finite case, the lateral rock-temperature distribution at any location $z$ and time $t$ is

$$
T_{R}(x, z, t)=T_{P}+\left(T_{R I}-T_{P}\right)\left(1-\frac{x}{d}-\frac{2}{\pi} S U M\right), \quad \text { for } z \leq l(t), t>t_{0}(z)
$$

where

$$
\begin{gathered}
S U M=\sum_{n=1}^{\infty} \frac{1}{n} \exp \left(-\pi^{2} n^{2} \lambda\right) \sin \left(\frac{n \pi x}{d}\right), \\
\lambda=\frac{\kappa\left(t-t_{0}(z)\right)}{d^{2}} .
\end{gathered}
$$

Then the temperature gradient at $x=0$ becomes

$$
\left.\frac{\partial T_{R}}{\partial x}(z, t)\right|_{x=0}=-\frac{T_{R I}-T_{P}}{d}\left(1+2 \sum_{n=1}^{\infty} \exp \left(-\pi^{2} n^{2} \lambda\right)\right),
$$

and the change of mass flow rate is finally given as

$$
\frac{\partial m(z, t)}{\partial z}=-\frac{2 w k_{m}}{h} \frac{T_{R I}-T_{P}}{d}\left(1+2 \sum_{n=1}^{\infty} \exp \left(-\pi^{2} n^{2} \lambda\right)\right) .
$$

The maximum time period for application of this equation is limited by Equation (10). Note that the front arrival time $t_{0}(z)$, hidden in the expression for $\lambda$, is unknown prior to the solution of Equation (17). Again, the governing equation for mass flow rate cannot be solved in a direct analytical manner.

\subsubsection{Finger Flow Velocity Representation}

The front penetration of the liquid finger in the superheated rock is governed by the nature of flow in the fracture, generally influenced by gravity, viscous and capillary forces, and mass losses as a result of vaporization effects. The crucial question is how these flow characteristics change when more and more water is boiled off. It is not easy to develop a simplified but appropriate conceptual model for the flow characteristics in a liquid finger with decreasing mass flow rate. We may start by describing undisturbed flow in a sub-boiling environment, just above the superheated region, so that the water temperature is already close to boiling. The simplifying assumptions are that flow in the fracture is laminar and fully developed and that a parallel-plate 
representation of the fracture plane can be applied. As hysteretic effects are neglected (i.e., air entry pressure at the end of the pulse is equal to water entry pressure at the tip of the pulse), only gravity forces are relevant. With these assumptions, the flow velocity $v_{P}$ in the finger can be approximated as follows:

$$
v_{P}=\frac{(2 b)^{2}}{12} \frac{\rho_{l} g}{\mu},
$$

using boiling-point values for liquid density, $\rho_{l}$, and liquid viscosity, $\mu$. Multiplying velocity with cross-sectional area and liquid density gives the mass flow rate $m_{P}$

$$
m_{P}=(2 b) w \rho_{l} v_{P} .
$$

This flow behavior changes as the pulse enters the superheated region and part of the water is boiled off. Obviously, the relevant processes occur on a very small (pore) scale, and cannot be modeled by well-known characteristic relationships between relative permeability, saturation, and capillary pressure used for macroscopic scales. For discussion, let us assume that flow of the liquid finger is dominated by gravity force. Then, as the driving force for flow is constant, the relative permeability $\mathrm{k}_{\mathrm{r}}$ is simply equal to the ratio between the mass flow of the liquid pulse in the superheated rock $m(z, t)$ and the undisturbed mass flow $m_{P}$. Let us also assume that flow in the liquid finger may become partially saturated with saturation $S_{l}\left(0 \leq S_{l} \leq 1\right)$, and that the width of the ribbon remains unchanged. Then, the flow velocity in the liquid finger at location $z$ and time $t$ can be estimated from the mass flow rate divided by cross-sectional area and saturation:

$$
v(z, t)=\frac{1}{S_{l}} \frac{m(z, t)}{(2 b) w \rho_{l}} .
$$

Scaling Equation (20) by the undisturbed flow velocity $v_{P}$, one arrives at the following relationship between dimensionless flow velocity $v(z, t) / v_{P}$ and dimensionless mass flow $m(z, t) / m_{P}$

$$
\frac{v(z, t)}{v_{P}}=\frac{1}{S_{l}} \frac{m(z, t)}{m_{P}}=\frac{k_{r}}{S_{l}} .
$$

We have plotted this relationship in Figure 3 considering different possible scenarios. There are two bounding cases:

- A lower bound for flow velocity in the superheated environment is provided by assuming that flow is always fully developed and the saturation in the liquid finger remains at its initial value (i.e., $S_{l}=1$ ). (This scenario was used by Nitao and Buscheck [1991], studying liquid infiltration into a fracture under the influence of matrix imbibition.) Flow velocity in the liquid finger changes linearly with mass flow rate $\left(v(z, t) / v_{P}=m(z, t) / m_{P}=k_{r}\right)$, which gives rise to a significant decrease of $v(z, t)$ as vaporization becomes effective. The assumption of $S_{l}=1$ forces the penetrating front to slow down such that the liquid finger is always saturated despite the mass losses. Solution of this scenario provides a lower estimate for the front penetration, as two mechanisms act to delay the front: (1) complete vaporization of water at the tip of the pulse and (2) a decrease in flow velocity in response to mass losses.

- The upper bound for flow velocity is defined by the assumption that saturation in the liquid finger decreases linearly with the decreasing mass flow rate (i.e., $S_{l}=m(z, t) / m_{P}=k_{r}$ ). In this scenario, the flow velocity of water traveling down the fracture remains constant at its initial value $v_{P}$, as long as water is available $\left(v(z, t) / v_{P}=1\right)$. Here, front penetration is delayed 
compared to the undisturbed flow velocity $v_{P}$ by only one of the above mechanisms: by vaporization of water at the tip of the moving front. Solution of this scenario provides an upper estimate for the front penetration of a liquid pulse.

For illustrative purposes, we have also plotted a typical characteristic relationship for relative permeability as a function of saturation, used for macro-scale representation of partially saturated porous media. As an example, we apply Corey's definition [Corey, 1954] where $k_{r}=$ $\left(S_{l}\right)^{4}$, using a residual saturation value of zero for both liquid and gas phases. Inserting this definition into Equation (21) gives dimensionless velocity $v(z, t) / v_{P}=\left(m(z, t) / m_{P}\right)^{0.75}$. In Figure 3, Corey's curve is bounded between the aforementioned scenarios; however, it is closer to the linear formulation in the first scenario. Apparently, the first scenario formulates an extreme example of a macro-scale characteristic function, indicating that the underlying assumption may not be applicable on the relevant pore scale.

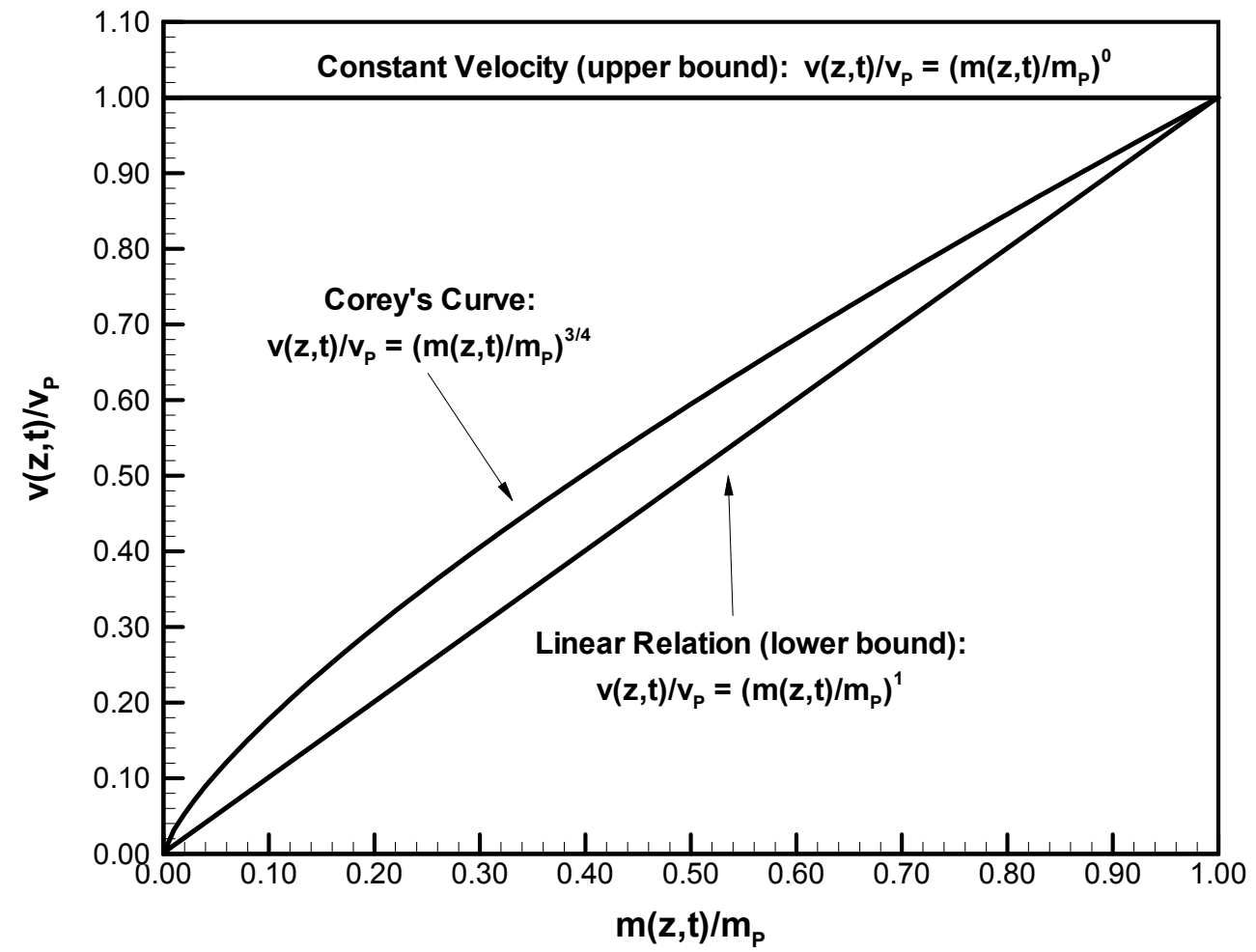

Figure 3: Different concepts for change of flow velocity as a function of mass flow rate

It is difficult to postulate which one of the above scenarios is more realistic in a natural fracture. The experiments performed by Kneafsey and Pruess [1998] clearly demonstrate the potential of gravity-driven fingers forming above and penetrating into superheated rock; however, the length scale of the experiment was too small to suggest preference of one scenario over the other. In a conservative approach, TH_PULSE assesses a worst-case scenario with the upper bound assumption that water saturation $\bar{S}_{l}=m(z, t) / m_{P}=k_{r}$. Here, the flow velocity of water remains constant and retardation of the liquid front is a result of vaporization only. This provides upper limits for the potential of liquid pulses penetrating into superheated rock. Future work should be directed towards appropriately designed laboratory experiments that help to improve our understanding of liquid finger flow in hot rock and allow us to validate (or adjust) the simplified assumptions of the above conservative conceptual model. 


\subsection{Semi-Analytical Solution Scheme}

A simple Lagrangian solution approach is developed for the mass flow of liquid pulses in a fractured superheated regime as described by Equations (9), (12), or (17). In this approach, a time-marching algorithm tracks the movement of small submasses of water traveling downwards while considering the liquid mass losses caused by vaporization. This straightforward technique allows for a very fast and robust solution and can serve as a tool to investigate and understand the nature of the physical processes involved. The general strategy of the solution procedure is similar for all three of the above equations; the only difference is that the energy exchange is calculated from slightly different analytical expressions. In the following, we will use Equation (9) as an example; solution of the other two rock-temperature representations follows from this example in a straightforward manner.

A schematic of the general solution procedure is given in Figure 4. The total liquid mass $M_{P}$ of the infiltration event, given as $M_{P}=m_{P} t_{P}$, is discretized into $n_{\text {Mass }}$ small submasses $M_{j}$ ("buckets"). Starting at $t=0$, these submasses are subsequently introduced into the superheated region at $z=0$ until the episodic infiltration event has ended. With the time-step size chosen to be $d t=t_{P} / n_{\text {Mass }}$, exactly one bucket is released within each time step. Following the discussion in Section 2, we assume for the flow of each submass: (1) a constant flow velocity v independent of the change of mass caused by vaporization and (2) gravity-driven flow neglecting capillarity differences within the liquid ribbon. We divide the solution space into uniform vertical space increments of length $d z=v_{P} d t$. This way we assure that the buckets move from one space increment $i$ to the next downward space increment $i+1$ within the exact time step interval $d t$. The total number of space increments $n_{z}$ is given by $n_{z}=L_{S} / d z$, where $L_{S}$ is the vertical extent of the solution domain (i.e., vertical extent of superheated regime below boiling-point isotherm.).

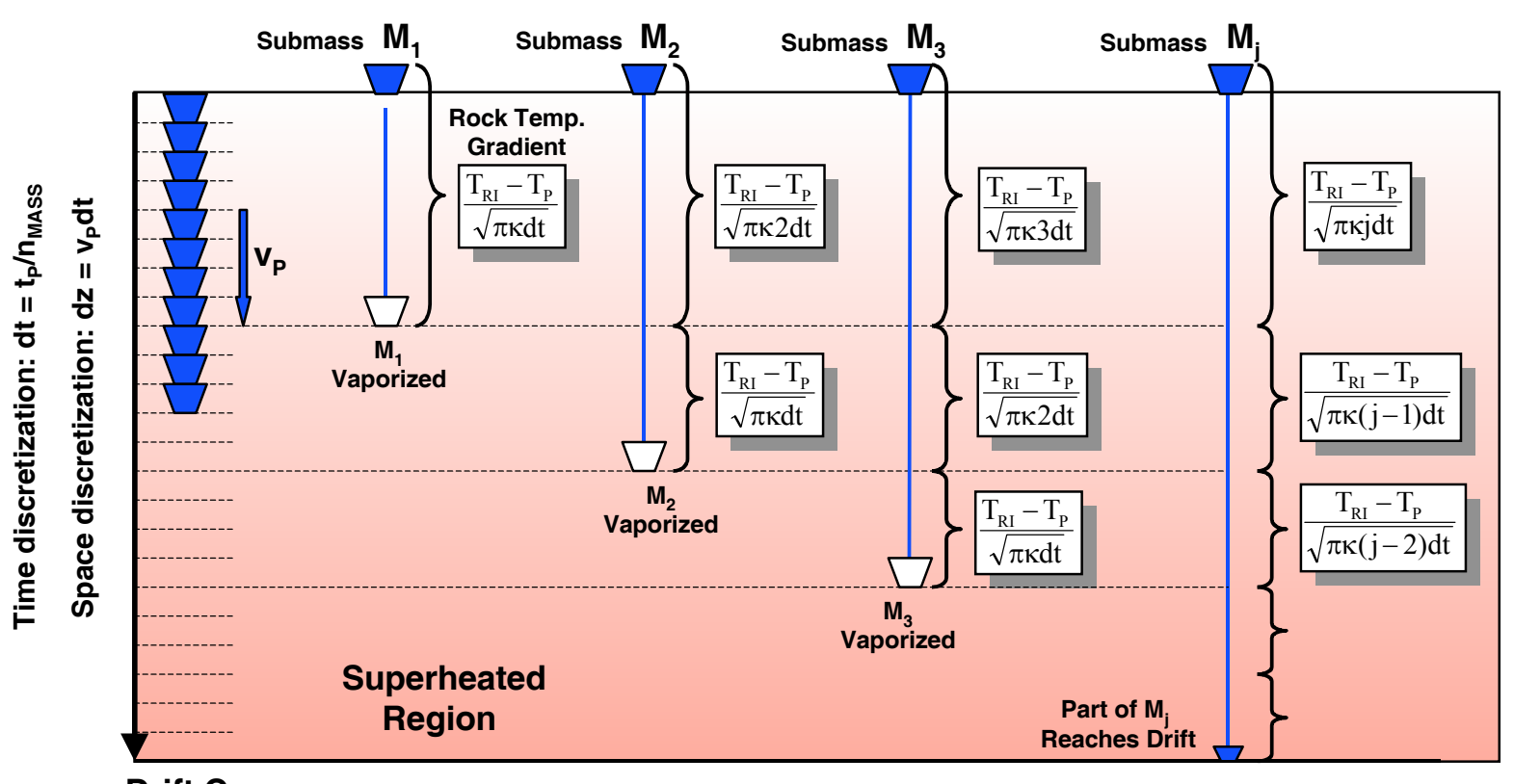

Drift Crown

Figure 4: Schematic illustration of the time-marching algorithm proposed for the flow of finite submasses $M_{j}$ introduced into superheated rock 
For each submass $M_{j}\left(j=1, n_{\text {Mass }}\right)$, the change of mass caused by water vaporization along the vertical distance $d z$ is calculated using Equation (9) in its discrete form

$$
\frac{d M_{j}}{d z}=-d t \frac{2 w k_{m}}{h} \frac{T_{R I}-T_{P}}{\sqrt{\pi \kappa\left(t-t_{0}(z)\right)}} .
$$

Equation (22) can be solved for each submass independently from the other submasses. The solution is trivial as long as the rock temperature field is known at all locations along the flow path of each submass. This is easily achieved by consecutively solving one submass after the other and accounting for the times when the rock temperatures were first being perturbed from the liquid front penetrating in the fracture. For each submass $M_{j}$, the rock-temperature information needed is collected from the solution for the previously released submasses. The mass flow rate $m(z, t)$ of the liquid pulse is immediately given after solving Equation (22).

For a better understanding of the physical processes, let us follow a few submasses on their way down the superheated regime (Figure 4). For the first submass $M_{1}$, the surrounding rock temperature at any location $z$ along the fracture is still at initial value $T_{R I}$ before $M_{1}$ arrives. If we solve Equation (22) using the rock temperature distribution at the end of each time step (fully implicit scheme), the time interval in this equation, $t-t_{0}(z)$, is simply the time step size $d t$, for all space increments along the infiltration of submass $M_{l}$. Consequently, the resulting temperature gradient at the fracture-rock interface is given as

$$
\frac{T_{R I}-T_{P}}{\sqrt{\pi \kappa d t}},
$$

which will be referred to as $T^{\prime}$ hereafter. Because $d t$ is small, $T^{\prime}$ is very steep, and the available water mass $M_{l}$ vaporizes rapidly. Eventually, at some distance $l_{l}$, the water has completely vanished and the penetration of the first bucket has ended.

The second submass $M_{2}$, introduced immediately after the first one, will move part of the way down in a rock-temperature field that has already cooled down to boiling temperature $T_{P}$ one time step earlier. Thus along distance $l_{1}$, the time interval in Equation (12), $t$ - $t_{0}(z)$, becomes $2 d t$ and the temperature gradient at the fracture-rock interface is

$$
\frac{1}{\sqrt{2}}\left(\frac{T_{R I}-T_{P}}{\sqrt{\pi \kappa d t}}\right),
$$

The rate of vaporization for submass $M_{2}$ is smaller than for $M_{1}$, and it will penetrate further into the superheated region before the available water mass has vanished. Let $l_{2}$ be the maximum penetration of the second bucket before the water has completely vaporized. Along the additional penetration distance, $l_{2}-l_{1}$, the temperature of the surrounding rock has not been disturbed earlier, so that the temperature gradient at the fracture-rock interface is equal to $T$ ' and the rate of vaporization is as high as for the first bucket.

It follows that a third bucket would see smaller thermal gradients along $1_{2}$ compared to submass $M_{2}$, and thus penetrate to a distance $l_{3}>l_{2}$; a fourth bucket would see smaller thermal gradients along $l_{3}$ compared to submass $M_{3}$ and travel to a distance $l_{4}>l_{3}$, and so forth. On its way down, bucket $M_{3}$ would experience rock-interface thermal gradients of $T^{\prime} / 3^{1 / 2}, T^{\prime} / 2^{1 / 2}$ and $T^{\prime}$ for penetration distances 0 to $l_{1}, l_{1}>l_{2}$ and $l_{2}>l_{3}$, respectively; while bucket $M_{4}$ faces thermal gradients of $T^{\prime} / 4^{1 / 2}, T^{\prime} / 3^{1 / 2}, T^{\prime} / 2^{1 / 2}$ and $T^{\prime}$ for travel distances 0 to $l_{1}, l_{1}>l_{2}, l_{2}>l_{3}$ and $l_{3}>l_{4}$, 
respectively. We may generalize these findings for submass $M_{j}\left(j=1, n_{\text {Mass }}\right)$ with an associated maximum penetration distance of $l_{j}$. It can easily be found that in a given distance interval, $l_{k-1}-l_{k}$ $(k=1, j)$, the rock-surface temperature-gradient is given as follows:

$$
\frac{1}{\sqrt{j-(k-1)}}\left(\frac{T_{R I}-T_{P}}{\sqrt{\pi \kappa d t}}\right)=\frac{1}{\sqrt{j-(k-1)}} \mathrm{T}_{1} \text {. }
$$

This means that the temperature gradient is always largest at the tip of the front (i.e., for $k=j$ ), and it is smallest at the end of the liquid pulse close to $z=0$ (i.e., for $j=n_{\text {Mass }}$ and $k=1$ ).

Several interesting implications follow from the aforementioned simple considerations:

1. The penetration distance of the tip of the moving liquid front versus time can easily be derived by obtaining the maximum penetration distance $1_{j}$ of each submass $M_{j}$ and calculating the time when this submass has reached its maximum penetration.

2. The maximum penetration of an episodic pulse is defined by the distance that the last submass penetrates into the superheated region before it has completely boiled off. At this time, all water has vanished and the liquid pulse flow event has ended.

3. Since submasses of water have completely vaporized at a certain distance from the boiling-point isotherm and only later submasses will reach further penetration distances, the apparent penetration of the tip of the liquid front is much slower than the actual flow velocity $v_{P}$. Only for the first bucket is the penetration velocity equal to the actual flow velocity. The second is already delayed by one time step $d t$ when it reaches its maximum penetration distance, the third by two time steps, and so forth. The longer the infiltration event, the more the penetration velocity deviates from the actual velocity of flow in the liquid ribbon. Thus, there are two major flow periods: (1) at early times, front propagation is governed by the gravity-driven flow behavior in the fracture, influenced slightly by conduction from the matrix; (2) at later times, boiling of water significantly retards the frontal advance, and the front penetration velocity is much smaller than the gravity-driven flow velocity $v_{P}$.

4. Even if a liquid pulse reaches the location of interest in the superheated zone (e.g., a waste emplacement drift), the remaining liquid mass may be much smaller than the total mass injected at the top. The cumulative amount of water can easily be derived by adding up the individual submasses arriving at this location. 


\section{User's Manual for TH_PULSE}

\subsection{Main Features}

TH_PULSE calculates the change of mass flow rate of a liquid finger infiltrating down a fracture in a superheated rock environment. The calculation is performed for liquid pulses of given initial mass flow rate, duration, and geometry. Different representations of the rock matrix temperature field can be chosen; e.g., semi-infinite or finite boundary conditions in lateral direction; uniform, constant gradient, or square-function representation of the initial rock temperature field in vertical direction (see Figure 5). More complicated vertical representations can be easily adopted, but have not been implemented in the current version of TH_PULSE. Spatial and temporal discretization is calculated internally according to numerical requirements, with initial values for maximum time step and maximum space increment provided by the user. Output from the code is provided in different ways:

1. Several parameters are written to desktop during simulation, providing information about the flow behavior, discretization, and progress of simulation. Also listed is the maximum penetration of the pulse, and the amount of water accumulated at the drift wall.

2. Output files are written for postprocessing of results, containing penetration depth versus time (FRONT.TEC), cumulative water mass versus location (TOTMASS.TEC), mass breakthrough at given locations (BREAK.TEC), and mass profiles at given time steps (PROFILE.TEC).

Several built-in control mechanisms ensure that during simulation, (a) the maximum array allocation is not exceeded, (b) numerical requirements concerning accuracy of the code are met, and (c) non physical input of pulse properties is corrected (e.g., mass flow larger than saturated finger flow capacity).

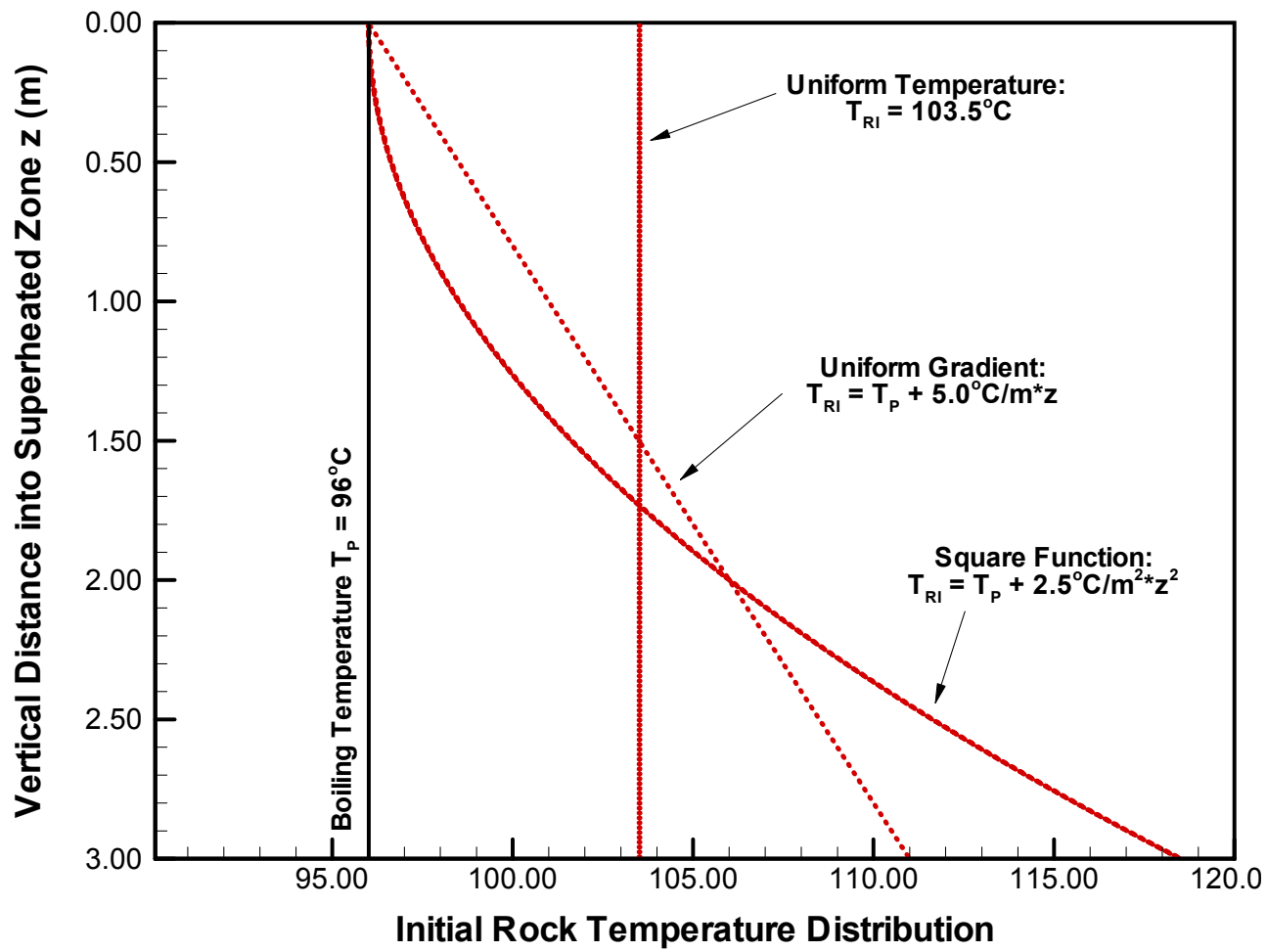

Figure 5: Examples of vertical rock temperature distributions incorporated in TH_PULSE 


\subsection{Compiling and Running the Code}

TH_PULSE is written in FORTRAN 77. The code has been compiled on a variety of machines. A few minor changes might be necessary in porting from one machine to the next. In general, these changes have not been noted in this document. The release version of the code was compiled and executed on a SUN Sparc Workstation.

The dimension of arrays in the codes is determined in the first few lines of the code, using the PARAMETER option to set maximum sizes for arrays. The dimension should be adjusted from case to case according to the size of the problem to be solved. The names of these variables are: $N M A X$, for the maximum size of the time-marching storage array (time steps multiplied by space increments); NSMAX, for the maximum number of space increments (for storing output values); and NOUT, for the maximum number of breakthrough locations and/or profile time periods. NMAX may become very large for long pulse duration and long model extent. An internal control ensures that, should the array be exceeded, the code automatically switches to a simulation mode, in which less output is generated and less array space is required.

\subsection{Input File Structure}

The input data set read by TH_PULSE is named INP. For convenience, no special format is required for the different properties provided in INP. Properties provided in INP include definition of:

- Parameters describing the magnitude and duration of the infiltration event entering the superheated region

- Parameters related to the finger flow geometry (finger width and fracture aperture),

- Parameters describing the superheated rock zone (extent of superheated region, initial rock temperature distribution)

- Thermal properties of the rock

- Parameters describing spatial and temporal discretization

- Control parameters for the simulation run

See Table 2.3.1 for the general structure of INP. Note that the second column in this table denotes the parameter name as used in FORTRAN code TH_PULSE (see code listing in Appendix B). This code name may be different from the nomenclature used in this report. 


\section{Table 2.3.1 INP_Input File for TH_PULSE}

\begin{tabular}{|c|c|c|}
\hline Line & Code Name & Short Reference \\
\hline 1 & N/A & Simulation Identifier \\
\hline 2 & N/A & Headline for IROCK \\
\hline \multirow[t]{4}{*}{3} & IROCK & Choice of Rock Temperature Representation \\
\hline & & 1 Semi-Infinite with Fitting Function Solution (Equation (12)) \\
\hline & & 2 Semi-Infinite with Exact Analytical Solution (Equation (9)) \\
\hline & & 3 Finite with Exact Analytical Solution (Equation (17)) \\
\hline 4 & N/A & Headline for QFLUX \\
\hline 5 & QFLUX & Mass Flow Rate of Infiltration Event $m_{P}(\mathrm{~kg} / \mathrm{s})$ \\
\hline 6 & $\mathrm{~N} / \mathrm{A}$ & Headline for TDRAIN \\
\hline 7 & TDRAIN & Duration of Infiltration Event $t_{P}(\mathrm{~s})$ \\
\hline 8 & N/A & Headline for APER \\
\hline 9 & APER & Fracture Hydraulic Aperture $2 b(\mathrm{~m})$ \\
\hline 10 & N/A & Headline for DWEEP \\
\hline 11 & DWEEP & Width of Water Finger $w(\mathrm{~m})$ \\
\hline 12 & N/A & Headline for DHEAT, DEXT \\
\hline \multirow[t]{2}{*}{13} & DHEAT & Vertical Extent of Superheated Region above Drift Crown $L(\mathrm{~m})$ \\
\hline & DEXT & Total Vertical Extent of Superheated Region (Model Extent) $L_{S}(\mathrm{~m})$ \\
\hline 14 & N/A & Headline for DCON \\
\hline 15 & DCON & Thermal Conductivity of Rock Matrix $k_{m}(\mathrm{~W} / \mathrm{m}-\mathrm{K})$ \\
\hline 16 & N/A & Headline for XRDEN \\
\hline 17 & XRDEN & Rock Grain Density $\rho_{m}\left(\mathrm{~kg} / \mathrm{m}^{3}\right)$ \\
\hline 18 & N/A & Headline for DCAP \\
\hline 19 & DCAP & Rock Heat Capacity $C_{m}(\mathrm{~J} / \mathrm{kg}-\mathrm{K})$ \\
\hline 20 & N/A & Headline for INUM, VALUE \\
\hline \multirow[t]{5}{*}{21} & INUM & Choice of Initial Rock Temperature in Vertical Direction \\
\hline & & 1 Uniform Temperature $T_{R I}=V A L U E$ \\
\hline & & 2 Uniform Gradient, $T_{R I}=T_{P}+V A L U E^{*} z$ \\
\hline & & 3 Square Dependence, $T_{R I}=T_{P}+V A L U E^{*} z^{2}$ \\
\hline & VALUE & Parameter Needed for Initial Rock Temperature Definition \\
\hline 22 & N/A & Headline for DZMAX \\
\hline 23 & DZMAX & Maximum Value of Space Increment $d z(\mathrm{~m})$ \\
\hline 24 & $\mathrm{~N} / \mathrm{A}$ & Headline for DTMAX \\
\hline 25 & DTMAX & Maximum Value of Time Increment $d t(\mathrm{~m})$ \\
\hline 26 & N/A & Headline for IPULSE \\
\hline \multirow[t]{4}{*}{27} & IPULSE & Choice of Rock Cooling Start (IPULSE $=1$ is strongly recommended) \\
\hline & & 1 Rock starts cooling when pulse first reaches space increment \\
\hline & & 2 Rock starts cooling when pulse has migrated halfway through increment \\
\hline & & 3 Rock starts cooling when pulse has migrated entirely through increment \\
\hline 28 & N/A & Headline for ICASE \\
\hline \multirow[t]{3}{*}{29} & ICASE & Choice of Geometry Adjustment when Fracture Flow Capacity is exceeded \\
\hline & & 1 Finger width is increased so that QFLUX can flow though fracture \\
\hline & & 2 Aperture is increased so that QFLUX can flow through fracture \\
\hline 30 & N/A & Headline for NPROF, TIME(NPROF) \\
\hline 31 & NPROF & Number of Time Steps for Output of Mass Flow Profiles \\
\hline 32 & TIME(NPROF) & Time Values for Output of Profiles (s) \\
\hline 33 & N/A & Headline for NBREA, BREA(NBREA) \\
\hline 34 & NBREA & Number of Infiltration Distances for Output of Mass Flow Breakthrough Curves \\
\hline 35 & BREA(NBREA) & Infiltration Distances for Output of Breakthrough Curves (m) \\
\hline \multicolumn{3}{|c|}{ only for IROCK = 3: } \\
\hline 36 & $\mathrm{~N} / \mathrm{A}$ & Headline for DBOUN \\
\hline 37 & DBOUN & Finite Distance for Definition of Fixed Rock Temperature Boundary $d(\mathrm{~m})$ \\
\hline
\end{tabular}


Table 2.3.2 gives an example of input file INP, referred to as Case 1. Simulation results generated using this data set are presented in a later section of this report (Section 3.2).

\section{Table 2.3.2 Sample Data Set INP for Case 1}

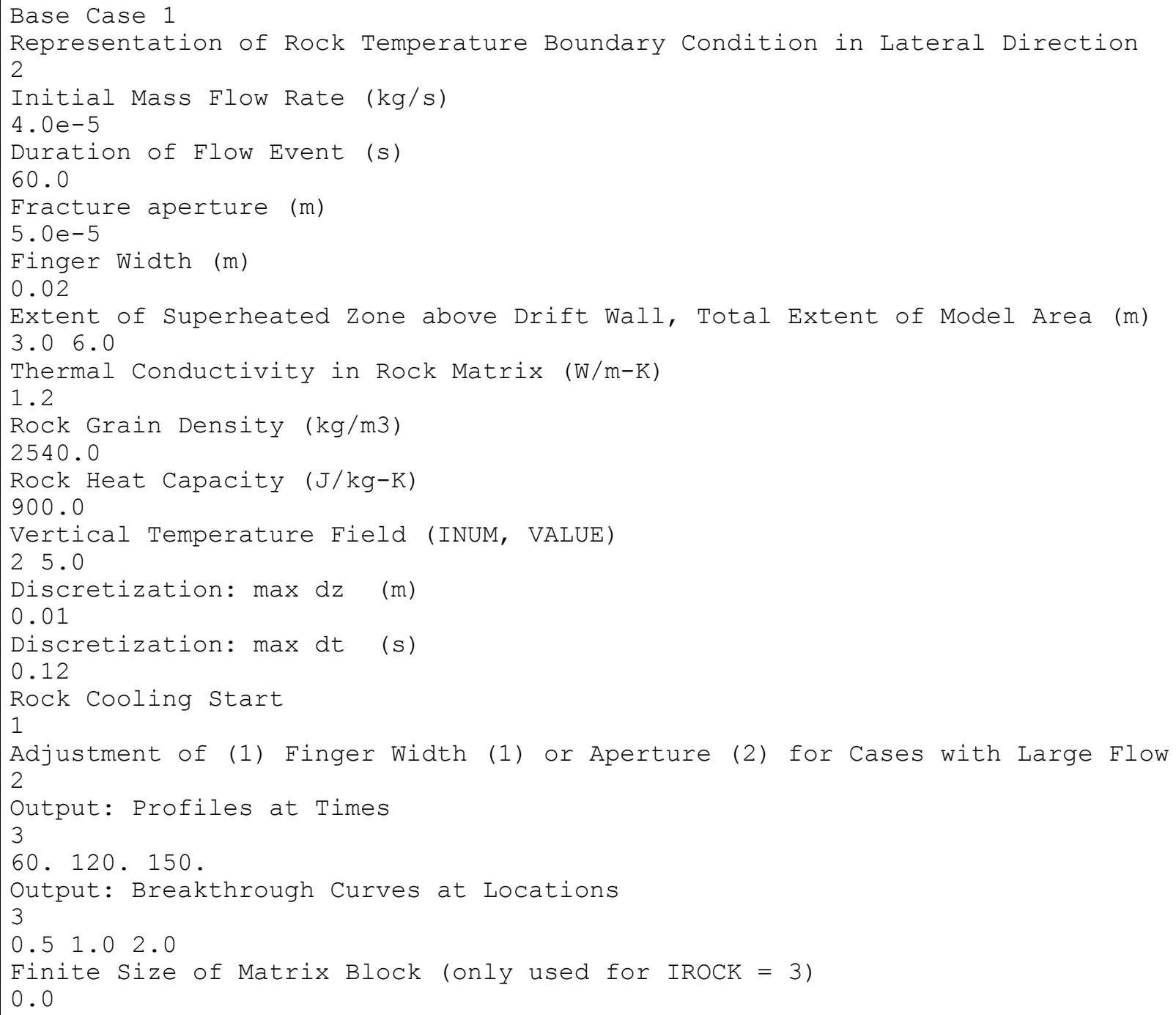

The above example analyzes an infiltration event with an initial mass flow rate of $4.0 \times 10^{-5} \mathrm{~kg} / \mathrm{s}$ and an initial duration of $60 \mathrm{~s}$. Water flows downwards with gravity in a fracture of $5.0 \times 10^{-5} \mathrm{~m}$ in a finger of $0.02 \mathrm{~m}$ width. The water enters a superheated rock region of $3.0 \mathrm{~m}$ vertical extent above the drift wall (DHEAT). The entire vertical extent of the solution domain is set to $6.0 \mathrm{~m}$ $(D E X T)$. In cases, where a pulse reaches the drift, TH_PULSE calculates the amount of water potentially entering into the drift. However, one may also be interested in the front propagation of the pulse without the presence of the drift. This can be done by setting $D E X T$ larger than DHEAT.

The rate of vaporization depends on the heat transfer from the adjacent rock surfaces. Setting $I R O C K=2$ defines a semi-infinite rock adjacent to the fracture and indicates that an exact analytical solution is applied to calculate the temperature gradient at the fracture-rock interface. As initial condition, the rock formation is assigned a linear vertical rock temperature gradient of 
$5.0^{\circ} \mathrm{C} / \mathrm{m}$. In TH_PULSE, a boiling temperature of $T_{P}=96^{\circ} \mathrm{C}$ is hardwired into the code, representative of approximately atmospheric pressure conditions within the formation. With the temperature at the top end of the superheated region equal to $96^{\circ} \mathrm{C}$ and with a gradient of $5.0^{\circ} \mathrm{C} / \mathrm{m}$, the temperature at the drift crown is $111^{\circ} \mathrm{C}$, and temperature at the bottom end of the model area is $126^{\circ} \mathrm{C}$. Thermal properties of the rock are based on site-specific data for Yucca Mountain.

Maximum discretization values are $d z=0.01 \mathrm{~m}$ (300 space increments) and $d t=0.12 \mathrm{~s}$ (500 time increments). TH_PULSE uses these maximum values as starting points for deciding on the appropriate discretization level. With IPULSE set to 1, TH_PULSE assumes that the rock walls are cooled down to water temperature as soon as water first arrives in a space increment. This is important for calculating the time period $t_{0}(z)$ in Equations (9), (12), or (17). The user is strongly advised to always use IPULSE $=1$.

In case the saturated gravity-driven flow capacity of a pulse with finger width $0.02 \mathrm{~m}$ is smaller than the given mass flow rate, TH_PULSE will either adjust the fracture aperture or the finger width. In this case, $I C A S E=2$ is chosen, so that fracture aperture is adjusted. The following six lines of INP prescribe output requirements: A total number of three mass flow profiles is requested, at times $60 \mathrm{~s}, 120 \mathrm{~s}$, and $150 \mathrm{~s}$ after initial entry into the superheated zone. Breakthrough curves are written at three locations, at $0.5 \mathrm{~m}, 1.0 \mathrm{~m}$, and $2.0 \mathrm{~m}$. The final two lines are not needed in this specific case, as $I R O C K=2$; they are merely added for completeness.

\subsection{Simulation Section}

This section of the user's manual is intended to briefly walk the reader through the code and demonstrate its main features. The section is subdivided according to the respective structure of the code (see Appendix B).

\subsubsection{Array Allocation}

The size of arrays is provided by parameters NMAX, NSMAX, and NOUT. These parameters must be set before compiling the code.

The largest array needed is $X M F$, with maximum size $N M A X$, used for storing mass flow rates at all times and locations. This storage is needed if mass flow profiles, breakthrough curves, or cumulative mass breakthrough are to be written into output files for postprocessing of results. Roughly, the size of $X M F$ is $n_{M a s s}{ }^{*} n_{z}$ (number of time steps multiplied by number of space increments). The default value for $N M A X\left(N M A X=2 \times 10^{8}\right)$ should be sufficient for all "normal" applications. Only for infiltration events of large duration (e.g., long-term pulse flow) may $X M F$ be exceeded. Then, TH_PULSE automatically switches from a "full output" mode to a "selected output" mode, and a note is written to the screen. Selected output means that the only one output file generated is FRONT.TEC, giving infiltration of the tip of the front versus time. Writing FRONT.TEC does not require storage of a full set of mass flow rates at all times and locations.

NSMAX gives the maximum number of space increments. NOUT defines the maximum number of times for output of profiles or the maximum number of locations for output of breakthrough curves. Default settings are $2 \times 10^{6}$ and 50, respectively. 


\subsubsection{Initial Setting of Hardwired Properties}

Some physical properties are hardwired into the code instead of being provided in input file INP. These parameters are:

$g=9.80665 \quad$ gravitational acceleration $\left(\mathrm{m} / \mathrm{s}^{2}\right)$

$T_{P}=96.0 \quad$ liquid (boiling) temperature $\left({ }^{\circ} \mathrm{C}\right)$

$h=2.27 \times 10^{6} \quad$ specific enthalpy of vaporization $(\mathrm{J} / \mathrm{kg})$

$\mu=2.913 \times 10^{-4} \quad$ dynamic viscosity of water at boiling temperature $(\mathrm{kg} / \mathrm{m}-\mathrm{s})$

$\rho_{l}=961.0 \quad$ liquid density of water at boiling temperature $\left(\mathrm{kg} / \mathrm{m}^{3}\right)$

$\pi=3.4159265 \quad$ pi

It is implicitly assumed in TH_PULSE that the prevailing pressure in the formation is close to atmospheric. If pressure is higher, the boiling point temperature may be different. The user may adjust $T_{P}$ in the code, if required. It should be noted, however, that dynamic viscosity and density of water are functions of temperature and have to be manually adjusted as well, according to the choice of $T_{P}$.

\subsubsection{Reading Input File INP}

See Section 2.3.

\subsubsection{Calculation of Thermal and Flow Properties}

After reading INP, TH_PULSE calculates several properties from the prescribed parameter values, and written to the screen. These properties are (for example) rock thermal diffusivity, fracture permeability, gravity-driven flow velocity, maximum saturated mass flow in the finger.

TH_PULSE checks whether the flow capacity is large enough for the prescribed input mass flow rate. If not, the pulse flow geometry is adjusted, depending on the choice of ICASE. For $I C A S E=1$, the suggested width is increased such that the given mass flow can be conducted at fully developed flow conditions in the finger. For $I C A S E=2$, the fracture aperture is adjusted instead, again assuming fully developed flow conditions in the fracture. The latter means adjustment of derived parameters as well, such as fracture permeability and flow velocity. Users of TH_PULSE may use this feature to avoid calculation of pulse geometry prior to simulation. For example, if mass flow rate and fracture aperture is known, users may set a very small finger width in INP using ICASE $=1$, so that TH_PULSE calculates the correct width of the finger.

With the finalized pulse geometry, TH_PULSE calculates the maximum time period for validity of the conceptual model from Equation (10) and writes the value to the desktop.

\subsubsection{Calculation of Characteristic Properties}

This code section calculates characteristic parameters that help to estimate the relative impact of vaporization on liquid-front movement. One parameter is the characteristic length $L^{*}$, the other is the characteristic vaporization rate $V^{*}$. Both parameters are estimated at the length scale of interest, i.e., at the location of the drift crown $L$ (parameter DHEAT).

To derive $L^{*}$ and $V^{*}$, we define a characteristic time interval $t^{*}$ as the time needed for the liquid finger to flow from $z=0$ to $z=L$ with velocity $v_{P}$. Thus, $t^{*}$ denotes the front arrival time at the drift crown in the absence of vaporization. Then the average temperature gradient at the rock surface is calculated for this time interval from Equation (8), with the simplifying 
assumptions that (1) temperature perturbation starts at $t=0$ at all locations, independent of actual front arrival time (i.e., $t_{0}(z)=0$ ), and (2) the initial rock temperature distribution can be represented by an average value $\bar{T}_{R I}$. Integration from 0 to $t^{*}$ and dividing by $t^{*}$ gives the average gradient as follows

$$
\frac{1}{t^{*}} \int_{0}^{t^{*}} \frac{T_{R I}-T_{P}}{\sqrt{\pi \kappa t}} d t=2 \frac{\left(\bar{T}_{R I}-T_{P}\right)}{\sqrt{\pi \kappa t^{*}}} .
$$

Introducing this average gradient into Equation (9) and integrating from $\mathrm{z}=0$ to $\mathrm{Z}=\mathrm{Z}$ gives

$$
m(Z)=m_{P}-Z \frac{2 w k_{m}}{h} 2 \frac{\left(\bar{T}_{R I}-T_{P}\right)}{\sqrt{\pi \kappa t^{*}}} .
$$

Using Equation (9) means that the semi-infinite temperature solution is applied to calculate $L^{*}$ and $V^{*}$. It can be safely assumed that these are representative of the finite temperature solution as long as the time period $t^{*}$ is smaller than $t_{m}$.

The characteristic length $L^{*}$ is defined as the infiltration distance needed to vaporize the total mass of water $m_{P}$ injected at the top of the superheated region. Thus, setting $m(Z)=0$ and $Z=L^{*}$ defines the characteristic length as follows:

$$
L^{*}=\frac{m_{P} h}{4 w k_{m}} \frac{\sqrt{\pi \kappa t^{*}}}{\left(\bar{T}_{R I}-T_{P}\right)} .
$$

If $L^{*}$ is much smaller than $L$, the extent of the superheated zone above the drift, vaporization effects are strong, and the water is not likely to reach the drift crown. For $L^{*}$ much larger than $L$, vaporization effects are small, if not negligible.

For the characteristic vaporization rate $V^{*}$, we rearrange Equation (27) and $\operatorname{set} Z=L$

$$
m_{P}-m(Z)=L \frac{2 w k_{m}}{h} 2 \frac{\left(\bar{T}_{R I}-T_{P}\right)}{\sqrt{\pi \kappa t^{*}}},
$$

yielding the approximate change in mass flow that would occur resulting from vaporization as the liquid front travels distance $L$ into the superheated region. Relating this change of mass flow to the initial mass flow $\mathrm{m}_{\mathrm{P}}$ gives the characteristic vaporization rate $V^{*}$ as follows:

$$
V^{*}=\frac{1}{m_{P}}\left(L \frac{2 w k_{m}}{h} 2 \frac{\left(\bar{T}_{R I}-T_{P}\right)}{\sqrt{\pi \kappa t^{*}}}\right) .
$$

If $V^{*}$ is much smaller than 1 , the intensity of vaporization is negligible compared to the magnitude of flow in the liquid ribbon. Neither mass flow rate nor apparent penetration velocity of the tip of the liquid pulse is significantly affected for the time and length scale considered. If $V^{*}$ is close to or even larger than 1 , vaporization is intense, and mass flow is expected to either decrease significantly along distance $L$ or vanish completely before reaching $L$.

Both characteristic properties are calculated in TH_PULSE and written to the screen. The average initial temperature value is derived according to the respective vertical temperature distribution case (parameter INUM). 


\subsubsection{Discretization}

The time-marching scheme in TH_PULSE subdivides the total liquid mass $M_{P}$ of the infiltration event into $n_{\text {Mass }}$ small submasses $M_{j}$ ("buckets"). Starting at $t=0$, these submasses are subsequently introduced into the superheated region at $z=0$ until the episodic infiltration event has ended. With the time-step size chosen to $d t=t_{P} / n_{\text {Mass }}$, exactly one bucket is released within each time step. In space, the superheated region is divided into $n_{z}$ uniform vertical increments of length $d z=v_{P} d t$. (Buckets move from one space increment to the next downward space increment within time interval $d t$ ). Thus, setting the time step size $d t$ automatically defines space increment size $d z$, and vice versa.

The user is required to provide maximum values dtmax and dzmax in INP. Both of these maximum constraints are accounted for in TH_PULSE, and the more rigorous one is used to generate the final discretization. TH_PULSE ensures that (1) $d z \leq d z \max$, (2) $d t \leq d t \max$, and (3) $d z=v_{P} d t$. One additional check is performed during simulation: If the first submass $M_{l}$ boils off within less than ten space increments, the spatial discretization is too coarse for sufficient accuracy. In this case, dzmax and dtmax are automatically adjusted to smaller values, and simulation is restarted.

A final note: The time-marching algorithm in TH_PULSE is very fast. It is recommended to use a very fine discretization in space and time, because simulation efficiency is not an issue. (Typically, discretizations of several thousand increments in time and space can be performed within a few seconds.) The user is encouraged to test simulation runs with different initial discretization setups and analyze the accuracy of the results.

\subsubsection{Time-Marching Simulation}

The simulation part in TH_PULSE utilizes an outer loop over $n_{\text {Mass }}$ submasses $M_{j}$ ("buckets") and an inner loop over $n_{z}$ space increments $i$. One submass after the other is introduced at the top boundary of the superheated region, and the downward movement of each submass into the superheated region is tracked. Within each space increment, the water loss as a result of boiling is calculated and subtracted from the initial mass. The calculation of boiled-off water is performed according to the respective choice in IROCK, using the right-hand-side of Equations (9), (12), or (17), respectively. Depending on IROCK, the simulation loop calls one of the following three subroutines to perform this calculation:

VINSOME.F Semi-Infinite Matrix Conduction with Fitting-Function Solution

CARSLAW1.F Semi-Infinite Matrix Conduction with Exact Analytical Solution

CARSLAW2.F Finite Matrix Conduction with Exact Analytical Solution

In each of these subroutines, the time of first arrival of water at a given space increment is stored into array IFLAG. This information is needed to determine the time interval $\left(t-t_{0}(z)\right)$ in Equations (9), (12), and (17).

As long as a submass $M_{j}$ has not boiled off (i.e., $M_{j}>0$ ), the respective mass flow rate $m$ at location $i$ is stored into array $X M F(i, j)$ for each space increment $i$. However, the initial water mass has completely vaporized, so that $M_{j}$ becomes zero or negative. In this case, the respective location and time of this zero-mass event is stored into array FRO. The information is used to determine the maximum infiltration of the tip of the liquid finger versus time. Once a submass $M_{j}$ has either boiled off or reached the bottom boundary, the next submass $j+1$ is introduced at the 
top, and a similar procedure is performed until all submasses $n_{\text {Mass }}$ have been analyzed. To avoid using excessive amounts of array space, only non-zero masses $m$ are stored into $X M F$.

The maximum extent of the very last submass, $j=n_{\text {Mass }}$, gives the maximum penetration of the episodic flow event. This maximum extent and the related travel time is written to the desktop. In cases where the pulse duration is long or the model area is relatively short, the liquid pulse may penetrate all the way to the bottom of the model area. Note that the maximum penetration depth is calculated assuming that the drift is not present. In cases where the maximum penetration depth is longer than the superheated region above a drift, DHEAT, the code TH_PULSE will consider two cases: (1) the drift is not present, and the pulse travels down the superheated region until it has completely boiled off; (2) the drift is present, and the seepage into the drift is calculated. In the latter case, the respective time of first arrival is stored and written to the screen. The cumulative amount of water at the drift is calculated by adding up all mass flow rates $m$ arriving at that location. The ratio between water collected at the drift wall and the total injected water is derived and written to the screen.

The initial choice of time and space discretization is reviewed within the time-marching procedure, and adjustments are made if required. TH_PULSE makes sure that each submass travels at least 10 space increments down into the superheated region before it is boiled off. In case this requirement is not met, the time and space increments are automatically adjusted to smaller values, and the entire simulation loop is restarted. The minimum number of 10 has been derived in scoping simulations, in which different temporal and spatial resolutions were compared for several test cases.

During the simulation loop, TH_PULSE constantly checks whether the maximum size of array $X M F$ will be exceeded with the next entry. As explained in Section 2.4.1, the code automatically switches to a "selected output" mode for cases, where $N M A X$ is not sufficient.

\subsubsection{Postprocessing and Output of Results}

Selected output from the simulation is written to the desktop. This includes (1) maximum penetration of the episodic flow event and related time, and (2) cumulative mass arriving at the drift wall and related time of first arrival. All other relevant output is written to different output files (explained in Section 2.5).

Simple bookkeeping procedures are required to relate the calculated mass flow rate $m$ in a space increment $i$ at time increment $j$ to the space and time variables $z$ and $t$. It can be easily shown that the space index $i$ corresponds to

$$
z=i d z
$$

while the time index $j$ relates to

$$
t=(j-1) d t+i d t .
$$

In this expression for $t$, the first term $(j-1) d t$ denotes the time interval from $t=0$ to the time at which submass $M_{j}$ is released; the second term $i d t$ denotes the time needed for $M_{j}$ to flow from $z=0$ to location $i d z$ ). 


\subsection{Output File Structure}

Output of TH_PULSE is explained here by presenting sample output files for the case considered in Section 2.3 (Case 1). In addition to information written to the screen, up to four output files for plotting results are generated from TH_PULSE. The format of these plot files allows direct use of the graphics tool TECPLOT ${ }^{\mathcal{O}}$, distributed by Amtec Engineering ${ }^{\mathcal{O}}$.

FRONT.TEC: maximum penetration of the tip of the pulse versus time $t$ maximum penetration of pulse versus pulse duration

TOTMASS.TEC: cumulative mass breakthrough versus location $z$ in superheated zone (cumulative mass breakthrough in \% of total injected mass)

PROFILE.TEC: mass flow rate versus location $z$ at given time steps pulse saturation versus location $z$ at given time steps

BREAK.TEC: $\quad$ mass flow rate versus time $t$ at given locations pulse saturation versus time $t$ at given locations

The latter three output files are generated only in the "full output" mode (i.e., the maximum array size for $X M F$ is sufficient).

Table 2.5.1 lists the information written to the desktop during simulation using the sample input data set given in Table 2.3.2. TH_PULSE first calculates thermal diffusivity, fracture permeability, maximum saturated mass flow, and maximum saturated velocity from the input properties given in INP. In this specific case, the maximum saturated mass flow rate is smaller than the input flow rate. With $I C A S E=2$, the fracture aperture is adjusted from $5.0 \times 10^{-5} \mathrm{~m}$ to $9.17 \times 10^{-5} \mathrm{~m}$, so that the flow capacity of the finger is identical to the initial finger mass flow rate $4.0 \times 10^{-5} \mathrm{~kg} / \mathrm{s}$. The related flow velocity is about $2.27 \mathrm{~cm} / \mathrm{s}$.

Characteristic properties are calculated at the location of interest, i.e., at the location of the drift wall at $L=3.0 \mathrm{~m}$. The estimated characteristic length $L *$ is $2.36 \mathrm{~m}$, indicating that the pulse may not be able to penetrate to the drift wall. The characteristic vaporization rate $V^{*}$ is 1.61 , indicating a rather strong impact of boiling. Indeed, TH_PULSE calculates a maximum penetration distance of $2.24 \mathrm{~m}$. The initial water mass has entirely boiled off after about $159 \mathrm{~s}$. Water does not reach the drift wall located at $3 \mathrm{~m}$ into the superheated zone.

In the postprocessing part, the desktop information summarizes some of the results that are presented in more detail in PROFILE.TEC and BREAK.TEC. First, TH_PULSE gives the total available pulse mass at the time steps chosen for output of profiles. For example, $78.0 \%$ of the total injected mass is still available after $60 \mathrm{~s}$, compared to $2.3 \%$ after $150 \mathrm{~s}$. Later, the cumulative mass passing given breakthrough locations is provided. For example, the cumulative mass collected at $0.5 \mathrm{~m}$ is $93.5 \%$, compared to $74.4 \%$ at $1 \mathrm{~m}$ and $9.8 \%$ at $2 \mathrm{~m}$.

The structure and detail of information written to the screen depends somewhat on the choice of input data. For example, if a pulse reaches the drift, the above screen dump has additional lines providing the cumulative amount of water collected at drift wall and the time of first arrival. Other additional lines include, for example, notification of discretization adjustments, array overflow, and pulse reaching end of model area. All this information is given in a straightforward manner and needs no further explanation here. 


\section{Table 2.5.1 Sample Screen Dump for Case 1}

\section{PROPERTIES :}

$========$

Thermal Diffusivity (m2/s): $\quad 5.2493438320210 \mathrm{D}-07$

Fracture Permeability (m2) 2.0833333333333D-10

Maximum Saturated Flow (kg/s): 6.4794007659756D-06

Maximum Saturated Flow Velocity (m/s) : 6.7423525140224D-03

Adjusted Aperture due to Large Flow Event: 9.1723028788946D-05

Adjusted Fracture Permeability (m2) 7.0109283418481D-10

Adjusted Maximum Saturated Flow (kg/s): 4.0000000000000D-05

Adjusted Maximum Saturated Flow Velocity (m/s): 2.2689672159020D-02

Maximum Time for 1D Conduction Assumption (s): 762.00000000000

CHARACTERISTIC PARAMETERS

$==================$

Evaluation at $\mathrm{L}=3.0000000000000$

Characteristic Time, Length: $132.21874599926 \quad 2.3636016523714$

Characteristic Time, Vaporization Rate: 132.2187459992611 .6109940618346

INITIAL DISCRETIZATION

$================$

Space discretization

$\mathrm{dz}, \mathrm{zmax}, \mathrm{nz} \quad 2.7227606590823 \mathrm{D}-03 \quad 6.0009644926175 \quad 2204$

Time discretization

dt, tmax, nmass $0.12000000000000 \quad 60.000000000000 \quad 500$

SIMULATION LOOP

$==========$

Maximum Penetration of First Volume: 0.57881677111759

Maximum Penetration Length without Drift: 2.2387226575583

Reached at Time: 158.54703414083

POSTPROCESSING

$==========$

Profile Data:

- Time, nt 60.000000000000500

Mass available at Time 1.8718514087045D-03

Ratio Available/Injected: $\quad 0.77993808696020$

- Time, nt 120.00000000000 1000

Mass available at Time 5.3726996592048D-04

Ratio Available/Injected: $\quad 0.22386248580020$

- Time, nt 150.000000000001250

Mass available at Time 5.4789905296048D-05

Ratio Available/Injected: $\quad 2.2829127206687$ D-02

Breakthrough Data:

- Length Z, nz 0.50000000000000184

Collected Mass at Location 2.2442428335650D-03

Ratio Collected/Injected: $\quad 0.93510118065207$

- Length Z, nz 1.0000000000000 367

Collected Mass at Location 1.7852343411699D-03

Ratio Collected/Injected: $\quad 0.74384764215414$

- Length Z, nz 2.0000000000000 735

Collected Mass at Location 2.3428537861628D-04

Ratio Collected/Injected: $\quad 9.7618907756784 \mathrm{D}-02$ 
Table 2.5.2 gives an extract of the output file FRONT.TEC. The first variable is time $t$, measured after the liquid pulse has first entered the superheated region. The second variable is the penetration of the tip of the pulse $l(t)$ at time $t$. These variables allow for plotting penetration distance versus time. Values are given for each time step calculated. The third variable gives pulse duration $t_{p}$; this variable can be interpreted as the pulse duration needed to allow for a maximum penetration distance $l(t)$. For example, the data point at pulse duration $t_{p}=1.2 \mathrm{~s}$ relates to $t=41.1 \mathrm{~s}$ and $l(t)=0.91 \mathrm{~m}$. This means that a pulse of $1.2 \mathrm{~s}$ duration would penetrate $0.91 \mathrm{~m}$ until the water completely boiled off. The penetration distance $0.91 \mathrm{~m}$ is reached at $t=41.1 \mathrm{~s}$. Note that the last data point in FRONT.TEC always relates to the end of the prescribed pulse duration, i.e., at $t_{p}=60 \mathrm{~s}$. This data point corresponds with $t=158.5 \mathrm{~s}$ and a maximum penetration of $2.24 \mathrm{~m}$.

\begin{tabular}{|c|c|c|}
\hline \multicolumn{3}{|c|}{ Table 2.5.2 Sample Output File FRONT.TEC for Case 1} \\
\hline $\begin{array}{l}\text { TITLE="Front Pen } \\
\text { VARIABLES = "T } \\
\text { ZONE, I = } 501 \\
0.000000 \mathrm{E}+00 \\
0.255101 \mathrm{E}+02 \\
0.291475 \mathrm{E}+02 \\
0.315970 \mathrm{E}+02 \\
0.335431 \mathrm{E}+02 \\
0.351694 \mathrm{E}+02 \\
0.366049 \mathrm{E}+02 \\
0.378881 \mathrm{E}+02 \\
0.390314 \mathrm{E}+02 \\
0.401060 \mathrm{E}+02 \\
0.411065 \mathrm{E}+02\end{array}$ & $\begin{array}{l}\text { tration" } \\
\text { )", "Penetr. } \\
0.000000 \mathrm{E}+00 \\
0.578817 \mathrm{E}+00 \\
0.658625 \mathrm{E}+00 \\
0.711479 \mathrm{E}+00 \\
0.752914 \mathrm{E}+00 \\
0.787091 \mathrm{E}+00 \\
0.816939 \mathrm{E}+00 \\
0.843332 \mathrm{E}+00 \\
0.866550 \mathrm{E}+00 \\
0.888210 \mathrm{E}+00 \\
0.908187 \mathrm{E}+00\end{array}$ & $\begin{array}{l}n, \quad \text { TP }(\mathrm{s}) " \\
0.000000 \mathrm{E}+00 \\
0.120000 \mathrm{E}+00 \\
0.240000 \mathrm{E}+00 \\
0.360000 \mathrm{E}+00 \\
0.480000 \mathrm{E}+00 \\
0.600000 \mathrm{E}+00 \\
0.720000 \mathrm{E}+00 \\
0.840000 \mathrm{E}+00 \\
0.960000 \mathrm{E}+00 \\
0.108000 \mathrm{E}+01 \\
0.120000 \mathrm{E}+01\end{array}$ \\
\hline $\begin{array}{l}\cdots \cdots \\
\cdots \cdots \\
\cdots \cdots\end{array}$ & & \\
\hline $\begin{array}{l}0.157035 \mathrm{E}+03 \\
0.157208 \mathrm{E}+03 \\
0.157374 \mathrm{E}+03 \\
0.157552 \mathrm{E}+03 \\
0.157707 \mathrm{E}+03 \\
0.157876 \mathrm{E}+03 \\
0.158048 \mathrm{E}+03 \\
0.158215 \mathrm{E}+03 \\
0.158392 \mathrm{E}+03 \\
0.158547 \mathrm{E}+03\end{array}$ & $\begin{array}{l}0.222893 \mathrm{E}+01 \\
0.223012 \mathrm{E}+01 \\
0.223118 \mathrm{E}+01 \\
0.223247 \mathrm{E}+01 \\
0.223328 \mathrm{E}+01 \\
0.223440 \mathrm{E}+01 \\
0.223558 \mathrm{E}+01 \\
0.223663 \mathrm{E}+01 \\
0.223792 \mathrm{E}+01 \\
0.223872 \mathrm{E}+01\end{array}$ & $\begin{array}{l}0.589200 \mathrm{E}+02 \\
0.590400 \mathrm{E}+02 \\
0.591600 \mathrm{E}+02 \\
0.592800 \mathrm{E}+02 \\
0.594000 \mathrm{E}+02 \\
0.595200 \mathrm{E}+02 \\
0.596400 \mathrm{E}+02 \\
0.597600 \mathrm{E}+02 \\
0.598800 \mathrm{E}+02 \\
0.600000 \mathrm{E}+02\end{array}$ \\
\hline
\end{tabular}

Output file TOTMASS.TEC is listed in Table 2.5.3. Column 1 gives location $z$ in the superheated region, Column 2 gives the cumulative breakthrough of water mass at this location. Values are provided for each space increment of the discretization. The cumulative mass is listed

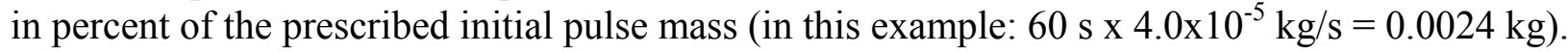
It is obvious from TOTMASS.TEC that the water mass flowing past a location $z$ gradually decreases with distance. 


\section{Table 2.5.3 Sample Output File TOTMASS.TEC for Case 1}

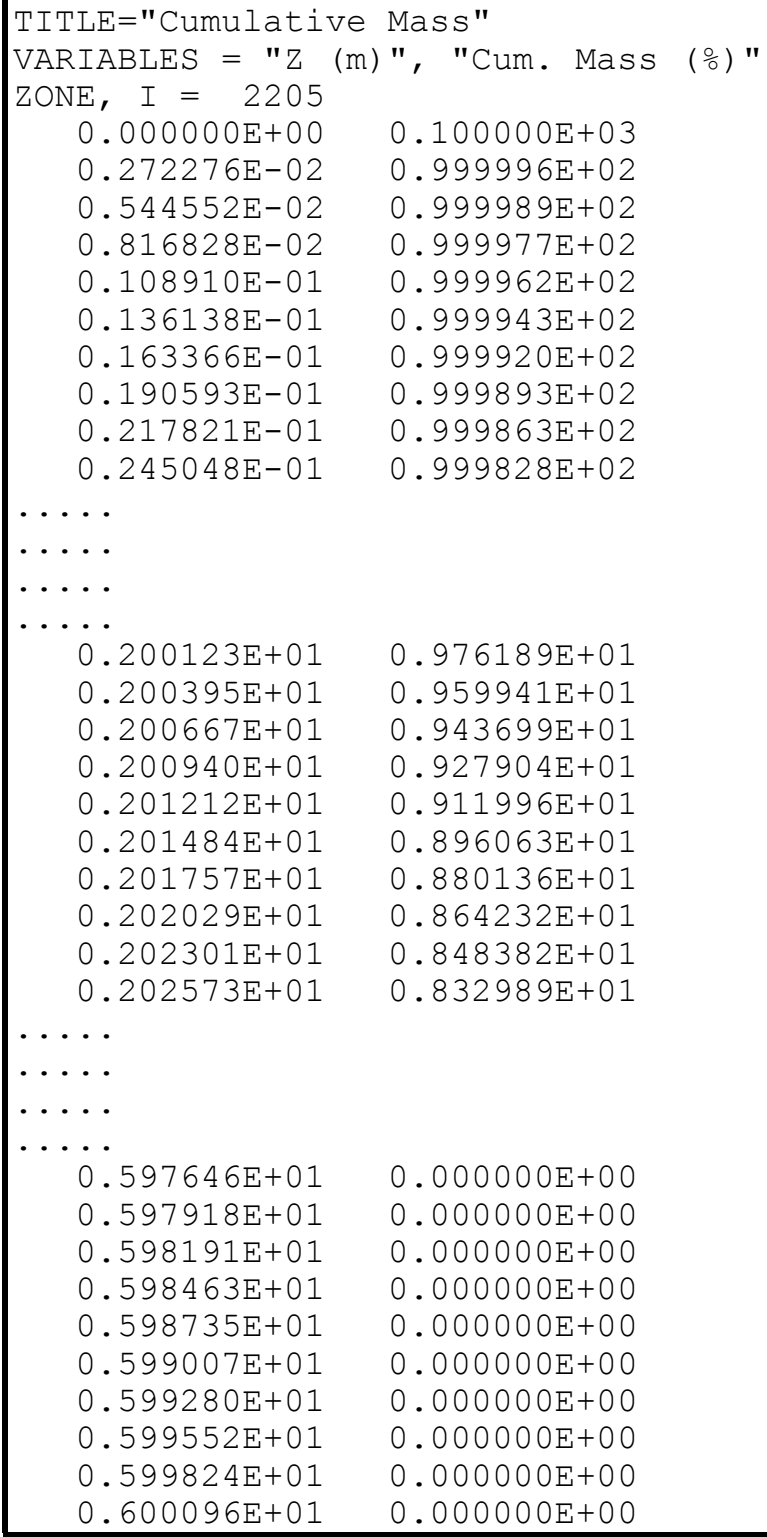

An extract of PROFILE.TEC is given in Table 2.5.4, giving mass flow profiles and saturation profiles at prescribed time steps $t=60 \mathrm{~s}, t=120 \mathrm{~s}$, and $t=150 \mathrm{~s}$. The different time steps are assigned to different "ZONES" in the data set, so that they can be plotted as separate curves. The first column of PROFILE.TEC gives location $z$ in the superheated region, the second column gives mass flow rate $m(z, t)$ at a given time, and the third column gives water saturation in the liquid finger. According to Section 1.2.4, water saturation is assumed to be equal to relative permeability, which is defined as the ratio between $m(z, t)$ and the initial mass flow rate $m_{P}$. Only where the pulse flow is present are values written into PROFILE.TEC; locations with zero mass flow are omitted to limit the size of the data set. 


\section{Table 2.5.4 Sample Output File PROFILE.TEC for Case 1}

TITLE="Mass Flow Profiles"

VARIABLES = "Z (m)", "Mass Flow (kg/s)", "Saturation ( )" $\mathrm{ZONE} \mathrm{T}=\mathrm{T}=0.600 \mathrm{E}+02 ", \mathrm{I}=460$
$0.000000 \mathrm{E}+00$
$0.000000 \mathrm{E}+00$
$0.000000 \mathrm{E}+00$
$0.272276 \mathrm{E}-02$
$0.399999 \mathrm{E}-04$
$0.544552 \mathrm{E}-02$
$0.399998 \mathrm{E}-04$
$0.999998 \mathrm{E}+00$
$0.816828 \mathrm{E}-02$
$0.399995 \mathrm{E}-04$
$0.999994 \mathrm{E}+00$
$0.108910 \mathrm{E}-01$
$0.399992 \mathrm{E}-04$
$0.999988 \mathrm{E}+00$
$0.136138 \mathrm{E}-01$
$0.399988 \mathrm{E}-04$
$0.999980 \mathrm{E}+00$
$0.999970 \mathrm{E}+00$

$\cdots \cdots$

$\cdots \cdots$

$\cdots \cdots$

$0.123613 E+01$

$0.123886 \mathrm{E}+01$

$0.693233 E-05$

$0.173308 \mathrm{E}+00$

$0.587978 \mathrm{E}-05$

$0.146994 \mathrm{E}+00$

$0.124158 \mathrm{E}+01$

$0.464085 \mathrm{E}-05$

$0.116021 \mathrm{E}+00$

$0.124430 \mathrm{E}+01$

$0.315888 \mathrm{E}-05$

$0.789721 \mathrm{E}-01$

$0.124702 \mathrm{E}+01$

$0.124975 \mathrm{E}+01$

$0.101712 \mathrm{E}-05$

$0.000000 \mathrm{E}+00$

ZONE $\mathrm{T}=" \mathrm{~T}=0.120 \mathrm{E}+03 ", \mathrm{I}=$

$0.136138 \mathrm{E}+01 \quad 0.000000 \mathrm{E}+00$

$0.136410 \mathrm{E}+01 \quad 0.298933 \mathrm{E}-04$

$0.254281 \mathrm{E}-01$

$0.000000 \mathrm{E}+00$

$0.136683 \mathrm{E}+01$

$0.298404 \mathrm{E}-04$

218

$0.000000 \mathrm{E}+00$

$0.747332 E+00$

$0.136955 \mathrm{E}+01$

$0.297873 \mathrm{E}-04$

$0.746011 \mathrm{E}+00$

$0.137227 \mathrm{E}+01$

$0.297340 E-04$

$0.744683 \mathrm{E}+00$

$0.743350 \mathrm{E}+00$

$\cdots \cdots$

$\cdots$

$\ldots \ldots$

$0.193861 E+01$

$0.194133 E+01$

$0.398453 E-05$

$0.996131 \mathrm{E}-01$

$0.194405 E+01$

$0.341668 \mathrm{E}-05$

$0.854171 \mathrm{E}-01$

$0.194677 \mathrm{E}+01$

$0.278882 \mathrm{E}-05$

$0.697205 \mathrm{E}-01$

$0.194950 \mathrm{E}+01$

$0.204894 \mathrm{E}-05$

$0.512235 \mathrm{E}-01$

$0.195222 \mathrm{E}+01$

$0.109823 \mathrm{E}-05$

$0.274558 \mathrm{E}-01$

$0.000000 \mathrm{E}+00$

ZONE $\mathrm{T}=\mathrm{T} \mathrm{T}=0.150 \mathrm{E}+03 ", \mathrm{I}=$

$0.204207 \mathrm{E}+01 \quad 0.000000 \mathrm{E}+00$

53

$0.204479 \mathrm{E}+01$

$0.139116 \mathrm{E}-04$

$0.000000 \mathrm{E}+00$

$0.347791 \mathrm{E}+00$

$0.204752 \mathrm{E}+01$

$0.137660 \mathrm{E}-04$

$0.344149 \mathrm{E}+00$

$0.205024 \mathrm{E}+01$

$0.136185 \mathrm{E}-04$

$0.340464 \mathrm{E}+00$

$0.205296 \mathrm{E}+01$

$0.134693 \mathrm{E}-04$

$0.336734 \mathrm{E}+00$

$0.205568 \mathrm{E}+01$

$0.133183 \mathrm{E}-04$

$0.332958 \mathrm{E}+00$

.....

$\cdots \cdots$

$\cdots$

$0.217004 \mathrm{E}+01$

$0.217276 \mathrm{E}+01$

$0.327733 E-05$

$0.819333 E-01$

$0.274746 \mathrm{E}-05$

$0.686865 \mathrm{E}-01$

$0.217549 \mathrm{E}+01$

$0.214914 \mathrm{E}-05$

$0.537286 \mathrm{E}-01$

$0.217821 \mathrm{E}+01$

$0.141390 \mathrm{E}-05$

$0.353476 \mathrm{E}-01$

$0.218093 \mathrm{E}+01$

$0.450705 \mathrm{E}-06$

$0.112676 \mathrm{E}-01$

$0.218365 \mathrm{E}+01 \quad 0.000000 \mathrm{E}+00 \quad 0.000000 \mathrm{E}+00$

An extract of BREAK.TEC is given in Table 2.5.5, listing breakthrough curves of mass flow and related saturation values at prescribed locations $z=0.5 \mathrm{~m}, z=1.0 \mathrm{~m}$, and $z=2.0 \mathrm{~m}$. The different locations are assigned different to "ZONES" in the data set. The first column of PROFILE.TEC gives time $t$ after first penetration into the superheated region, the second column gives time-dependent mass flow rate $m(z, t)$ at this location, and the third column gives water 
saturation. Only where mass actually arrives at the considered location are time steps included in BREAK.TEC.

\section{Table 2.5.5 Sample Output File BREAK.TEC for Case 1}

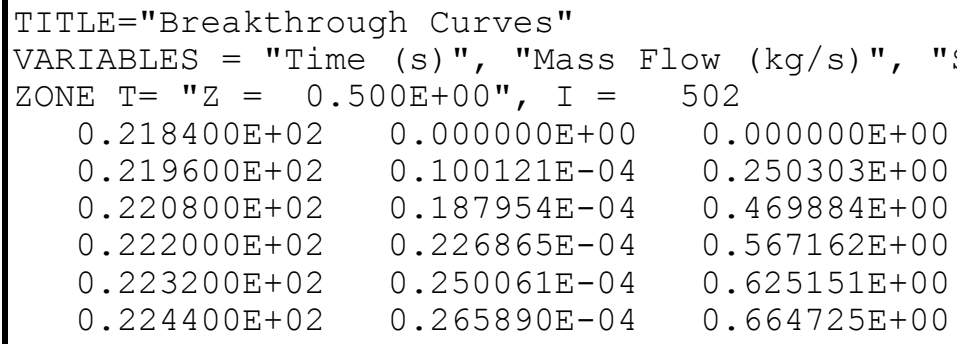

$\ldots \ldots$

$\cdots \cdots$

$\cdots \cdots$

$0.813600 \mathrm{E}+02$

$0.386535 \mathrm{E}-04$

$0.966338 \mathrm{E}+00$

$0.814800 \mathrm{E}+02$

$0.386549 \mathrm{E}-04$

$0.966371 E+00$

$0.816000 \mathrm{E}+02$

$0.386562 \mathrm{E}-04$

$0.966405 \mathrm{E}+00$

$0.817200 \mathrm{E}+02$

$0.386576 \mathrm{E}-04$

$0.966439 \mathrm{E}+00$

$0.818400 \mathrm{E}+02$

$0.386589 \mathrm{E}-04$

$0.819600 \mathrm{E}+02$

$0.000000 \mathrm{E}+00$

$\mathrm{ZONE} \mathrm{T}=\mathrm{Z}=0.100 \mathrm{E}+01 \mathrm{z}, \mathrm{I}=$

$0.966473 E+00$

$0.000000 \mathrm{E}+00$

$0.456000 \mathrm{E}+02$

$0.000000 \mathrm{E}+00$

487

$0.457200 \mathrm{E}+02$

$0.108507 \mathrm{E}-05$

$0.000000 \mathrm{E}+00$

$0.458400 \mathrm{E}+02$

$0.386465 \mathrm{E}-05$

$0.271266 \mathrm{E}-01$

$0.459600 \mathrm{E}+02$

$0.584363 E-05$

$0.966162 \mathrm{E}-01$

$0.460800 \mathrm{E}+02$

$0.742367 \mathrm{E}-05$

$0.462000 \mathrm{E}+02$

$0.874961 \mathrm{E}-05$

$0.146091 \mathrm{E}+00$

$0.185592 \mathrm{E}+00$

....

$\ldots$.

$\ldots$

$\ldots .$.

$0.103320 \mathrm{E}+03$

$0.346351 \mathrm{E}-04$

$0.218740 \mathrm{E}+00$

$0.103440 \mathrm{E}+03$

$0.103560 \mathrm{E}+03$

$0.103680 \mathrm{E}+03$

$0.103800 \mathrm{E}+03$

$0.103920 \mathrm{E}+03$

$0.125760 \mathrm{E}+03$

$0.125880 \mathrm{E}+03$

$0.346406 \mathrm{E}-04$

$0.346460 \mathrm{E}-04$

$0.346514 \mathrm{E}-04$

$0.346568 E-04$

$0.000000 \mathrm{E}+00$

$0.126000 \mathrm{E}+03$

$0.000000 \mathrm{E}+00$

$0.415808 \mathrm{E}-06$

$0.864361 \mathrm{E}-06$

$0.126120 \mathrm{E}+03$

$0.126240 \mathrm{E}+03$

$0.124645 E-05$

$0.158425 \mathrm{E}-05$

$0.126360 \mathrm{E}+03$

$0.188986 \mathrm{E}-05$

$0.865878 \mathrm{E}+00$

$0.866014 \mathrm{E}+00$

$0.866150 \mathrm{E}+00$

$0.866285 \mathrm{E}+00$

$0.866420 \mathrm{E}+00$

$0.000000 \mathrm{E}+00$

187

$0.000000 \mathrm{E}+00$

$0.103952 \mathrm{E}-01$

$0.216090 \mathrm{E}-01$

$0.311612 \mathrm{E}-01$

$0.396062 \mathrm{E}-01$

$0.472465 \mathrm{E}-01$

$\cdots \cdots$

$\cdots \cdots$

$\cdots \cdots$

$0.147480 \mathrm{E}+03$

$0.153754 \mathrm{E}-04$

$0.384384 \mathrm{E}+00$

$0.147600 \mathrm{E}+03$

$0.154104 \mathrm{E}-04$

$0.385260 \mathrm{E}+00$

$0.147720 \mathrm{E}+03$

$0.154452 \mathrm{E}-04$

$0.386131 \mathrm{E}+00$

$0.147840 \mathrm{E}+03$

$0.154799 \mathrm{E}-04$

$0.386999 \mathrm{E}+00$

$0.147960 \mathrm{E}+03$

$0.155145 \mathrm{E}-04$

$0.387862 \mathrm{E}+00$

$0.148080 \mathrm{E}+03$

$0.000000 \mathrm{E}+00$

$0.000000 \mathrm{E}+00$ 


\section{Sample Problems}

\subsection{Introduction}

Two categories of sample problems are presented below: short-term finger flow (in Section 3.2) and long-term behavior (in Section 3.3). A comparison of simulation results with results from alternative numerical and analytical solutions is presented in Section 3.4, for verification of the code. All input and output files used or generated in this report can be provided in electronic form by the author. Simulation input files for the respective problems of this section are listed below. Output files are generally not listed; rather their content is presented in the form of figures.

\subsection{Short-Term Finger Flow}

Two sample cases are analyzed to illustrate the behavior of short-term pulses penetrating a superheated zone. The first test case (Case 1) is the sample problem already introduced in Section 2.3. The second problem (Case 2) features identical hydrogeological and thermal conditions, except that the considered water pulse is larger in magnitude and shorter in duration. The following paragraphs briefly describe the input properties and explain some of the rationale behind the parameter choice. See Figure 6 for a schematic illustration of the two cases.

The chosen hydrogeological and thermal conditions are similar to the expected situation at Yucca Mountain after several hundred years of heating. Depending on the final design, the waste packages, placed into underground tunnels, will generate sufficient heat to boil ambient matrix water and establish a dry, superheated region of significant extent. In the test cases, an aboveboiling region extends $3 \mathrm{~m}$ above the crown of an emplacement drift. (This value represents the low range of predicted conditions at Yucca Mountain; it was mainly chosen for illustrative purposes.) Within this boiling region, a vertical rock temperature gradient of $\beta=5^{\circ} \mathrm{C} / \mathrm{m}$ is assumed (linear variation in rock temperature $T_{R I}=T_{P}+\beta z$ ). Note that the boiling temperature of water at prevailing pressure is $T_{P}=96^{\circ} \mathrm{C}$ (this value is hardwired into the code). Thermal properties of the rock are based on site-specific measurements for the stratigraphic unit in which the major part of the potential geological repository will reside (i.e., the Topopah Spring Lower Lithophysal Unit).

Realistic values of flow rate, duration, and geometry of episodic flow events are difficult to guess, because of the significant temporal and spatial variation of flow at Yucca Mountain. The two cases studied represent a reasonable range of possible episodic flow events. Case 1 features a small flow event of $4.0 \times 10^{-5} \mathrm{~kg} / \mathrm{s}$ of duration of $t_{P}=60 \mathrm{~s}$. Case 2 has assigned a larger mass flow rate of $8.0 \times 10^{-4} \mathrm{~kg} / \mathrm{s}$ related to a shorter duration $t_{P}=3 \mathrm{~s}$. In both cases, the respective total liquid volume is the same, $2.4 \mathrm{~mL}$. This corresponds well with the range of intermittent flow events observed in laboratory experiments of Su et al. [1999]. Note that the time- and spaceaveraged infiltration in the arid zone of Yucca Mountain is about 5 to $10 \mathrm{~mm} / \mathrm{a}$. Using the upper value of $10 \mathrm{~mm} / \mathrm{a}$ and assuming about one episodic flow event per square meter of crosssectional area, a water volume of $2.4 \mathrm{~mL}$ may be accumulated within 2.1 hours.

The finger width is $w=0.02 \mathrm{~m}$ in both cases. Comparable values of finger width have been measured in laboratory experiments of Nicholl et al. [1994], Kneafsey and Pruess [1998] or Su et al. [1999]. Assuming fully developed, gravity-driven ribbon flow according to Equations (18) and (19), the above given values for flow rate and finger geometry relate to fracture apertures of 
$0.917 \times 10^{-4} \mathrm{~m}$ (Case 1) and $2.490 \times 10^{-4} \mathrm{~m}$ (Case 2). These aperture values are quite typical for the fractures observed at Yucca Mountain.

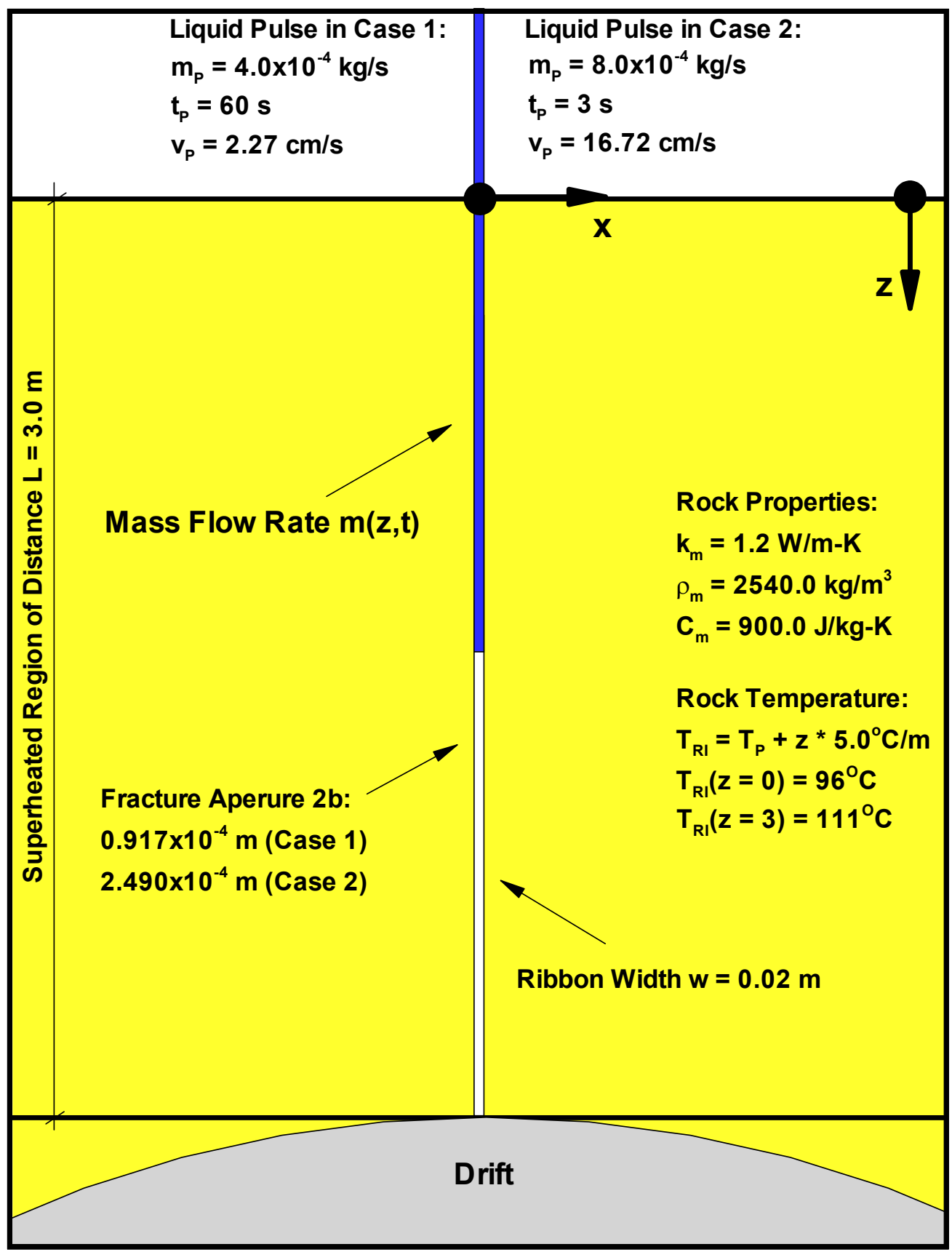

Figure 6: Schematic illustration of the sample cases

Table 3.2.1 lists the input file INP for Case 2. Table 3.2.2 gives the information written to the screen during the simulation run for Case 2. For comparison, the respective listings for Case 1 are presented in Tables 2.3.1 (INP) and 2.5.1 (screen dump). The two input files are fairly similar; the only differences are the initial mass flow rate, pulse duration, temporal discretization, and choice of time steps for output profiles. The temporal discretization is changed since the pulse flow in Case 2 is much smaller and more intense; therefore, the maximum time-step size must be set smaller than in Case 1 . Note that $I R O C K=2$ in both cases. 
Thus, the temperature distribution in the matrix is calculated using the exact analytical solution for semi-infinite boundary conditions (see Section 1.2.1).

\section{Table 3.2.1 Sample Data Set INP for Case 2}

Base Case 2

Representation of Rock Temperature in Lateral Direction

2

Initial Mass Flow Rate (kg/s)

8. 0 e-4

Duration of Flow Event (s)

3. 0

Fracture aperture (m)

$5.0 e-5$

Finger Width (m)

0.02

Extent of Superheated Zone above Drift Wall, Total Extent of Model Area (m)

3.06 .0

Thermal Conductivity in Rock Matrix (W/m-K)

1.2

Rock Grain Density $(\mathrm{kg} / \mathrm{m} 3)$

2540.0

Rock Heat Capacity ( J/kg-K)

900.0

Vertical Temperature Field (INUM, VALUE)

25.0

Discretization: $\max d z \quad(m)$

0.01

Discretization: $\max d t \quad(s)$

0.01

Rock Cooling Start

1

Adjustment of (1) Finger Width (1) or Aperture (2) for Cases with Large Flow 2

Output: Profiles at Times

3

3.09 .018 .0

Output: Breakthrough Curves at Locations

3

0.51 .02 .0

Finite Size of Matrix Block (only used for IROCK = 3)

0.0

The listing of desktop information in Table 3.2.2 shows the following differences between the two cases (compare Table 2.5.1 for Case 1): In Case 2, TH_PULSE adjusts the input fracture permeability to a much higher value of $2.490 \times 10^{-4} \mathrm{~m}$, so that the flow capacity of the liquid finger is identical to the comparably large input mass flow rate of $8.0 \times 10^{-4} \mathrm{~kg} / \mathrm{s}(I C A S E=2)$. The gravity-driven flow velocity associated with this large aperture is $16.72 \mathrm{~cm} / \mathrm{s}$, compared to $2.27 \mathrm{~cm} / \mathrm{s}$ in Case 1 . The characteristic properties, estimated at the drift wall at $L=3 \mathrm{~m}$, are $L^{*}=6.41 \mathrm{~m}$ and $V^{*}=0.22$. From these values, the relative effect of vaporization on finger flow is expected to be small, and the water pulse should reach the drift wall before boiling off. The simulation results confirm this estimate: The liquid pulse reaches the drift after $t=18.36 \mathrm{~s}$. The cumulative amount of water collected at the drift wall is $1.2 \times 10^{-3} \mathrm{~kg}$, which compares to about $49.9 \%$ of the total injected water mass. Note that the maximum penetration of the pulse would be $4.73 \mathrm{~m}$ when ignoring the presence of the drift. This is more than twice the penetration distance of Case 1. 


\section{Table 3.2.2 Sample Screen Dump for Case 2}

PROPERTIES :

$========$

Thermal Diffusivity (m2/s) : $\quad 5.2493438320210 \mathrm{D}-07$

Fracture Permeability (m2) 2.0833333333333D-10

Maximum Saturated Flow (kg/s): 6.4794007659756D-06

Maximum Saturated Flow Velocity (m/s): 6.7423525140224D-03

Adjusted Aperture due to Large Flow Event: 2.4897460519216D-04

Adjusted Fracture Permeability (m2) 5.1656961692158D-09

Adjusted Maximum Saturated Flow (kg/s): 8.0000000000000D-04

Adjusted Maximum Saturated Flow Velocity (m/s): 0.16717893385530

Maximum Time for 1D Conduction Assumption (s): 762.00000000000

CHARACTERISTIC PARAMETERS

$========================$

Evaluation at $\mathrm{L}=3.0000000000000$

Characteristic Time, Length: $17.944844669225 \quad 6.4158019638099$

Characteristic Time, Vaporization Rate: 17.9448446692250 .21864553308368

INITIAL DISCRETIZATION

$===================$

Space discretization

$\mathrm{dz}, \mathrm{zmax}, \mathrm{nz} \quad 1.6717893385530 \mathrm{D}-03 \quad 6.0000519360669 \quad 3589$

Time discretization

dt, tmax, nmass $1.0000000000000 \mathrm{D}-02 \quad 3.0000000000000 \quad 300$

SIMULATION LOOP

$===========$

Maximum Penetration of First Volume: 1.3932226965738

Maximum Penetration Length without Drift: $\quad 4.7308858842131$

Reached at Time: $\quad 31.288337446677$

Liquid Pulse reaches Drift at Length 3.0000000000000

Reached at Time: 18.360000000000

Collected Mass in Drift $1.1978566774241 \mathrm{D}-03$

Ratio Collected/Injected: $\quad 0.49910694892670$

POSTPROCESSING

$==========$

Profile Data:

- Time, nt 3.0000000000000300

Mass available at Time 2.3821555760118D-03

Ratio Available/Injected: 0.99256482333825

- Time, nt 9.0000000000000900

Mass available at Time 2.1546248354263D-03

Ratio Available/Injected: $\quad 0.89776034809428$

- Time, nt 18.0000000000001800

Mass available at Time 1.3451039523753D-03

Ratio Available/Injected: $\quad 0.56045998015636$

Breakthrough Data:

- Length Z, nz 0.50000000000000299

Collected Mass at Location 2.3657274750116D-03

Ratio Collected/Injected: $\quad 0.98571978125482$

- Length Z, nz 1.0000000000000 598

Collected Mass at Location 2.2631383835462D-03

Ratio Collected/Injected: $\quad 0.94297432647759$

- Length Z, nz 2.0000000000000 1196

Collected Mass at Location 1.8544546127910D-03

Ratio Collected/Injected: $\quad 0.77268942199627$ 
Plotting the output data allows for a more in-depth discussion of simulation results. The first results presented use Columns 1 and 2 in output file FRONT.TEC, giving penetration distance versus time. Figure 7 shows this curve for Case 1, exhibiting a front-arrival curve typical for a flow event affected strongly by heating. Very soon after the liquid first enters the superheated region, front penetration is already delayed compared to the undisturbed flow velocity $v_{P}$. The further the finger infiltrates, the stronger this effect. The front delay is caused by earlier submasses of water vanishing as a result of boiling and only later-released submasses progressing to further penetration lengths. After about $2.24 \mathrm{~m}$, the episodic infiltration event comes to a final stop, as all water has vaporized. Hence, for flow events similar to Case 1, the superheated region around a waste emplacement drift supplies an effective safety mechanism that prevents water from entering the tunnels. Note that the maximum pulse penetration relates to the maximum penetration of the last submass of water released at the end of the $60 \mathrm{~s}$ pulse duration.

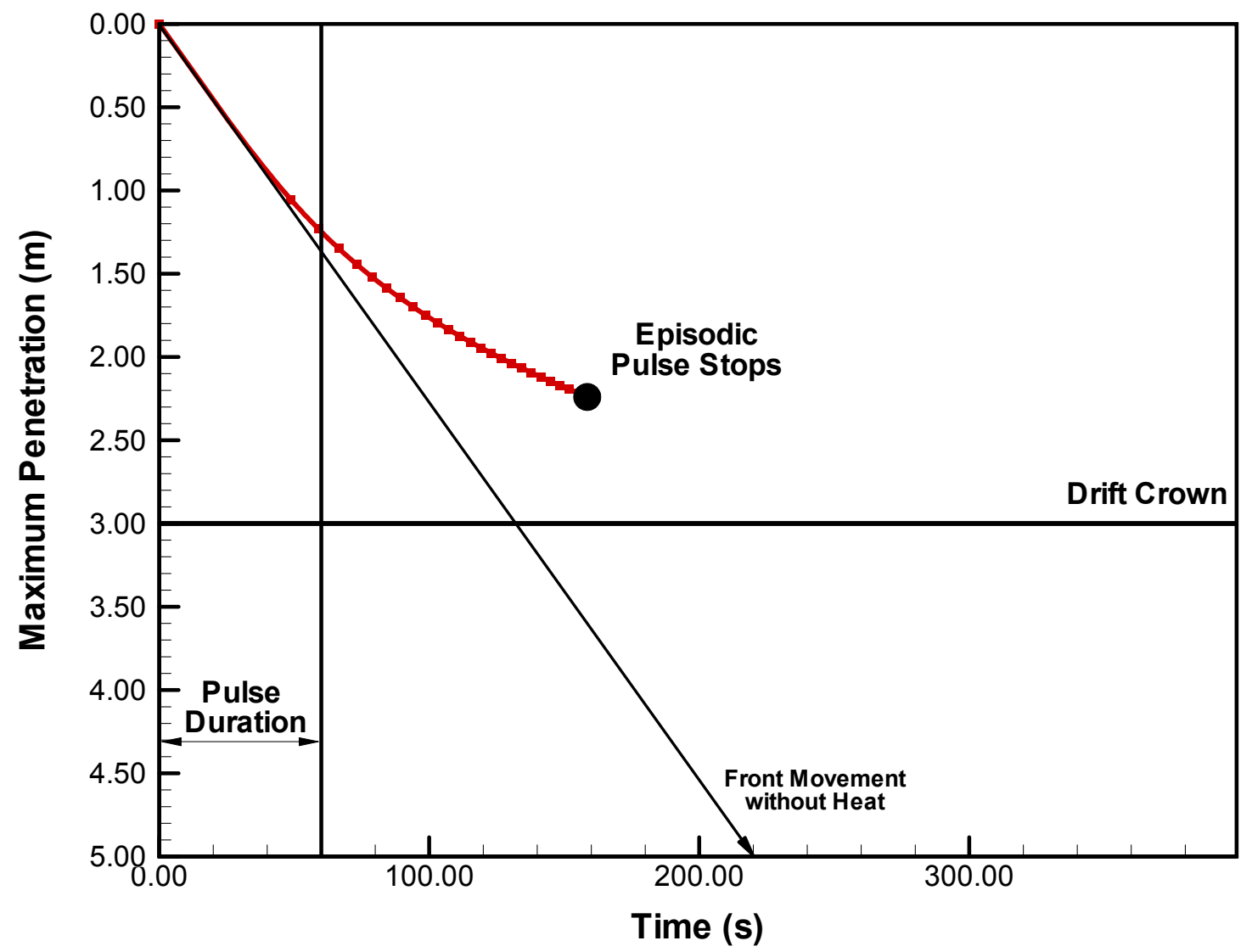

Figure 7: Penetration distance versus time for infiltration event Case 1

Results are very different for the infiltration event in Case 2 (presented in Figure 8). Note the different time scale; flow velocity $v_{P}$ is about eight times faster than in the previous case. The penetration length of the tip of the finger increases rapidly, and the apparent penetration velocity is similar to the actual flow velocity. The liquid finger reaches the drift crown after about $18 \mathrm{~s}$, at which time water may start seeping into the tunnel. However, because of vaporization, the total amount of water available for seepage is only about $50 \%$ of the total infiltrated mass. Although it is less obvious from the slope of the front-arrival curve, the hot rock environment still provides an important safety feature that reduces the amount of water seeping into drifts by a significant 
percentage. When ignoring the presence of the drift at $z=3.0 \mathrm{~m}$, the episodic infiltration event comes to a final stop after about $4.73 \mathrm{~m}$. At this distance, the effect of heating is more obvious: the front arrival curve deviates noticeably from the constant-velocity curve. At even larger scales, we may eventually expect to see behavior similar to Case 1 , in which vaporization has strong implications for the front penetration.

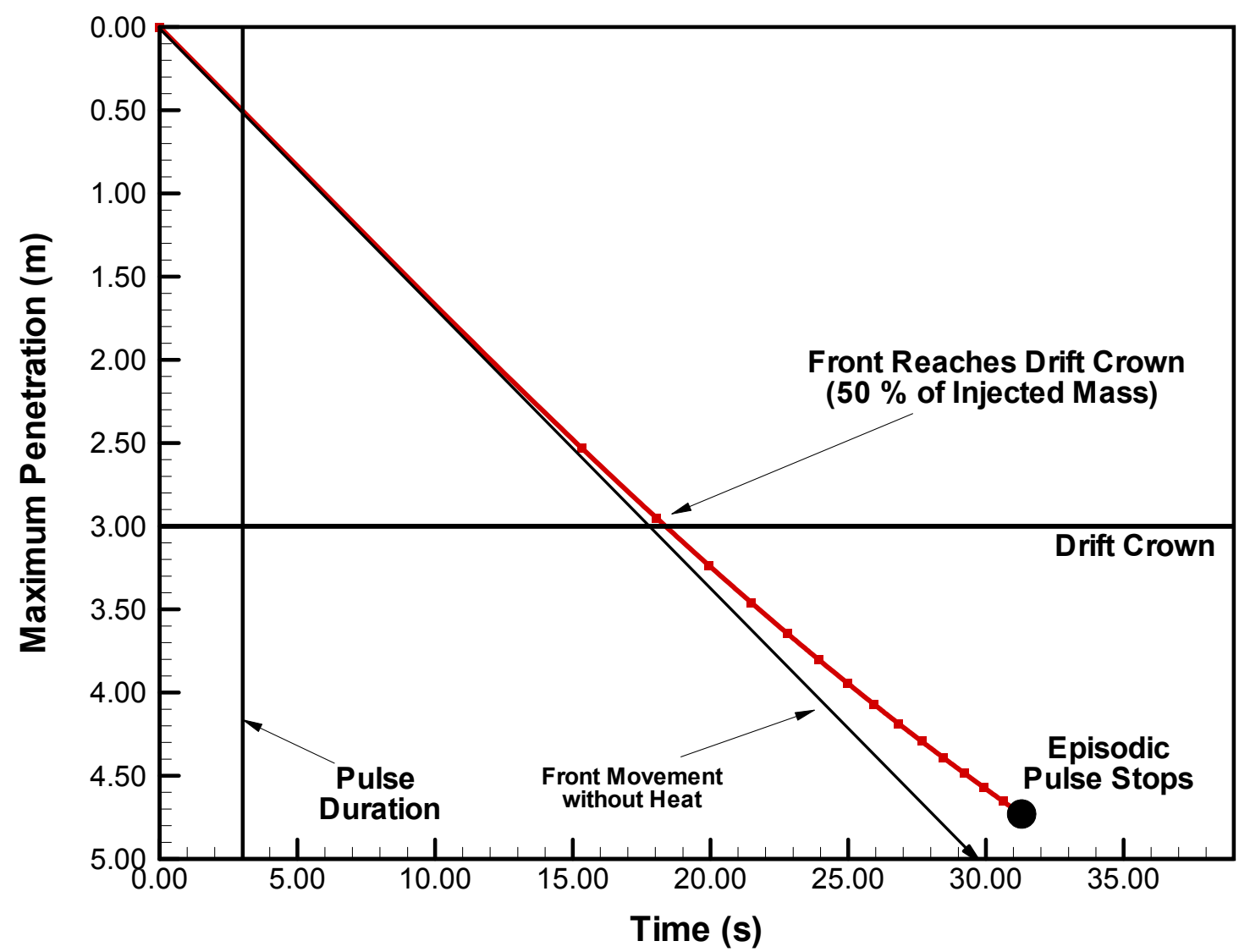

Figure 8: Penetration distance versus time for infiltration event Case 2

Output file FRONT.TEC can also be used to plot the maximum possible penetration distance, shown as a function of pulse duration (Figure 9). For this matter, the pulse duration in INP is set to a larger time period (e.g., $t_{P}=200 \mathrm{~s}$ ). Figure 9 shows that a flow event with initial flow rate of $4.0 \times 10^{-5} \mathrm{~kg} / \mathrm{s}$ must be maintained for about $195 \mathrm{~s}$ to reach the drift wall. For $t_{P}=60 \mathrm{~s}$, the maximum possible penetration is $2.24 \mathrm{~m}$, a result already seen in the earlier plots. 


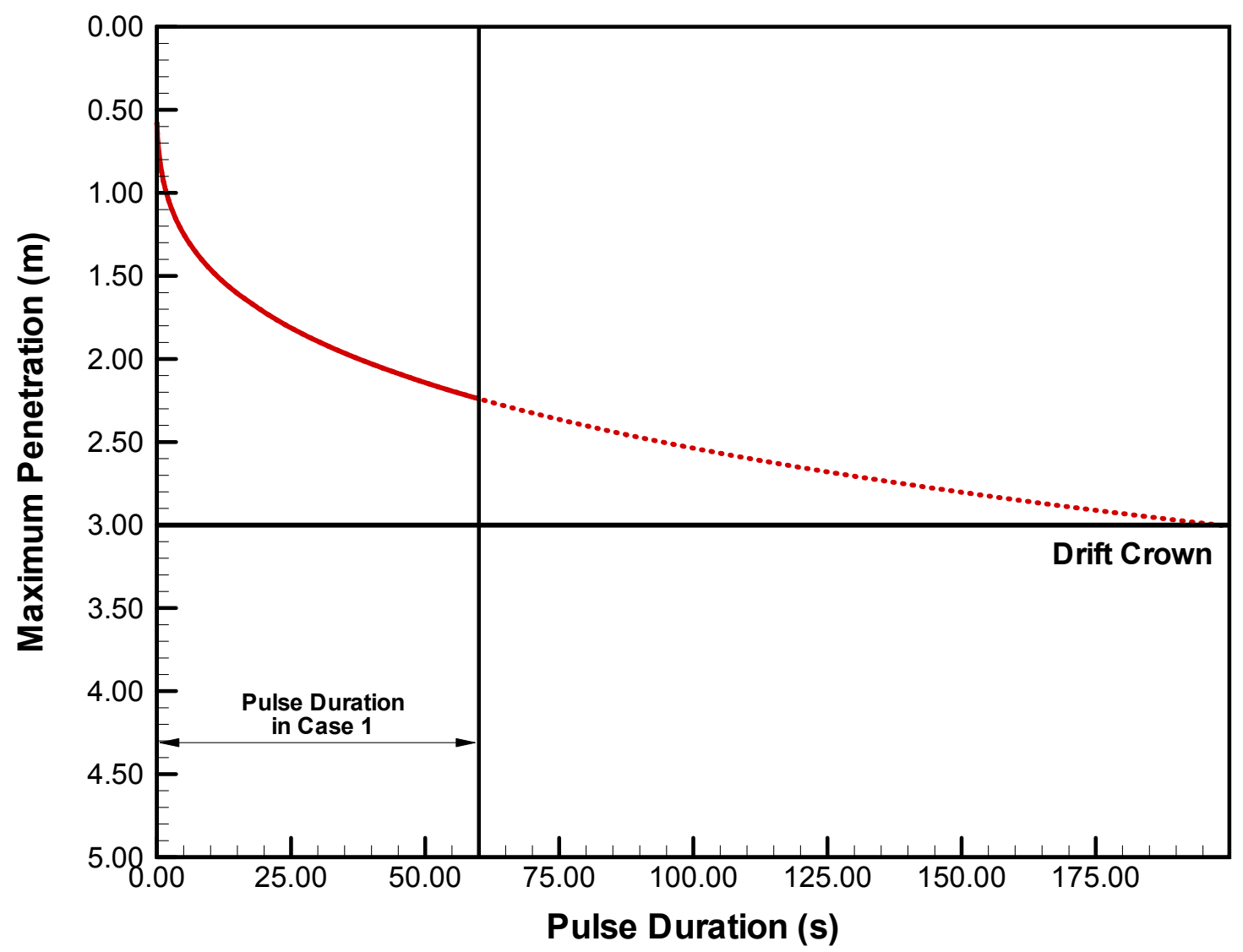

Figure 9: Maximum possible penetration versus pulse duration for infiltration event Case 1

Output file PROFILE.TEC can be used to analyze mass flow profiles. Figure 10 gives flow rate as a function of vertical location for Case 1, at $t=60 \mathrm{~s}, 120 \mathrm{~s}$, and $150 \mathrm{~s}$. (For comparison, we have also plotted the mass flow profile of a liquid pulse in absence of vaporization, at $150 \mathrm{~s}$ ). Typically, mass flow is highest at the end of the pulse and flow rates decrease rapidly towards the tip of the moving front. The total mass of water decreases significantly with time and travel distance. The decline of total mass can be seen in two ways: (1) the magnitude of flow decreases and (2) the vertical extension of the finger becomes smaller. Note that the change of vertical extension results from submasses vanishing at the tip of the pulse. There is no mechanical or numerical dispersion related to this observation. Figure 11 shows mass flow profiles for Case 2. Here, the curves are less affected by the superheated environment. In contrast to Case 1, in which the liquid front does not move much further after infiltration at the top has ended, Case 2 exhibits typical characteristics of a short, intense infiltration event flowing with large velocity. The liquid finger moves down the fracture with shape almost intact and vertical extent virtually unchanged.

Figures 12 and 13 demonstrate the use of output file BREAK.TEC. Breakthrough curves for mass flow versus time are presented at locations $\mathrm{z}=0.5 \mathrm{~m}, 1.0 \mathrm{~m}$, and $2.0 \mathrm{~m}$. At z $=2.0 \mathrm{~m}$, the breakthrough curves are shown in comparison with the breakthrough of similar pulses flowing in sub-boiling conditions (i.e., vaporization is neglected). In both figures, the general shape of the curves is quite similar. At first arrival of the front, mass flow increases rapidly and peaks at the end of the liquid finger. However, when vaporization effects are significant as in Case 1, the first arrival of the front can be strongly delayed compared to the arrival of an undisturbed flow event. 


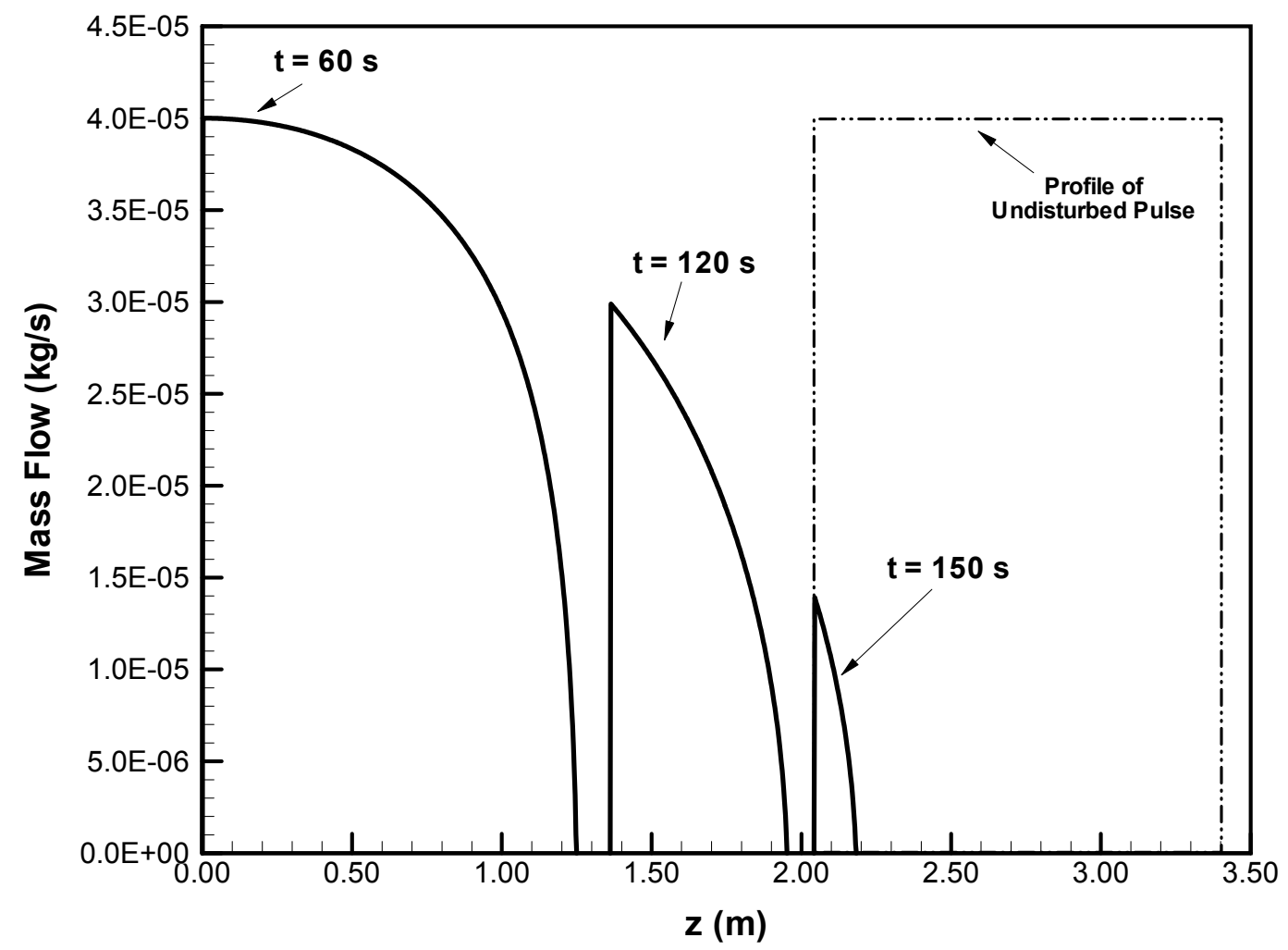

Figure 10: Profiles of mass flow for infiltration event Case 1, at $t=60 \mathrm{~s}, 120 \mathrm{~s}$, and $150 \mathrm{~s}$

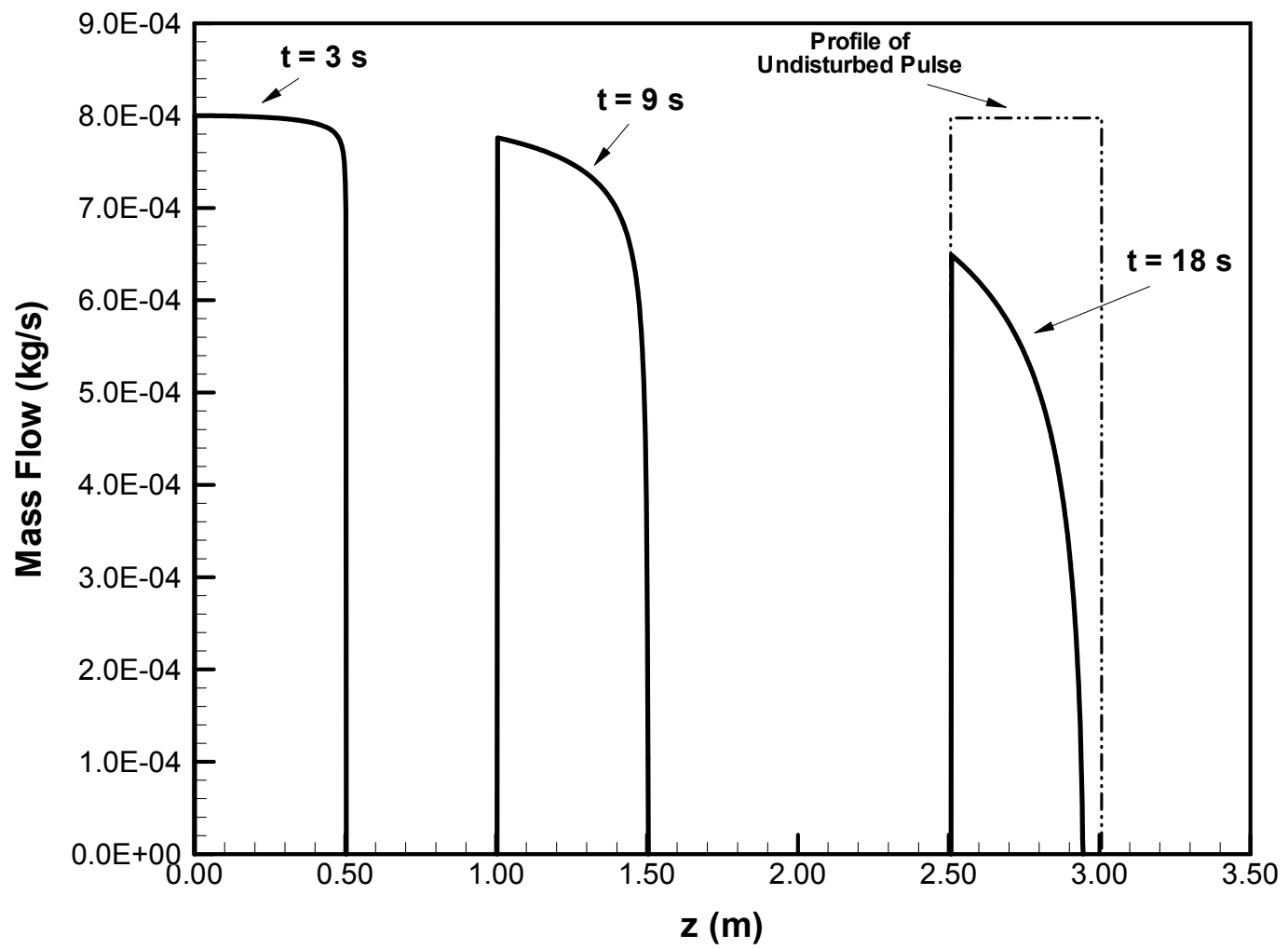

Figure 11: Profiles of mass flow for infiltration event Case 2, at $t=3 \mathrm{~s}, 9 \mathrm{~s}$, and $18 \mathrm{~s}$ 


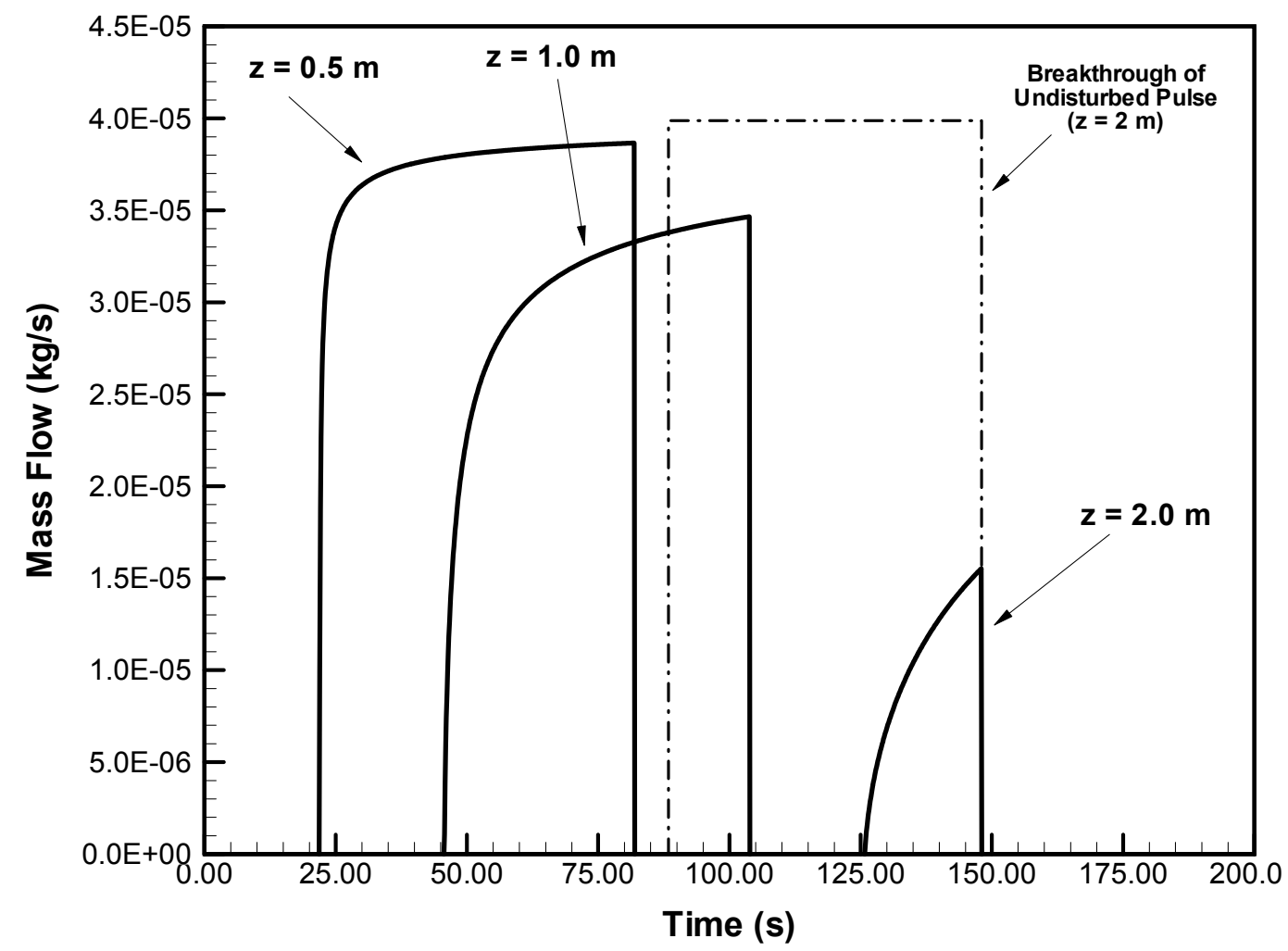

Figure 12: Breakthrough of mass flow for infiltration event Case 1, at $z=0.5 \mathrm{~m}, 1 \mathrm{~m}$, and $2 \mathrm{~m}$

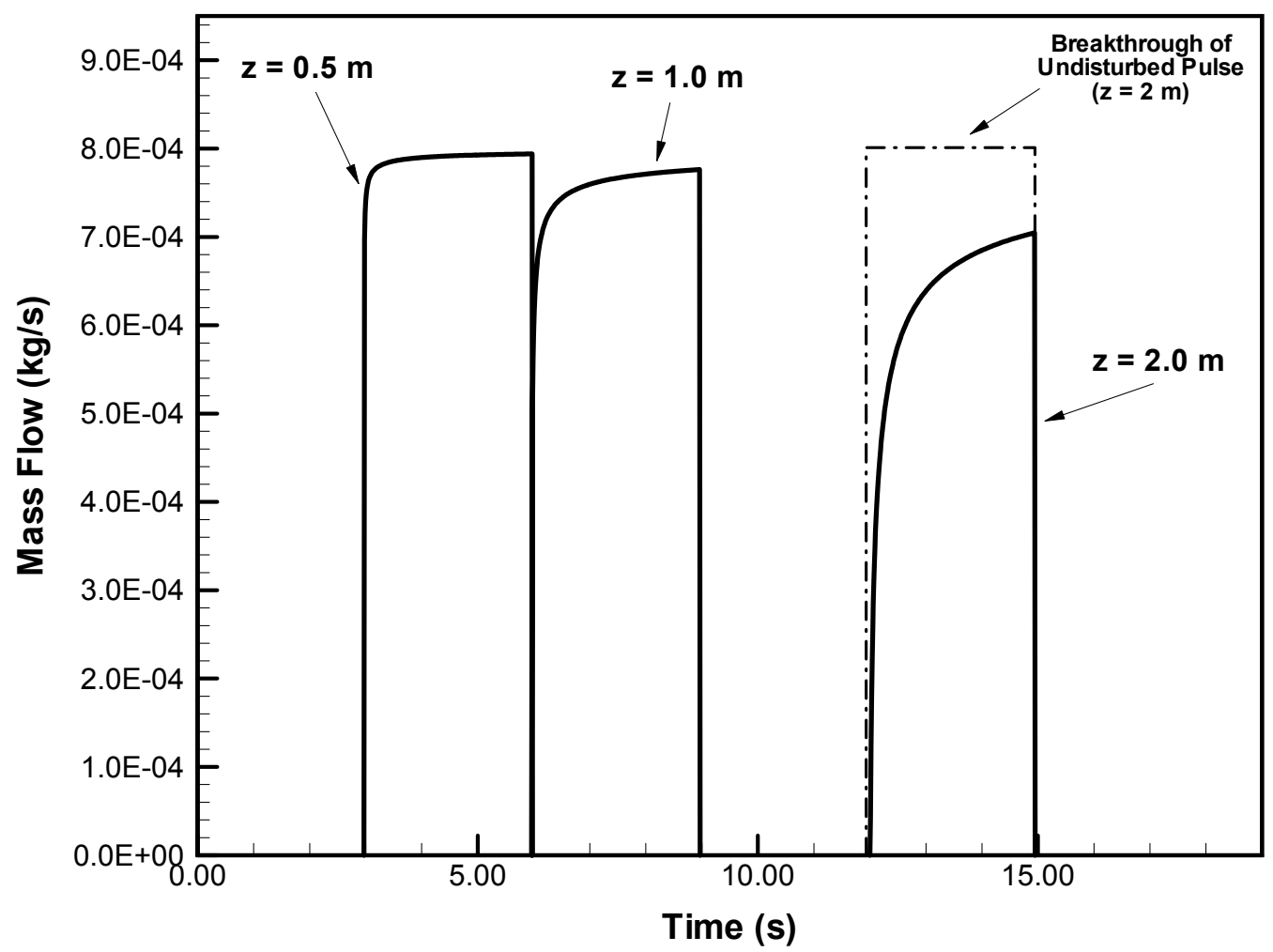

Figure 13: Breakthrough of mass flow for infiltration event Case 2, at $z=0.5 \mathrm{~m}, 1 \mathrm{~m}$, and $2 \mathrm{~m}$ 
It is obvious from Figures 12 and 13 that the total mass flowing past a given location decreases as the liquid pulse moves down the fracture. The further the infiltrating liquid front has penetrated into the superheated region, the less water is available. Therefore, during the heating phases of the repository, the potential of seepage into drifts at Yucca Mountain will be strongly affected by the extent of the superheated region forming above the drifts. This is demonstrated in Figure 14, where total breakthrough of mass is plotted as a function of vertical infiltration distance, using output file TOTMASS.TEC. For Case 1, 74\% of the injected mass arrives at the tunnel if the boiling-point isotherm is only $1 \mathrm{~m}$ away from the crown. About $10 \%$ of the total injected mass is captured for a superheated region of $2 \mathrm{~m}$ extent, and no water seeps into the drift for infiltration distances above $2.24 \mathrm{~m}$. A similar dependence is observed for Case 2, where total breakthrough of mass is $94 \%$ at $1 \mathrm{~m}, 77 \%$ at $2 \mathrm{~m}$, and $50 \%$ at $3 \mathrm{~m}$.

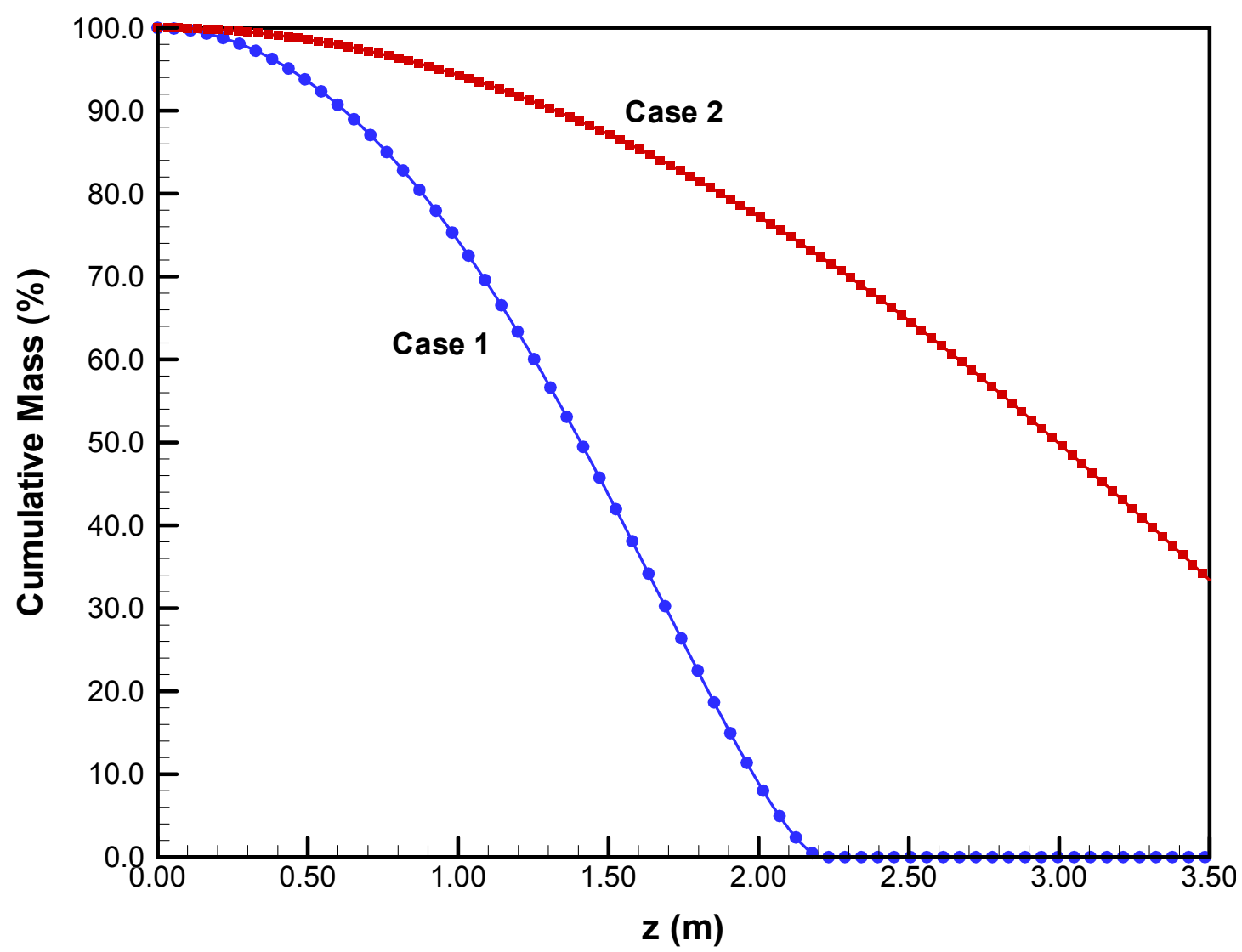

Figure 14: Cumulative mass collected at location z, compared to total injected mass (in \%)

Note that the exact analytical solution for the rock temperatures is recommended, because it gives exact results $(I R O C K=2)$. The approximate fitting-function solution $(I R O C K=1)$ is mainly included in this code for future development; it allows for time-dependent boundary conditions at the fracture-rock interface, needed in case of cyclic heating and cooling phases. Nevertheless, choice of $I R O C K=1$ gives results close to the exact solution for Cases 1 and 2. In Case 1, maximum penetration with $I R O C K=1$ is $2.25 \mathrm{~m}$, compared to $2.24 \mathrm{~m}$ for $I R O C K=2$. In Case 2, the water mass collected at the drift crown is $49.8 \%$ with $I R O C K=1$, compared to $49.9 \%$ with $I R O C K=2$. Maximum penetration in absence of the drift is $4.72 \mathrm{~m}$ compared to 4.73 $\mathrm{m}$. 


\subsection{Long-Term Finger Flow}

TH_PULSE can analyze the flow behavior of continuous infiltration events by setting pulse duration and extent of model area to appropriately large values in INP. This is demonstrated below, using the properties of Case 1 as an example. Note that pulse duration is set to 50,000 s, and that the total extent of the model area is $15.0 \mathrm{~m}$. The maximum time step size is $1 \mathrm{~s}$, in order to limit the number of simulation time steps (see Table 3.3.1). Since we are not interested in calculating potential seepage, the extent of the superheated zone above the drift wall is adjusted to a generic value of $16.0 \mathrm{~m}$, slightly larger than the model area. TH_PULSE will not calculate potential seepage if the drift is located outside the model area. In the first simulation run, it is assumed that the rock-temperature boundary condition is set at infinity $(\operatorname{IROCK}=2)$.

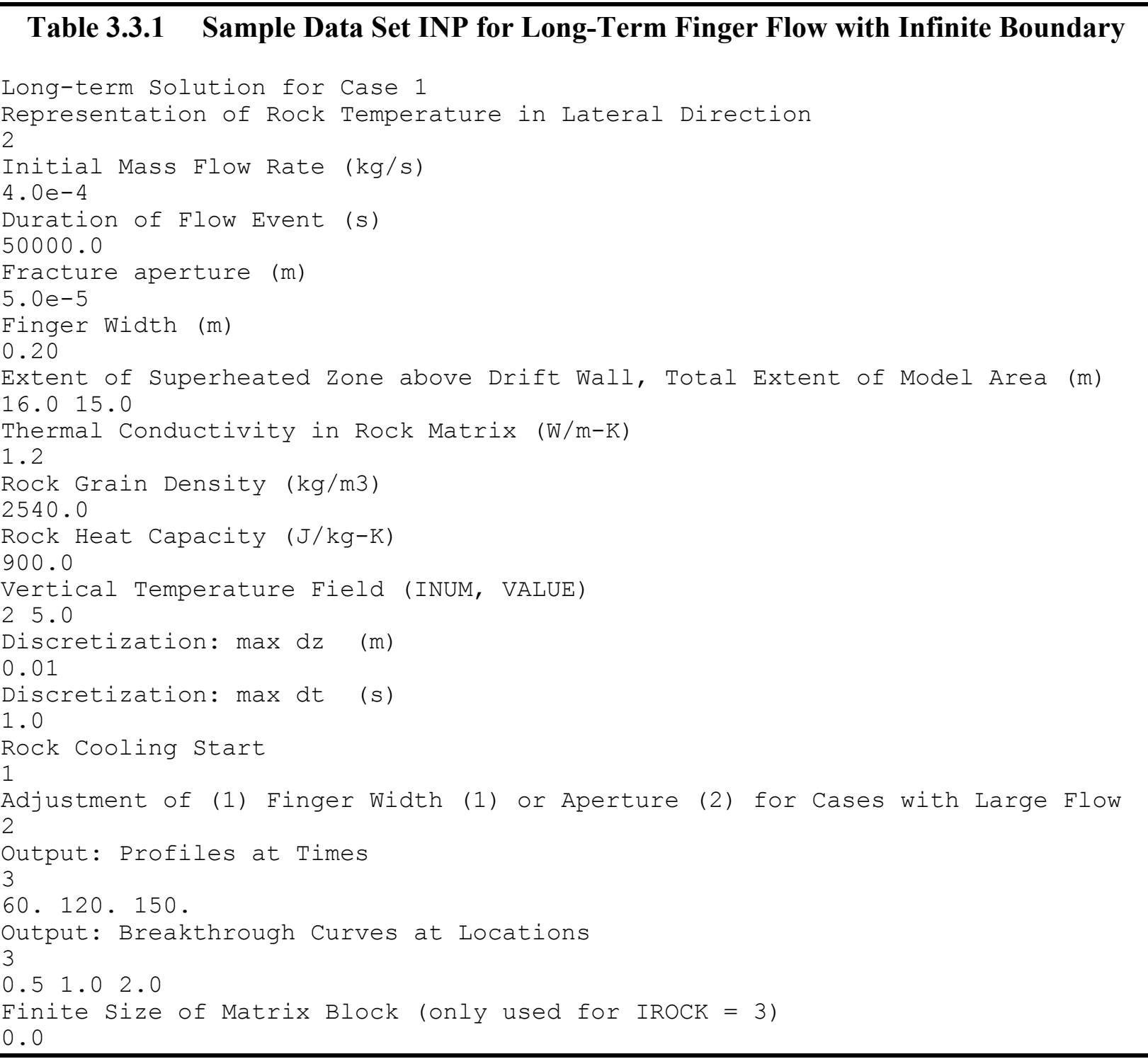

Note that the maximum time scale $t_{m}$ for validity of the semi-analytical solution is $762 \mathrm{~s}$, using Equation (10) and applying the properties of Case 1. This is much smaller than the time period chosen in this example. This problem is circumvented by increasing the ribbon width until Equation (10) is satisfied. Scaling mass flow rate by the same factor guarantees that the 
simulation results remain identical. A factor of 10 , for example, gives a finger width of $0.2 \mathrm{~m}$ and a mass flow rate of $4.0 \times 10^{-4} \mathrm{~kg} / \mathrm{s}$. Using this finger width, the maximum time becomes sufficiently large, i.e., $t_{P}=76,190 \mathrm{~s}$. The input file INP is adjusted accordingly.

Table 3.3.2 gives a listing of the screen information for the long-term simulation run. Although the number of space increments (and particularly the number of time steps) is very large, simulation time is on the order of a few minutes only. However, the maximum size NMAX of array $X M F$ is exceeded, and TH_PULSE switches to a "selected output" mode. Only one plotfile is generated, i.e., FRONT.TEC.

\section{Table 3.3.2 Sample Screen Dump for Long-Term Finger Flow with Infinite Boundary}

PROPERTIES :

$=======(2=0$

Thermal Diffusivity (m2/s): $\quad 5.2493438320210 \mathrm{D}-07$

Fracture Permeability $(\mathrm{m} 2)$
Maximum Saturated Flow $(\mathrm{kg} / \mathrm{s}): \quad 6.4794007659756 \mathrm{D}-05$

Maximum Saturated Flow Velocity (m/s): 6.7423525140224D-03

Adjusted Aperture due to Large Flow Event: 9.1723028788946D-05

Adjusted Fracture Permeability (m2) 7.0109283418481D-10

Adjusted Maximum Saturated Flow (kg/s): 4.0000000000000D-04

Adjusted Maximum Saturated Flow Velocity (m/s): 2.2689672159020D-02

Maximum Time for 1D Conduction Assumption (s): 76200.000000000

CHARACTERISTIC PARAMETERS

$==================$

Evaluation at $\mathrm{L}=15.000000000000$

Characteristic Time, Length: $661.09372999632 \quad 3.5344088501661$

Characteristic Time, Vaporization Rate: $\quad 661.09372999632 \quad 18.011461168053$

INITIAL DISCRETIZATION

$================$

Space discretization

$\begin{array}{llll}\mathrm{dz}, \text { zmax, nstep } & 1.0000031802685 \mathrm{D}-02 & 15.000047704027 & 1500\end{array}$

Time discretization

$d t$, tmax, nmass $0.44073055496791 \quad 50000.000000000 \quad 113448$

SIMULATION LOOP

$============$

Maximum Penetration of First Volume: $\quad 0.79817966350486$

Maximum Penetration Length without Drift: 11.926484550063

Reached at Time: 50525.194213241

POSTPROCESSING

$==========$

Required Array XMF too Large at Stream No.: 29224

Output Generation switched to Front Penetration only

Figure 15 shows penetration distance versus time for a period of 50,000 s. The increase in penetration distance becomes very small for large times; however, a steady-state situation is not reached. (Steady state means that the penetration of the liquid front comes to an end while infiltration at the top is ongoing.) In fact, a continuous infiltration event can never reach steady state due to the assumption of a laterally infinite rock matrix $(I R O C K=2)$. This assumption implies that the lateral perturbation of the rock temperature continues to spread for all times. Thus, there is always a (small) decrease of the rock surface temperature gradient from one 
bucket of water to the next one released, and each bucket will travel a little further than the previous one. This increase in travel length, however, may become infinitesimally small as time reaches infinity.

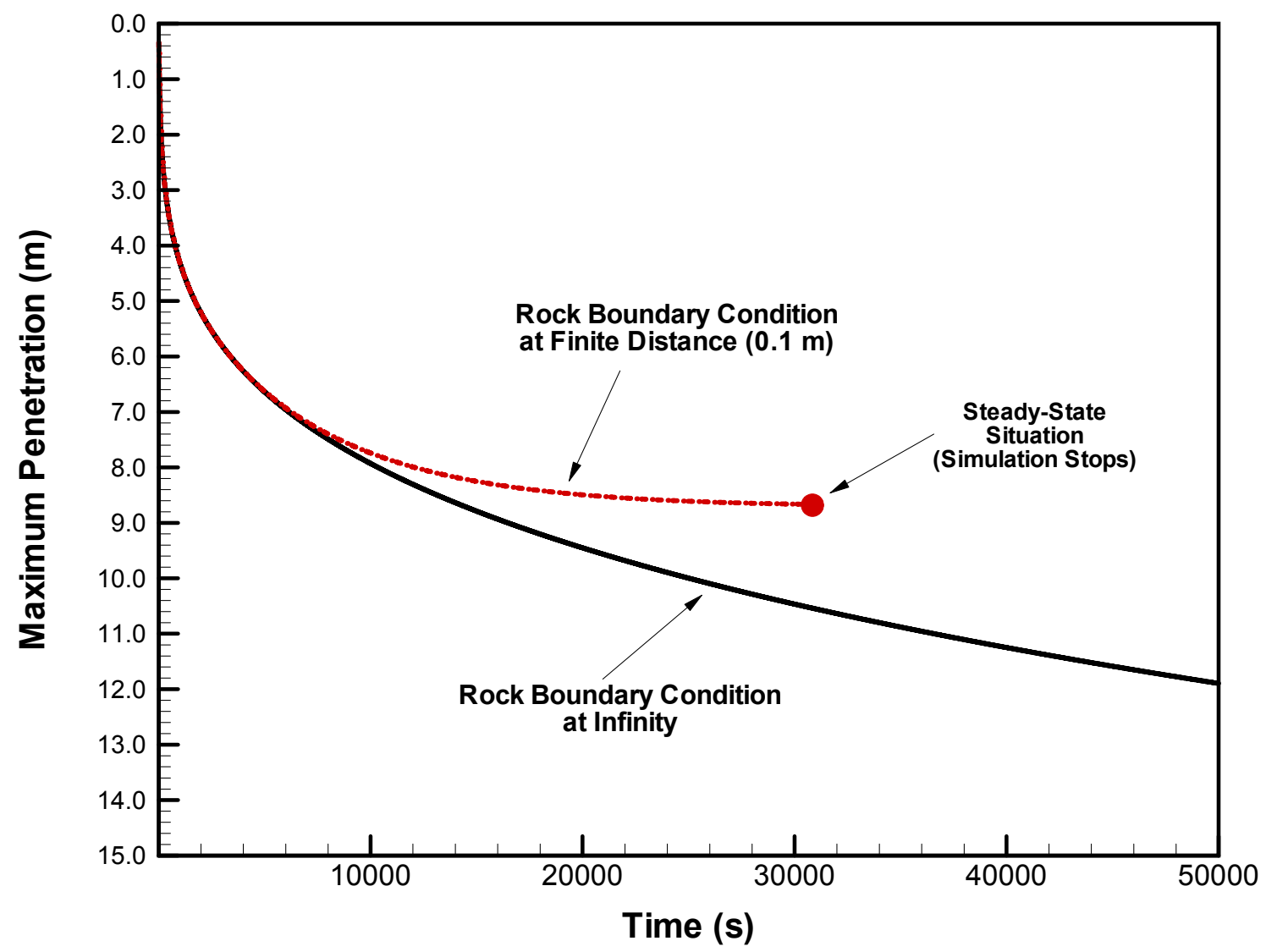

Figure 15: Penetration distance versus time for long-term simulation. Two rock boundary conditions are chosen: infinite boundary $(I R O C K=2)$ and finite boundary at $0.1 \mathrm{~m}$ $(\operatorname{IROCK}=3)$

A different result is obtained if a constant temperature boundary is applied at finite distance into the rock $(I R O C K=3)$. In this case, a steady-state rock temperature field is established at some large time after initial perturbation, and subsequent buckets of water experience identical rock-temperature gradients and identical vaporization rates along the penetration distance. The liquid mass injected at the top of the superheated region and the total vaporized mass eventually equilibrate, and the infiltration comes to a final stop, reaching steady-state conditions. Note, however, that the time scale for reaching a steady-state situation is generally larger than time scales of practical interest.

An example for long-term steady-state behavior is given in Figure 15, based on a simulation with $I R O C K=3$ and a finite distance $d=0.1 \mathrm{~m}$. All other parameters remain unchanged from the above simulation. The screen dump information for this new simulation run is listed in Table 3.3.3. The finite-boundary-condition curve starts to deviate significantly from the infiniteboundary results after about $10,000 \mathrm{~s}$. At this time, the temperature penetration in the rock has extended to the rock boundary at $\mathrm{d}=0.1 \mathrm{~m}$ and becomes affected by the fixed temperature. Steady-state conditions finally are established after about $31,000 \mathrm{~s}$. At this point, the rate of 
water vaporization equals the input mass flow at the top of the superheated region, and the water pulse remains at a constant length of $8.67 \mathrm{~m}$ as long as water is supplied at the top. TH_PULSE automatically checks for steady-state conditions. The simulation run is stopped in cases where subsequent submasses arrive at the same maximum penetration.

\section{Table 3.3.3 Sample Screen Dump for Long-Term Finger Flow with Finite Boundary}

PROPERTIES :

$=======+2=$

Thermal Diffusivity (m2/s): $\quad 5.2493438320210 \mathrm{D}-07$

Fracture Permeability (m2) 2.0833333333333D-10

Maximum Saturated Flow (kg/s): 6.4794007659756D-05

Maximum Saturated Flow Velocity (m/s): 6.7423525140224D-03

Adjusted Aperture due to Large Flow Event: 9.1723028788946D-05

Adjusted Fracture Permeability (m2) 7.0109283418481D-10

Adjusted Maximum Saturated Flow (kg/s): 4.0000000000000D-04

Adjusted Maximum Saturated Flow Velocity (m/s): 2.2689672159020D-02

Maximum Time for 1D Conduction Assumption (s): 76200.000000000

Time when rock gradient becomes linear (s): 38100.000000000

CHARACTERISTIC PARAMETERS

$========================$

Evaluation at $\mathrm{L}=16.000000000000$

Characteristic Time, Length: $705.16664532941 \quad 3.5918977642738$

Characteristic Time, Vaporization Rate: 705.16664532941 19.842300912279

INITIAL DISCRETIZATION

$=================$

Space discretization

dz, zmax, nstep $\quad 1.0000031802685 \mathrm{D}-02 \quad 15.000047704027 \quad 1500$

Time discretization

dt, tmax, nmass $0.44073055496791 \quad 50000.000000000 \quad 113448$

SIMULATION LOOP

$=========$

Maximum Penetration of First Volume: $\quad 0.79818636156700$

Continuous Liquid Pulse ends at Length: $\quad 8.6700276620348$

Reached at Time: 31116.899376327

POSTPROCESSING

$=========$

Required Array XMF too Large at Stream No.: 29603

Output Generation switched to Front Penetration only 


\subsection{Code Verification}

TH_PULSE is verified in two ways. First, an alternative numerical solution scheme is applied to compare results for the short-term pulse flow behavior. Second, the long-term results are verified using the approximate analytical solution of Phillips [1996].

\subsubsection{Short-Term Verification}

A standard finite-volume simulator (FVM) is applied for comparison with TH_PULSE. The fracture ribbon of length $L=3.0 \mathrm{~m}$ is represented with one-dimensional vertical finite volumes of uniform aperture and thickness. Simulations are performed using the TOUGH2 code that allows for the coupled transport of water, vapor, air, and heat in porous and fractured media [Pruess et al., 1999]. One component is considered (water) available in two co-existing phases (liquid, vapor). At initial state, no liquid water exists in the model domain; conditions are vaporstatic at temperature $T_{R I}$ and atmospheric pressure $P=87,000 \mathrm{~Pa}$. Starting with $t=0 \mathrm{~s}$, water with an enthalpy of $400 \mathrm{KJ} / \mathrm{kg}$, corresponding to a temperature of approximately $96^{\circ} \mathrm{C}$, is injected at the top of the superheated fracture domain.

For representation of the rock matrix, a special feature of TOUGH2 is applied that accounts for conductive heat exchange between fracture faces and adjacent semi-infinite half-spaces beyond the fracture walls. Following the methodology of Vinsome and Westerveld [1980], TOUGH2 approximates the temperature profile in the semi-infinite conductive rock layer by a simple, yet very accurate trial function (see Section 1.2.2). Note that the numerical simulator requires a uniform initial temperature field for the semi-infinite half-space. Therefore, the comparison between TOUGH2 results and results obtained with the TH_PULSE is conducted for a uniform initial temperature case with $T_{R I}=103.5{ }^{\circ} \mathrm{C}$ (settings in TH_PULSE: $I N U M=1$, $V A L U E=103.5$ ). All other properties are identical to the properties of Cases 1 and 2, as presented in Section 3.2.

Two aspects of the numerical simulation technique deserve mentioning. The first is related to the production of steam as water is vaporized. To avoid pressurization of the model domain, each fracture volume is connected to a large-volume boundary element. The vapor generated is allowed to release into this boundary element so that pressure in the model domain remains at atmospheric conditions. The second aspect considers the functional relationship between capillary pressure, saturation, and relative permeability that needs to be prescribed in TOUGH2. To precisely reproduce the hydraulic conditions assumed in the new semi-analytical solution scheme, we chose to neglect capillary forces while defining a simple linear relative permeability function with $k_{r}=S_{l}$. This guarantees a constant value of flow velocity $v_{P}$ for the infiltrating liquid pulse, independent of the decrease in mass flow rate (saturation) along the infiltration distance.

The finite-volume simulations performed are very sensitive to the vertical discretization. Different grids were analyzed with vertical increments ranging from $1 \mathrm{~mm}$ to $50 \mathrm{~mm}$, and significantly different front penetration patterns were observed. This is demonstrated in the dimensionless mass flow profiles $\left(m(z, t) / m_{P}\right)$ presented in Figure 16, for Case 1 at $90 \mathrm{~s}$ and Case 2 at $18 \mathrm{~s}$. The best agreement between the semi-analytical time-marching scheme and the finite-volume results is obtained for the $1 \mathrm{~mm}$ discretization. The less refined the TOUGH2 grid, the shorter the simulated maximum infiltration of the liquid finger, and the smaller the 
cumulative mass flow collected at a given location. Evidently, this effect is related to numerical dispersion phenomena that increase the available cross-sectional area for conductive heat transfer. This finding has two important implications: (1) standard Eulerian solution schemes using fixed grids (FEM, FDM, FVM) require highly refined discretizations for simulating flow events and heat-exchange processes that significantly depend on the dispersion characteristics; (2) natural (physical) dispersion processes (e.g., stemming from fracture aperture variation) may significantly increase the effect of vaporization on the propagating pulse flow.

Overall, the agreement between TOUGH2 results obtained with fine discretization and the new time-marching scheme is reasonably good. The main attributes of episodic pulse flow in a superheated regime are well captured in both Cases 1 and 2, which becomes particularly evident in comparison to the profiles of a front moving in absence of vaporization. Yet noticeable differences remain between the two methods, caused by the nature of the Eulerian versus Lagrangian solution schemes. A finite-volume scheme will never be able to precisely model the sharp-front propagation capability of a Lagrangian solution method. In terms of predicting the potential seepage into tunnels at Yucca Mountain, the solution method in TH_PULSE gives conservative estimates, since no accounting is made for spreading of the pulse.

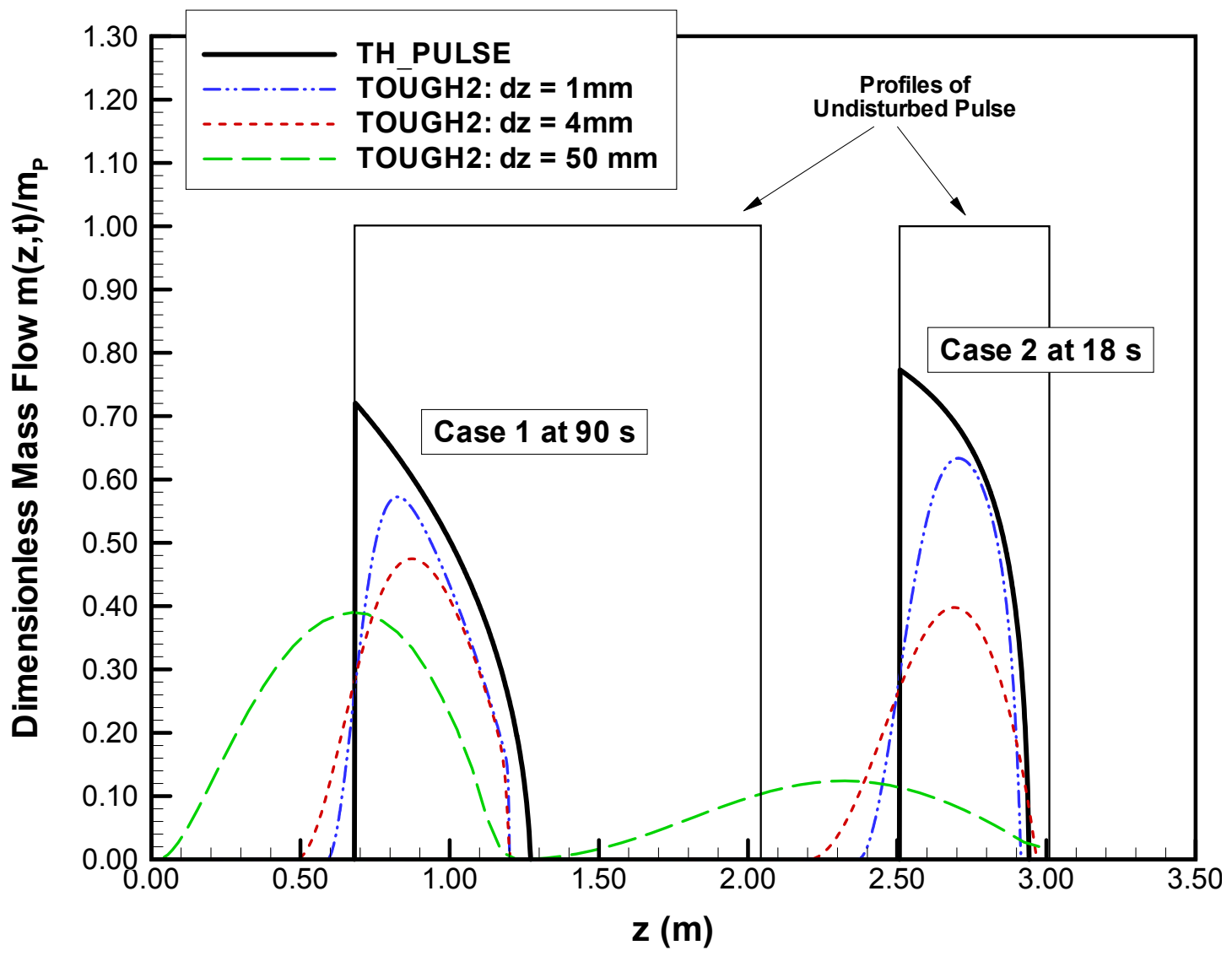

Figure 16: Profiles of dimensionless mass flow for infiltration event Case 1 at $t=90 \mathrm{~s}$ and infiltration event Case 2 at $t=18 \mathrm{~s}$. The initial rock temperature is uniform. Results compare new solution scheme with TOUGH2 simulation, using three different vertical discretization lengths. 


\subsubsection{Long-Term Verification}

At large time scales, the front penetration of a liquid pulse can be verified using an analytical solution given by Phillips [1996] (see Appendix A). Figure 17 shows this analytical solution compared with the simulation results of the infinite rock boundary case presented in Section 3.3. Also plotted is the constant-velocity curve $l(t)=v_{P} t$, with $v_{P}=2.27 \mathrm{~cm} / \mathrm{s}$. Clearly, TH_PULSE results agree favorably with the analytical solution at large times, and with the constant-velocity curve at short times. The analytical solution defines an asymptotic approximation function to estimate the long-term behavior of pulse infiltration. Similarly, the constant-velocity curve forms an asymptotic solution for very early times. The intermediate time scale, however, which is relevant in most cases of short-term episodic pulse events, cannot be represented by any of the approximate solutions. The exact solution must be used as calculated from the new semianalytical solution scheme.

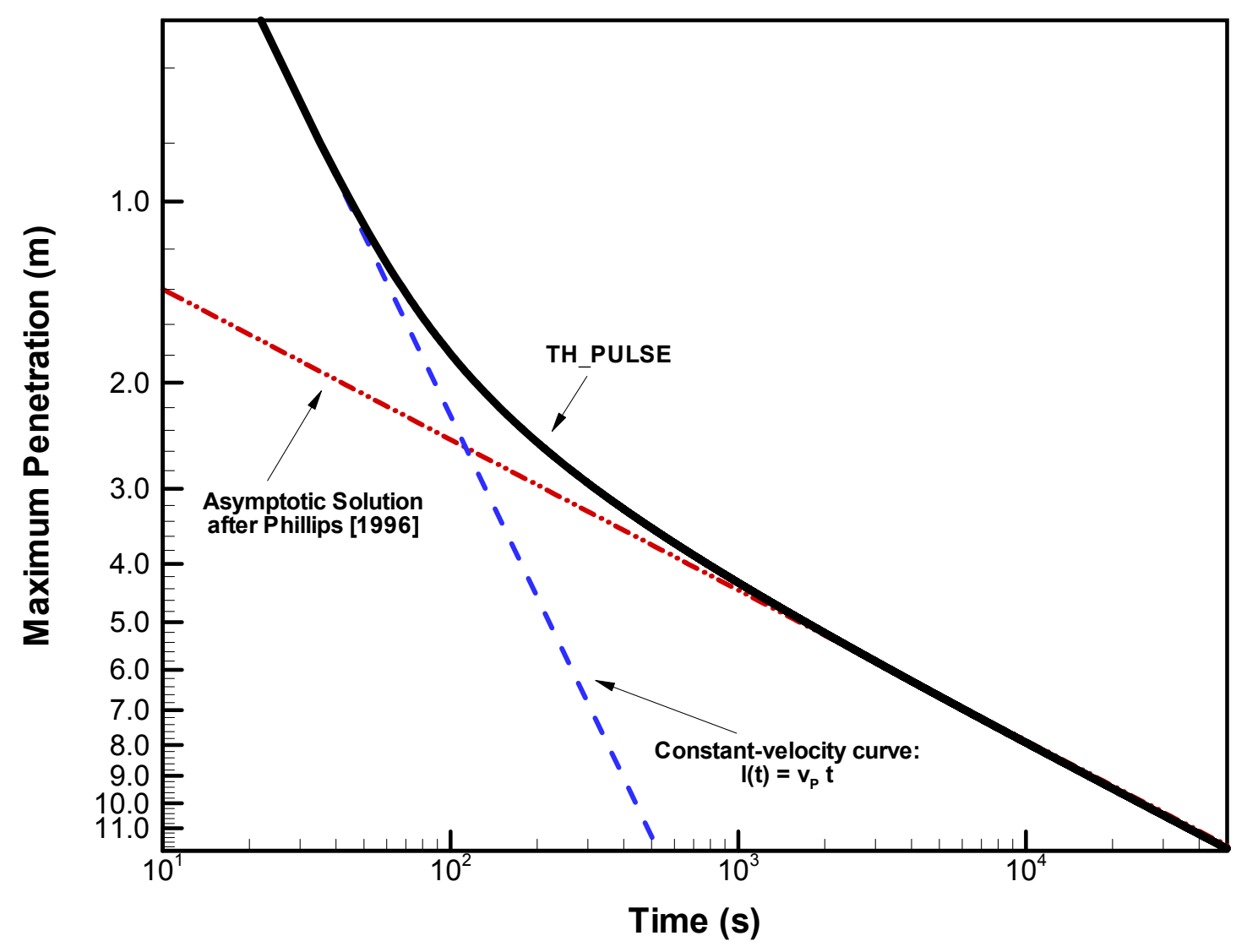

Figure 17: Penetration distance versus time, for continuous infiltration. Results compare TH_PULSE results with analytical solution for asymptotic long-term behavior. 


\section{Summary}

This report describes the code TH_PULSE developed at the Ernest Orlando Lawrence Berkeley National Laboratory (Berkeley Lab). The code features a new semi-analytical method for calculating the transient gravity-driven flow of liquid fingers in superheated fractured rock. The method is based on a simplified conceptual model of the complex fluid-flow and heattransfer behavior in a vertical fracture surrounded by hot rock. The solution scheme utilizes a time-marching algorithm that tracks the propagation of finite submasses of water, while different analytical and fitting-function solutions are applied to consider mass losses resulting from heat conduction and subsequent boiling from the adjacent hot rock. Note that the solution scheme can be adopted to comparable problems of liquid finger flow, e.g., when considering effects of matrix imbibition.

The numerical algorithm is simple, robust, and very fast, thus allowing for time-consuming Monte-Carlo-type analyses. Simulation results from the new solution compare favorably with results derived from an analytical asymptotic solution, as well as with results obtained using a standard finite-volume simulator. Several sample cases are presented to demonstrate the code's potential and range of applicability. 


\section{Nomenclature}

$C_{m} \quad$ rock heat capacity $(\mathrm{J} / \mathrm{kg}-\mathrm{K})$

$d \quad$ finite distance from rock surface to location of constant rock temperature boundary $(\mathrm{m})$

$d t \quad$ time step (s)

$d z \quad$ vertical space increment $(\mathrm{m})$

$g \quad$ gravitational acceleration $\left(\mathrm{m} / \mathrm{s}^{2}\right)$

$h \quad$ specific enthalpy of vaporization $(\mathrm{J} / \mathrm{kg})$

$k_{m} \quad$ rock thermal conductivity $(\mathrm{W} / \mathrm{m}-\mathrm{K})$

$k_{r} \quad$ relative permeability

$l(t) \quad$ penetration distance of the tip of the liquid front at time $t(\mathrm{~m})$

$L^{*} \quad$ characteristic length

$L \quad$ vertical extent of superheated region above drift crown (m)

$L_{S} \quad$ total vertical extent of superheated region (model extent) (m)

$M_{P} \quad$ total injected mass of infiltration event $(\mathrm{kg})$

$M_{j} \quad$ submass $(\mathrm{kg})$

$m_{P} \quad$ initial mass flow rate of infiltration event $(\mathrm{kg} / \mathrm{s})$

$m \quad$ mass flow rate $(\mathrm{kg} / \mathrm{s})$

$n_{\text {Mass }}$ number of submasses

$n_{z} \quad$ number of space increments

$P \quad$ pressure $(\mathrm{Pa})$

$p, q \quad$ fitting coefficients for approximate solution after $\lambda$

$S_{l} \quad$ liquid saturation

$T_{P} \quad$ liquid (boiling) temperature $\left({ }^{\circ} \mathrm{C}\right)$

$T_{R} \quad$ rock temperature $\left({ }^{\circ} \mathrm{C}\right)$

$T_{R I} \quad$ initial rock temperature $\left({ }^{\circ} \mathrm{C}\right)$

$T^{\prime} \quad$ temperature gradient at fracture-rock interface $\left({ }^{\circ} \mathrm{C} / \mathrm{m}\right)$

$t$ time (s)

$t^{*} \quad$ characteristic time $(\mathrm{s})$

$t_{P} \quad$ duration of infiltration event (s)

$t_{0}(z)$ time interval after initial infiltration until arrival of the liquid finger at location $\mathrm{z}(\mathrm{s})$

$t_{m} \quad$ maximum time interval for validity of $1-\mathrm{D}$ heat conduction assumption (s)

$t_{a} \quad$ time interval used for definition of validity range of asymptotic solutions (s)

$V^{*} \quad$ characteristic vaporization rate

$v_{P} \quad$ flow velocity $(\mathrm{m} / \mathrm{s})$

$w \quad$ finger width $(\mathrm{m})$

$x \quad$ distance from fracture wall (m)

$z \quad$ vertical distance $(\mathrm{m})$

(2b) fracture aperture (m)

$\alpha \quad$ parameter used for definition of initial rock temperature $\left({ }^{\circ} \mathrm{C} / \mathrm{m}^{2}\right)$

$\beta \quad$ initial rock temperature gradient $\left({ }^{\circ} \mathrm{C} / \mathrm{m}\right)$

$\kappa \quad$ rock thermal diffusivity, given as $k_{m} / \rho_{m} C_{m}\left(\mathrm{~m}^{2} / \mathrm{s}\right)$

$\lambda$ dimensionless parameter used for finite matrix conduction problem, $\lambda=\kappa\left(t-t_{0}(z)\right) / d^{2}$

$\mu \quad$ dynamic viscosity $(\mathrm{kg} / \mathrm{m}-\mathrm{s})$

$\rho_{m} \quad$ rock grain density $\left(\mathrm{kg} / \mathrm{m}^{3}\right)$

$\rho_{l} \quad$ liquid density $\left(\mathrm{kg} / \mathrm{m}^{3}\right)$ 


\section{Acknowledgment}

This work was supported by the Director, Office of Civilian Radioactive Waste Management, U.S. Department of Energy, through Memorandum Purchase Order EA9013MC5X between Bechtel SAIC Company, LLC, and the Ernest Orlando Lawrence Berkeley National Laboratory (Berkeley Lab). The support is provided to Berkeley Lab through the U.S. Department of Energy Contract No. DE-AC03-76SF00098. Review and comments of Dan Hawkes, Guoping Lu and Sumit Mukhophadhyay from Berkeley Lab are gratefully appreciated. We are also very grateful to Sumit Mukhophadhyay for making the analytical solution of the finite matrix conduction problem in Section 1.2.3 available for use in TH_PULSE.

\section{References}

Birkholzer, J.T., and Y.W. Tsang, Modeling the thermal-hydrologic processes in a large-scale underground heater test in partially saturated fractured tuff, Water Resour. Res., 36(6), 1431-1447, 2000.

Buscheck, T.A., and J.J. Nitao, The analysis of repository-heat-driven hydrothermal flow at Yucca Mountain, in Proceedings of the 4th Annual High-Level Radioactive Waste Management Conference, Las Vegas, NV, 449-471, 1993.

Carslaw, H.S., and J.C. Jaeger, Conduction of heat in solids, $2^{\text {nd }}$ edn, Oxford University Press, Oxford, 1959.

Corey, A.T., The interrelation between gas and oil relative permeabilities, Producers Monthly, 38-41, 1954.

Glass, R.J., Modeling gravity-driven fingering in rough-walled fractures using modified percolation theory, in Proceedings of the 4th Annual High-Level Radioactive Waste Management Conference, Las Vegas, NV, 1993.

Glass, R.J., and M.J. Nicholl, Physics of gravity fingering of immiscible fluids within porous media: An overview of current understanding and selected complicating factors, Geoderma, 70, 133-163, 1996.

Ho, C.K., and M.L. Wilson, Calculation of discrete fracture flow paths using dual-continuum models, in Proceedings of the 8th International High-Level Radioactive Waste Management Conference, Las Vegas, NV, 1998.

Kneafsey, T.J., and K. Pruess, Laboratory experiments on heat-driven two-phase flows in natural and artificial fractures, Water Resour. Res., 34(12), 3349-33676, 1998.

Nicholl M. J., R.J. Glass, and S.W. Wheatcraft, Gravity-driven infiltration instability in initially dry nonhorizontal fractures, Water Resour. Res., 30(9), 2533-2546, 1994.

Nitao, J.J., and T.A. Buscheck, Infiltration of a liquid front in an unsaturated, fractured porous medium, Water Resour. Res., 27(8), 2099-2112, 1991.

Nitao, J.J., T.A. Buscheck, and D.A. Chesnut, The implications of episodic nonequilibrium fracture-matrix flow on site-suitability and total system performance assessment, in Proceedings of the 3rd Annual High-Level Radioactive Waste Management Conference, Las Vegas, NV, 1992. 
Phillips, O.M., Infiltration of a liquid finger down a fracture into superheated rock, Water Resour. Res., 32(6), 1665-1670, 1996.

Pruess, K., On vaporizing water flow in hot sub-vertical rock fractures, Transport in Porous Media, 28(3), 335-372, 1997.

Pruess, K., On water seepage and fast preferential flow in heterogeneous, unsaturated rock fractures, J. Contam. Hydrol., 30, 333-362, 1998.

Pruess, K., Oldenburg, K., and G. Moridis, TOUGH2 user's guide, Version 2.0, Rep. LBL43134 Lawrence Berkeley Natl. Lab., Berkeley, CA, 1999.

Pruess, K., and Y.W. Tsang, Thermal modeling for a potential high-level nuclear waste repository at Yucca Mountain, Nevada, Rep. LBL-33597 UC-200, Lawrence Berkeley Natl. Lab., Berkeley, CA, 1993.

Pruess, K., and Y.W. Tsang, Modeling of strongly heat-driven flow processes at a potential highlevel nuclear waste repository at Yucca Mountain, Nevada, Rep. LBL-35381 UC-600, Lawrence Berkeley Natl. Lab., Berkeley, CA, 1994.

Pruess, K., Y.W. Tsang, and J.S.Y. Wang, Numerical studies of fluid and heat flow near a highlevel nuclear waste packages emplaced in partially saturated fractured tuff, Rep. LBL-18552, Lawrence Berkeley Natl. Lab., Berkeley, CA, 1984.

Pruess, K., J.S.Y. Wang, and Y.W. Tsang, Modeling of strongly heat-driven flow in partially saturated fractured porous media, Memoires, XVII, 486-497, 1985.

Pruess, K., J.S.Y. Wang, and Y.W. Tsang, Effective continuum approximation for modeling fluid and heat flow in fractured porous tuff, SAND86-7000, Rep. Sandia Natl. Lab., Albuquerque, NM, 1988.

Pruess, K., J.S.Y. Wang, and Y.W. Tsang, On thermohydrologic conditions near high-level nuclear wastes emplaced in partially saturated fractured tuff, 1, Simulation studies with explicit consideration of fracture effects, Water Resour. Res., 26, 1235-1248, 1990a.

Pruess, K., J.S.Y. Wang, and Y.W. Tsang, On thermohydrologic conditions near high-level nuclear wastes emplaced in partially saturated fractured tuff, 2, Effective continuum approximations, Water Resour. Res., 26, 1249-1261, $1990 \mathrm{~b}$.

Ramspott, L.D., The constructive use of heat in an unsaturated tuff repository, in Proceedings of the 2nd Annual High-Level Radioactive Waste Management Conference, Las Vegas, NV, 1991.

Su, G.W., J.T. Geller, K. Pruess, and F. Wen, Experimental studies of water seepage and intermittent flow in unsaturated, rough-walled fractures, Water Resour. Res., 35(4), 1019-1037, 1999.

Tsang, Y.W., and J.T. Birkholzer, Predictions and observations of the thermal-hydrological conditions in the single heater test, J. Contam. Hydrol., 38(1-3), 385-425, 1999.

Tsang, Y.W., and K. Pruess, A study of thermally induced convection near a high-level nuclear waste repository in partially saturated fractured tuff, Water Resour. Res., 23, 1958-1966, 1987.

Tsang, Y.W., and K. Pruess, Preliminary studies of gas phase flow effects and moisture migration at Yucca Mountain, Nevada, Rep. LBL-28819, Lawrence Berkeley Natl. Lab., Berkeley, CA, 1989. 
Vinsome, P.K.W., and J. Westerveld, A simple method for predicting cap and base rock heat losses in thermal reservoir simulations, J. Canad. Pet. Tech., 19(3), 87-90, 1980.

Wilder, D.G., Alternative strategies - a means for saving money and time on the Yucca Mountain project, in Proceedings of the 4th Annual High-Level Radioactive Waste Management Conference, Las Vegas, NV, 1993. 


\section{Appendix A: Phillips’ Analytical Solution}

Phillips [1996] developed an analytical solution for the infiltration distance of a liquid finger flowing in superheated fractured rock as a function of time. The solution is based on a conceptual and geometrical model similar to the one introduced in Section 1.2.1 of this paper. The proposed validity range is identical to the range defined by Equation (10), giving an upper time constraint $t_{m}$. A lower limit is not provided by Phillips [1996], implying that the analytical solution is applicable at all times $t \leq t_{m}$. However, in Figure 17, the analytical solution is plotted in comparison with the TH_PULSE results. It severely overestimates infiltration distance at early times. In fact, Phillips' solution involves such a rapid initial increase of infiltration distance that the corresponding flow velocity is much larger than $v_{P}$, the gravity-driven flow velocity in the absence of vaporization (Equation (18)). The constant-velocity curve $l(t)=v_{P} t$ in Figure 17 provides an upper bound for the infiltration distance, because the liquid pulse flow cannot be faster than $v_{P}$. The rapid initial increase of infiltration distance calculated by Phillips's solution is clearly unphysical. Consequently, while his solution does provide an asymptotic approximation of the long-term flow behavior, it cannot be used for early time periods.

One must analyze Phillips' analytical solution in more detail to understand why his solution is erroneous at early times. Using the nomenclature given in this paper, the governing equation solved for in Phillips [1996] is

$$
\frac{\partial m(z, t)}{\partial z}=-f_{1} \frac{2 w k_{m}}{h} \frac{\beta z}{\sqrt{\pi \kappa\left(t-t_{0}(z)\right)}},
$$

which is similar to Equation (9). Note that the temperature term in Equation (9), $\left(T_{R I}-T_{P}\right)$, has been replaced by the term $(\beta z)$, as a uniform vertical gradient $\beta$ of the initial rock temperature field is assumed. (Also note that Phillips introduced an additional factor $f_{1}=2^{1 / 2}$ on the righthand side of Equation (A1). We have not been able to follow Phillips' rationale for using this factor. Thus, for better comparison with our results in Figure 17, we adjusted the analytical solution by using a factor of $f_{1}=1$. This shifts the resulting infiltration curve slightly, but does not change its general behavior.) For solution of Equation (A1), Phillips [1996] utilizes a simple energy balance for the vaporization of water entering the superheated region, assuming that the energy needed to completely boil off the mass of infiltrating water is proportional to the energy extracted from the rock at all times $t \leq t_{m}$. The resulting proportionality between infiltration distance and time, $l(t) \approx t^{1 / 4}$, is used to substitute the unknown time $t_{0}(z)$ in Equation (A1). Then, integration from $z=0$ to $z=l(t)$ can be readily performed, and the following relationship for the penetration of the tip of the front as a function of time is derived:

$$
l(t)=\left(\frac{4}{f_{l}^{2} \pi}\right)^{1 / 4}\left(\frac{m_{P} h}{k_{m} \beta}\right)^{1 / 2}\left(\frac{\kappa t}{w^{2}}\right)^{1 / 4} .
$$

The reason for the early-time differences between Equation (A2) and the exact solution is obvious: The above mentioned energy balance is not valid for small t. At early times, only a small fraction of the infiltrating water boils off, while the bulk of the liquid pulse moves with gravity-driven flow velocity; thus the proportionality $l(t) \approx t^{1 / 4}$ does not hold. At late times, however, the propagation of the tip of the front is dominated by retardation effects caused by boiling, independent of the characteristics of flow in the fracture. (This explains the interesting observation that Phillips' solution is independent of fracture aperture (2b), which governs the 
gravity-driven flow behavior in the fracture.) In this case, the energy balance holds, and Equation (A2) is valid.

To define an adjusted validity range for Phillips' solution, we may calculate the time period $t_{a}$ at which Equation (A2) and the constant-velocity curve $l(t)=v_{P} t$ :

$$
\left(t_{a}\right)^{3 / 4}=\frac{1}{v_{P}}\left(\frac{4}{\pi}\right)^{1 / 4}\left(\frac{m_{P} h}{k_{m} \beta}\right)^{1 / 2}\left(\frac{\kappa}{w^{2}}\right)^{1 / 4} .
$$

For $t>>t_{a}$, Equation (A1) provides an accurate asymptotic solution for the infiltration problem. In conjunction with the limiting condition $t \leq t_{m}$ given in Equation (10), the resulting validity range of Phillips' solution is thus $t_{a}<<t \leq w^{2} / \kappa$. 


\section{Appendix B: Listing for CODE TH_PULSE V1.0}

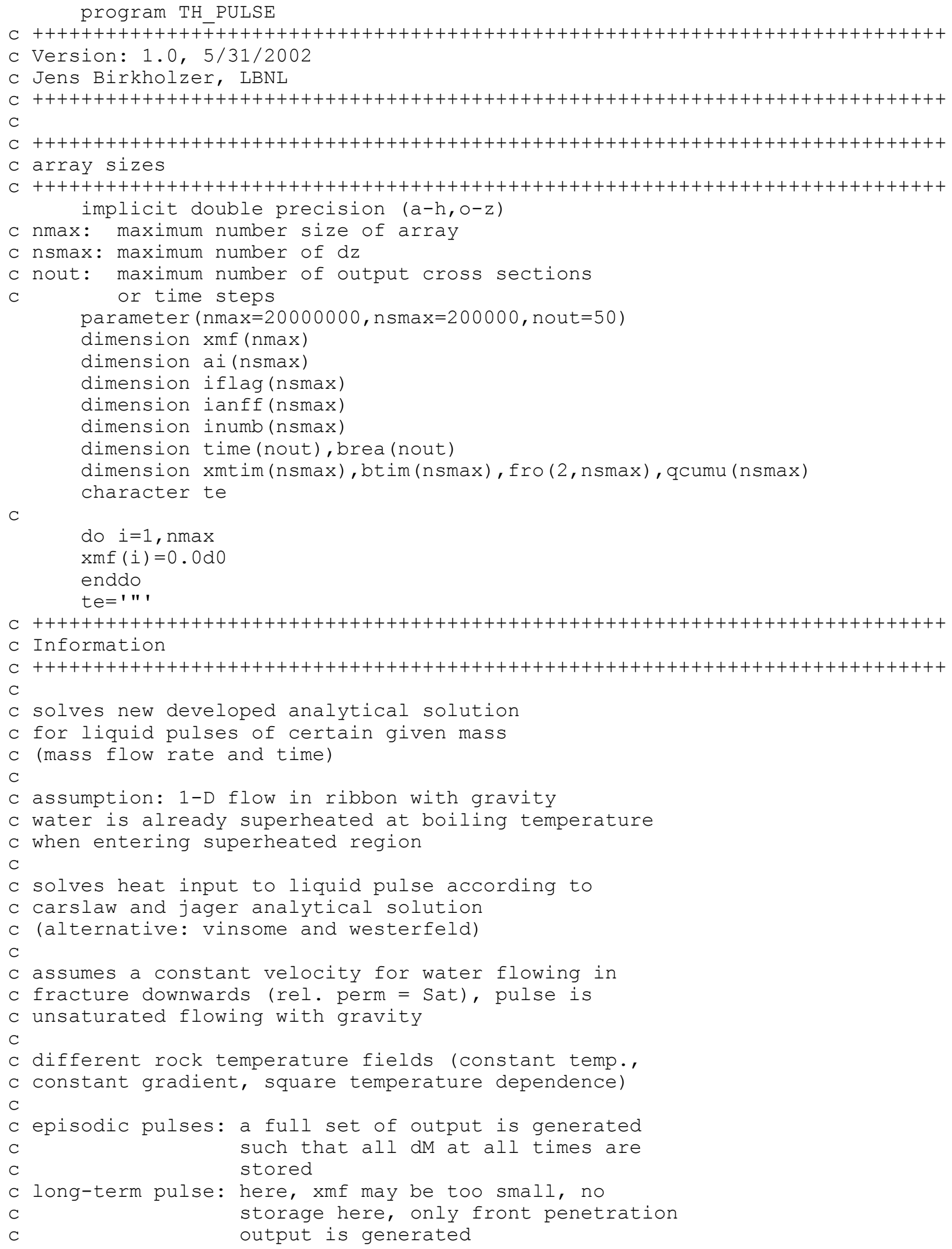




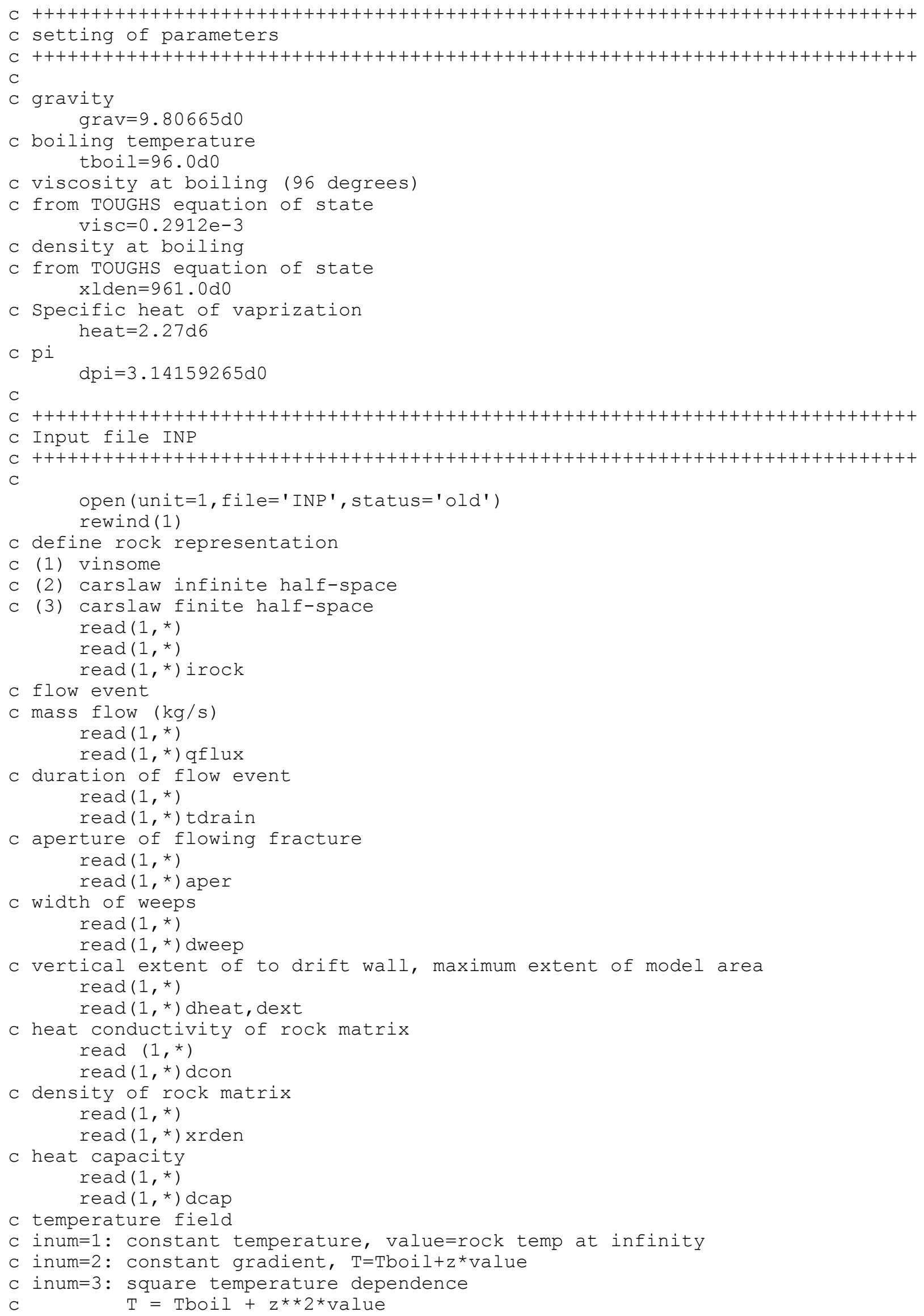


$c \max d z$

$\operatorname{read}(1, *)$

read $(1, *)$ inum, value

$\operatorname{read}(1, *)$

read $(1, *) d z \max$

$c \max d t$

$\operatorname{read}(1, *)$

read $(1, *)$ dtmax

c starting for for rock cooling

C (1) when pulse first hits dz element

C (2) when pulse makes it through middle of element

c (3) when pulse has made it through entire element

$\operatorname{read}(1, *)$

read $(1, *)$ ipulse

if (ipulse.eq.1) then

dzcrit $=0.0$

else if(ipulse.eq.2) then

dzcrit $=0.5$

elseif (ipulse.eq.3) then

dzcrit $=1.0$

endif

$\mathrm{C}$

c for flow events that exceed the maximum saturated gravity

c flow in fracture ribbon, two cases are possible:

c 1. the ribbon width is adjusted

c 2. the fracture aperture is adjusted

c (otherwise there would be a pressure buildup and a higher

c flow velocity, which can not be solved with the time marching

c scheme)

$\operatorname{read}(1, *)$

$\operatorname{read}(1, *)$ icase

c output: profiles at times $t$

read $(1, *)$

read $(1, *)$ nprof

$\operatorname{read}(1, *)$ (time (i), $i=1$, nprof)

c output: breakthrough curves at location z

$\operatorname{read}(1, *)$

read $(1, *)$ nbrea

read $(1, *)$ (brea (i), $i=1$, nbrea)

$c$ for finite half-space matrix representation

c read extent of half-space

if (irock.eq.3) then

$\operatorname{read}(1, *)$

read $(1, *)$ dboun

endif

close (1)

$\mathrm{C}$

C +++++++++++++++++++++++++++++++++++++++++++++++++++++++++++++++++++++++++++

c Calculation of thermal and flow properties

$\mathrm{C}+++++++++++++++++++++++++++++++++++++++++++++++++++++++++++++++++++++++++++$

$\mathrm{C}$

thermal diffusivity

dif $=$ dcon $/$ xrden $/$ dcap

c fracture permeability dperm=aper $* * 2.0 \mathrm{~d} 0 / 12.0 \mathrm{~d} 0$

c conductivity (equals liquid flow velocity, as $\mathrm{kr}=\mathrm{S}$ )

dvelo=dperm*xlden*grav/visc

C check if liquid flux exceeds the saturated gravity

c driven flux in fracture of width $\mathrm{w}$ gmax $=$ dvelo* $x l$ den $*$ aper* dweep

$c$ associated saturation in fractures at inlet smax =qflux / qmax

$c$ if finite half space 
C approximate time when gradient becomes linear if (irock.eq.3) tline $=2.0 \mathrm{~d} 0 * \mathrm{dboun} * \mathrm{dboun} / \mathrm{dif}$

C

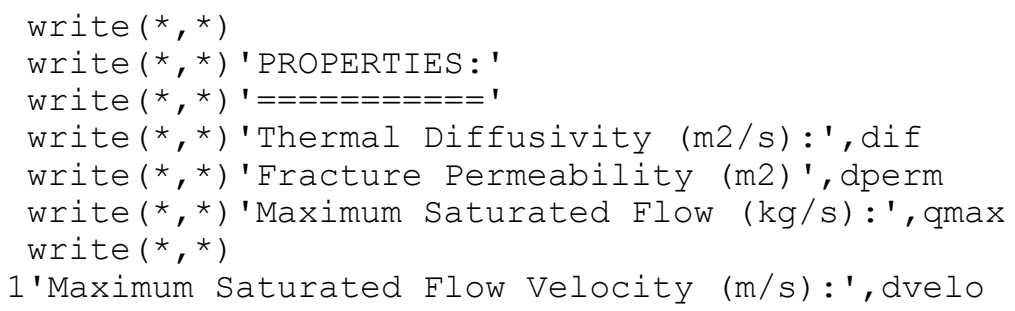




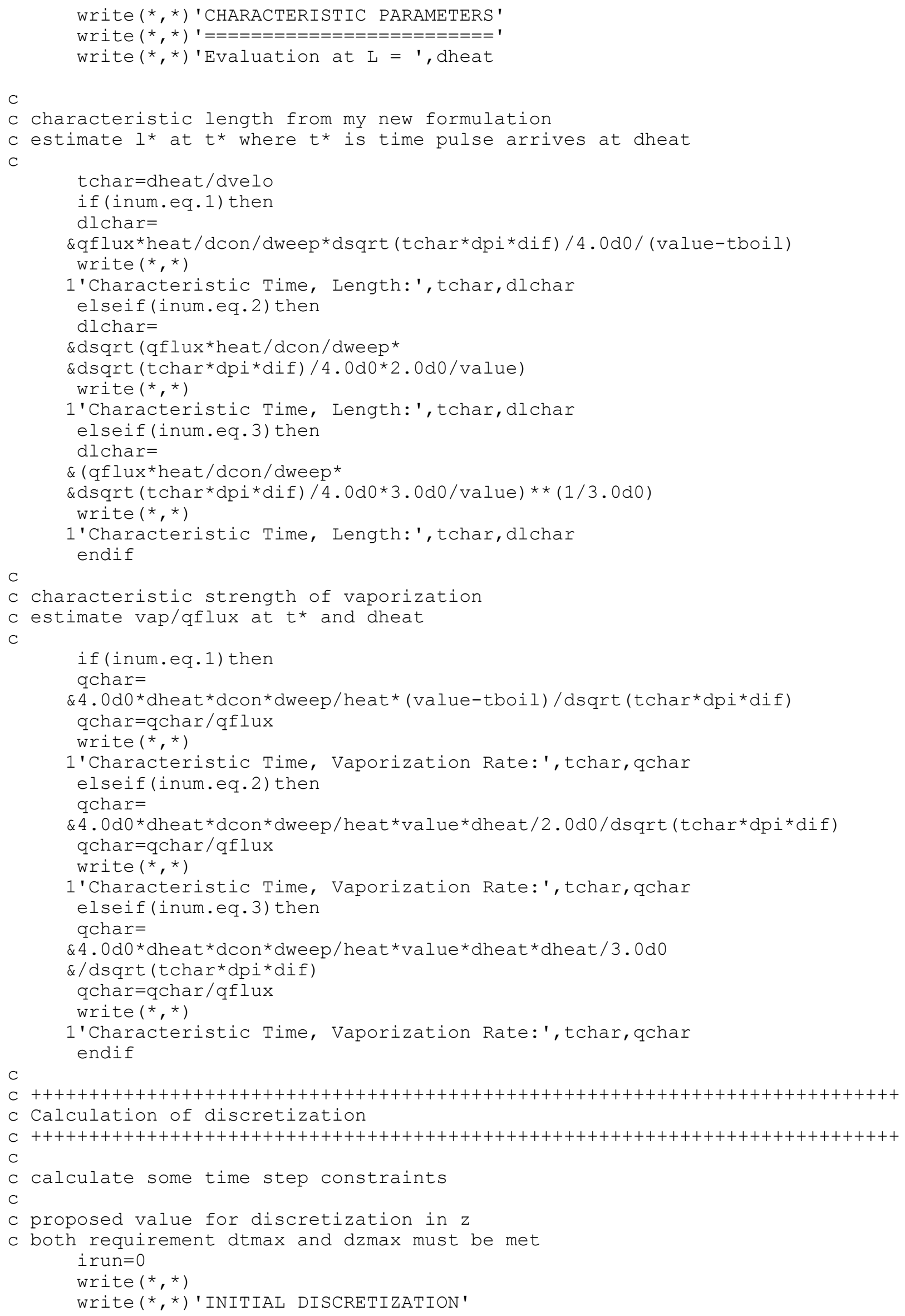


write $(*, *)^{\prime}====================$ ' $^{\prime}$

$99 \mathrm{dtzmax}=\mathrm{dzmax} / \mathrm{dvelo}$

if (dtzmax.gt.dtmax) then

dzmax $=d v e l o * d t \max$

else

dtmax $=d t z \max$

endif

c make sure that time step and number give the pulse

c drainage time

deltex $=$ dtmax

nstrea=idint (tdrain/deltex+0.5d0)

deltex=tdrain/nstrea

$\mathrm{dz}=$ deltex ${ }^{*}$ dvelo

nstep=idint $(\operatorname{dext} / d z+0.5 d 0)$

ttmax $=$ nstrea*deltex

z zmax $=$ nstep $* d z$

if (irun.eq.0) then

write $(*, *)$ 'Space discretization'

else

write $(*, *)$ 'New Space discretization'

endif

write (*,*) 'dz, zmax, nstep', dz, zzmax, nstep

write $(*, *)$ 'Time discretization'

write $(*, *)$ 'dt, tmax, nmass', deltex, ttmax, nstrea

if (nstep.gt.nsmax) stop'nstep too large'

$\mathrm{C}+++++++++++++++++++++++++++++++++++++++++++++++++++++++++++++++++++++++++++$

c Initialization of simulation part

$\mathrm{C}+++++++++++++++++++++++++++++++++++++++++++++++++++++++++++++++++++++++++++$ gdrift $=0.0 \mathrm{~d} 0$

nfro $=0$

do $i=1, n \operatorname{smax}$

ai $(i)=0.0 \mathrm{~d} 0$

iflag $(i)=0$

enddo

C

c istream: mass volume number i send out at i*deltex

c for istream: follow along flow path with istep

$\mathrm{C}$

c istep number for location of interest dheat istepd=idint (dheat/dz+0.5d0)

c loop istream

ilast $=0$

ireach $=0$

istop $=0$

iend $=0$

iepiso $=0$

ianfa $=1$

write $(*, *)$

write $(*, *)$ 'SIMULATION LOOP'

write $(*, *)^{\prime}============$ '

$\mathrm{C}+++++++++++++++++++++++++++++++++++++++++++++++++++++++++++++++++++++++++++$

c Loop over time increments

$\mathrm{C}+++++++++++++++++++++++++++++++++++++++++++++++++++++++++++++++++++++++++++$ do $i=1$, nstrea

istrea $=i$

$q 0=q f \operatorname{lux}$

ianff (i)=ianfa

c write $(*, *)$ 'istrea', istrea

$\mathrm{C}+++++++++++++++++++++++++++++++++++++++++++++++++++++++++++++++++++++++++++$

c Loop over space increments

$\mathrm{C}+++++++++++++++++++++++++++++++++++++++++++++++++++++++++++++++++++++++++++$ do $j=1$, nstep 


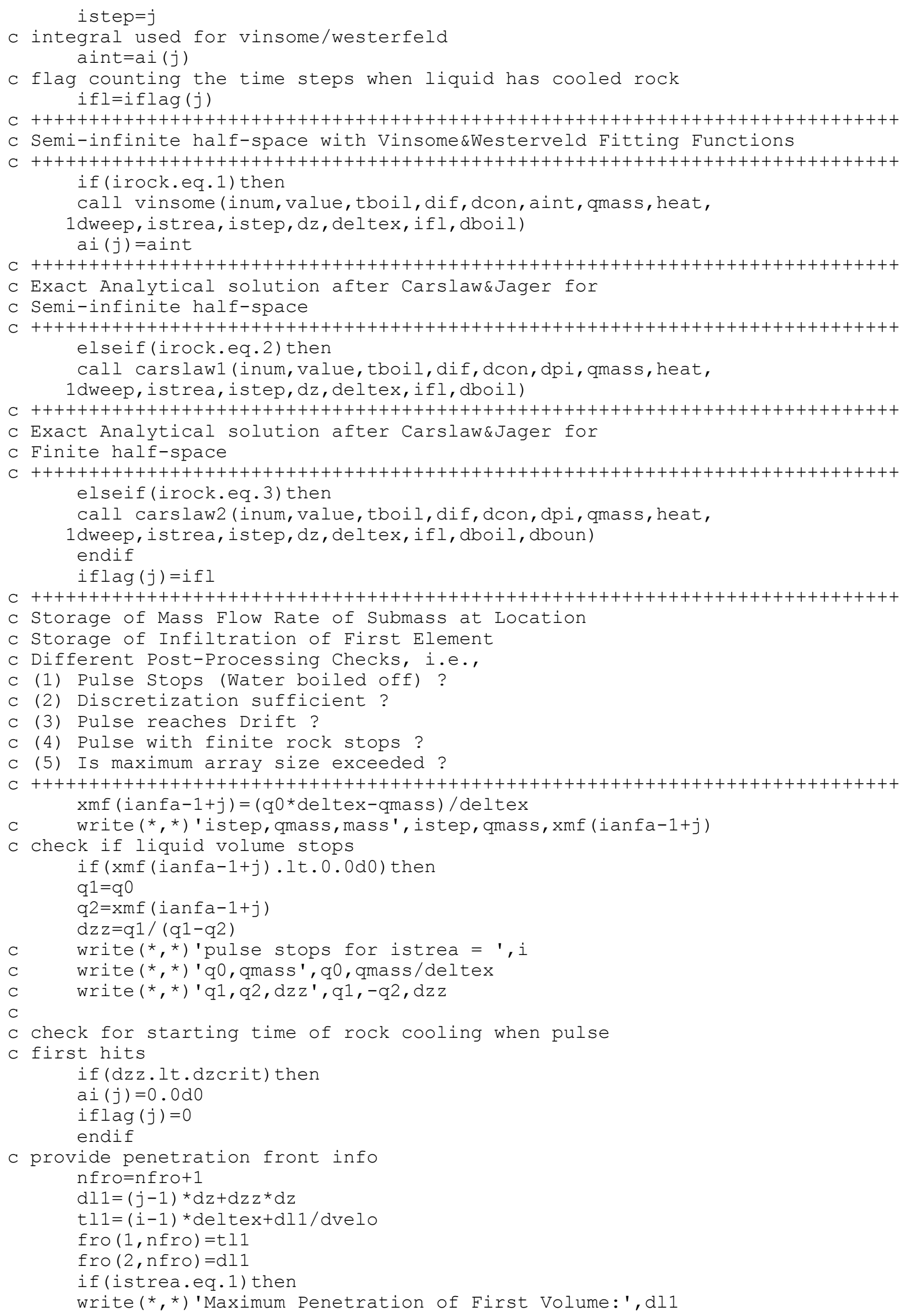


c check if first volume makes it at least over $10 \mathrm{dz}$ elements $\mathrm{zr}=\mathrm{d} l 1 / \mathrm{dz}$

if (zr.lt.10.0d0) then

write $(*, *)$

1'WARNING: first pulse only penetrates dz times', zr

irun=irun+1

$\mathrm{dzmax}=\mathrm{dl} 1 /(2.0 \mathrm{~d} 0+10.0 \mathrm{~d} 0)$

goto 99

endif

endif

$c$ find maximum penetration for last volume at tdrain

if (istrea.eq.nstrea) then

ilast $=1$

$\mathrm{dlmax}=\mathrm{dl} 1$

$t l \max =t 11$

endif

$\operatorname{xmf}(i \operatorname{anfa}-1+j)=0.0 \mathrm{~d} 0$

c check if pulse for finite boundary gets to stop

if (irock.eq.3.and.istrea.gt.1) then

$\mathrm{dll}=\mathrm{dabs}(\mathrm{dl} 1-\mathrm{dll}$ last $)$

if (dll/dll.lt.1.0e-08) then

istop $=1$

endif

endif

goto 5

endif

$c$ check if pulse reaches end of model area

if $(j . e q . n s t e p \cdot$ and. $x m f(i a n f a-1+j) \cdot g t .0 .0 d 0)$ then

c check for first arrival

if (iend.eq.0) then

iend=istrea+nstep-1

dlmax $=$ dext

tlmax $=$ iend ${ }^{*}$ deltex

endif

endif

c check if liquid volume reaches drift wall

c calculate mass reaching drift

if $(j . e q . i s t e p d$. and. $x m f(i a n f a-1+j) \cdot g t .0 .0 d 0)$ then

c calculate mass

qdrift=qdrift $+\mathrm{xmf}(i \operatorname{anfa}-1+j)$

c check for time of first arrival at drift

if (ireach.eq.0) then

ireach=istrea+istepd-1

ddmax $=$ dheat

tdmax $=$ ireach*deltex

endif

endif

$\mathrm{q} 0=\operatorname{xmf}(i \operatorname{anf} a-1+j)$

enddo

5 continue

inumb $(i)=j+1$

ianfa $=i a n f a+j+1$

if (ianfa+nstep.gt.nmax) then

if (iepiso.eq.0) nepiso=i

iepiso=1

ianfa $=1$

endif

dllast $=$ dl 1

if (istop.eq.1) goto 6

enddo

6 continue

$\mathrm{C}$

$\mathrm{C}+++++++++++++++++++++++++++++++++++++++++++++++++++++++++++++++++++++++++++$ 


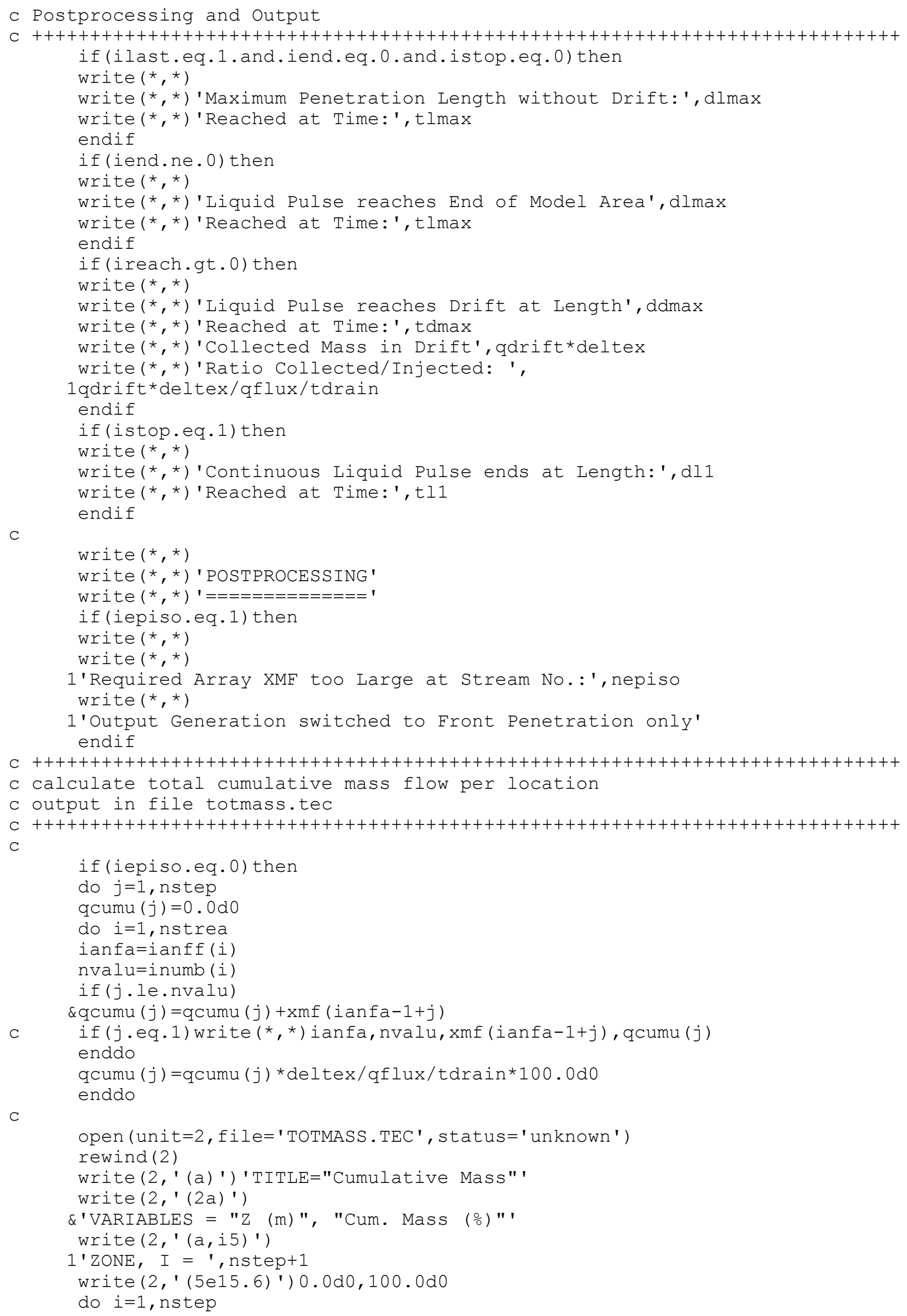




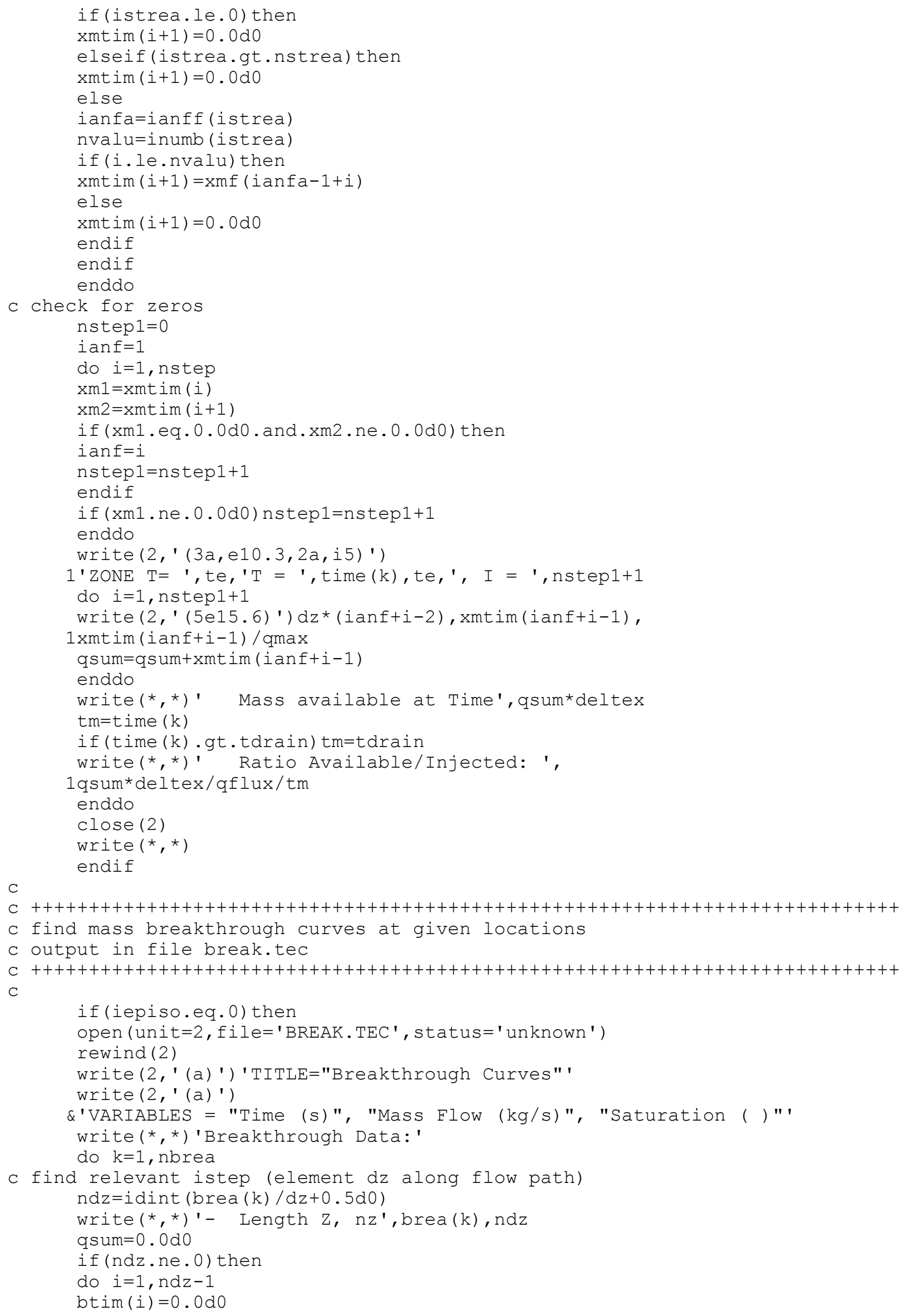




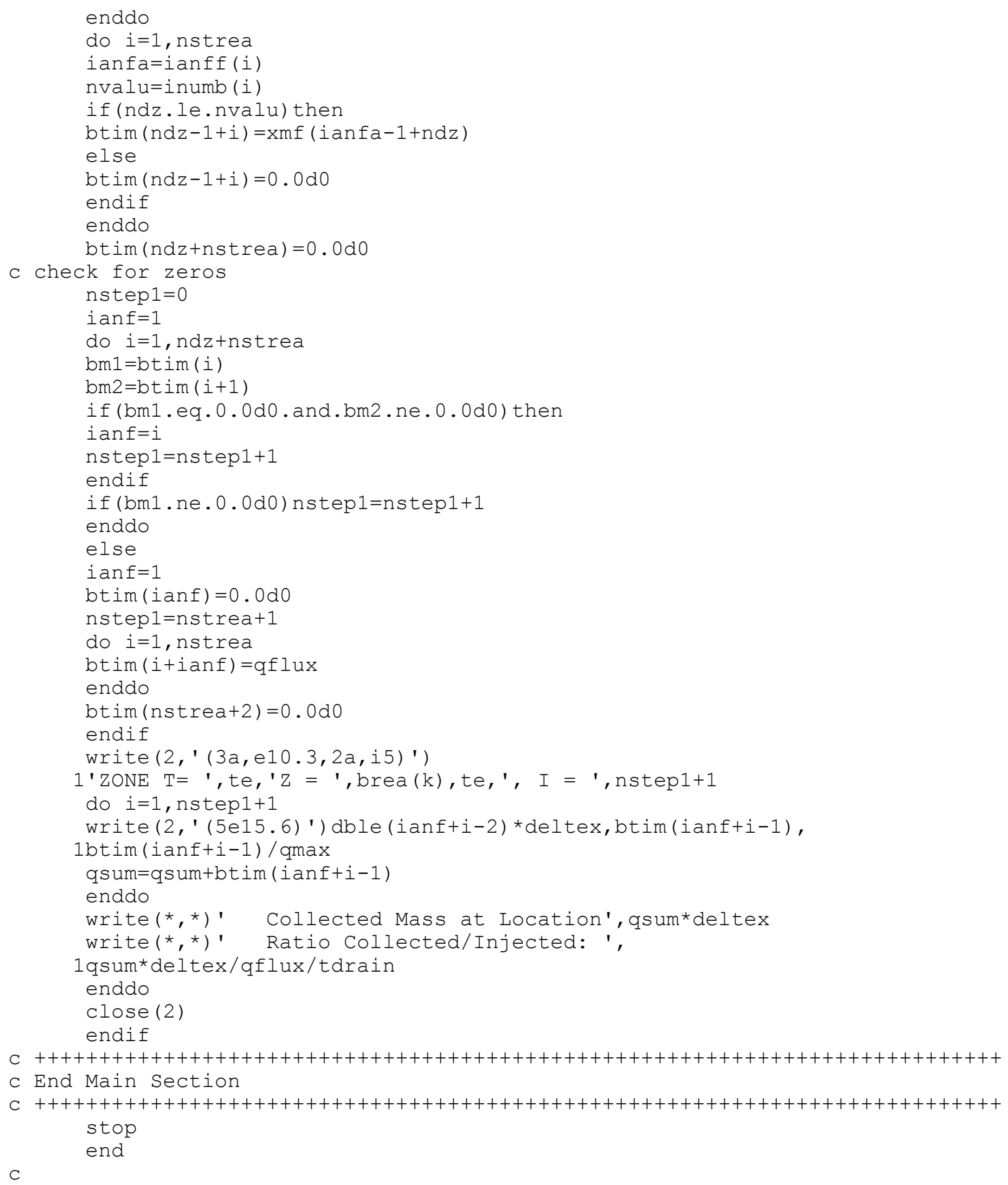




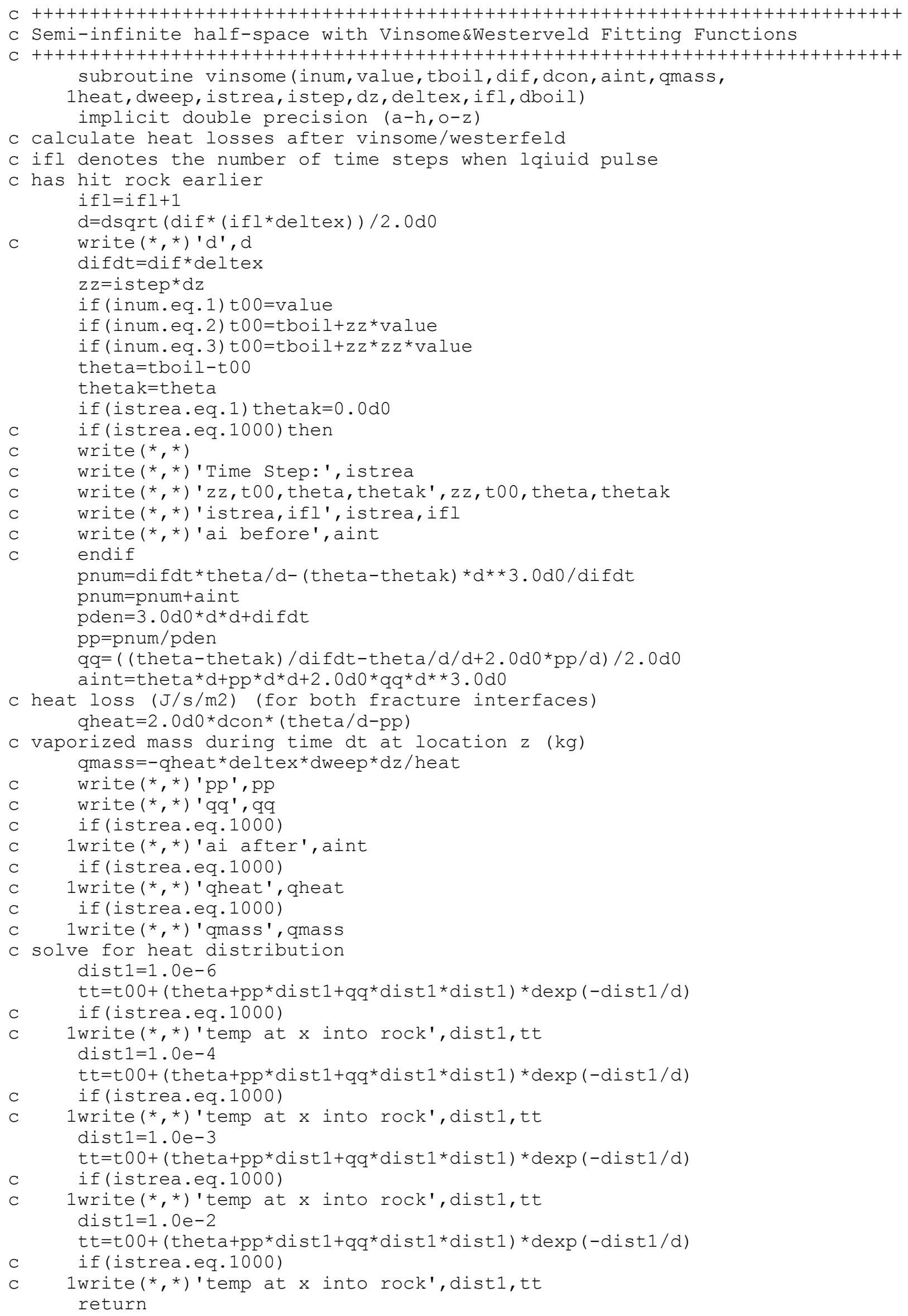


end

$\mathrm{C}+++++++++++++++++++++++++++++++++++++++++++++++++++++++++++++++++++++++++++$

c Exact Analytical solution after Carslaw\&Jager for

c Semi-infinite half-space

C +++++++++++++++++++++++++++++++++++++++++++++++++++++++++++++++++++++++++++ subroutine carslawl (inum, value, tboil, dif, dcon, dpi, qmass,

1heat, dweep, istrea, istep, dz, deltex, ifl, dboil)

implicit double precision $(a-h, o-z)$

c calculate heat losses after carslaw for semi-infinite half-space ifl=ifl+1

$d=\operatorname{dsqrt}(\operatorname{dif} *(i f l * \operatorname{deltex}))$

$z z=i$ step ${ }^{\star} d z$

if (inum.eq.1) t00=value

if (inum.eq.2) t00=tboil+zz*value

if (inum.eq. 3) t00=tboil $+z z^{*} z z^{*}$ value

theta $=$ t00-tboil

$c$ heat loss ( $\mathrm{J} / \mathrm{s} / \mathrm{m} 2$ ) (for both fracture interfaces)

qheat $=2.0 d 0 *$ dcon*theta/d/dsqrt (dpi)

c vaporized mass during time dt at location $\mathrm{z}$ (kg)

qmass $=$ qheat $*$ del tex $*$ dweep $* d z /$ heat

c if (istrea.eq.1000)then

c write $(*, *)$

write $(*, *)$ 'Time Step: ', istrea

write $(*, *) ' z z$, t00, theta', zz, t00, theta

write $(*, *)$ 'istrea, ifl', istrea, ifl

write $(*, *)$ 'qheat', qheat

write $(*, *)$ 'qmass', qmass

endif

solve for heat distribution

dist $1=1 \cdot 0 e-6$

tt=tboil+theta*derf (dist1/2.0d0/d)

c if(istrea.eq.1000)

c 1write (*,*)' temp at $\mathrm{x}$ into rock', dist1, tt dist $1=1 \cdot 0 e-4$

tt=tboil+theta*derf (dist1/2.0d0/d)

c if(istrea.eq.1000)

c lwrite (*,*) 'temp at $x$ into rock', dist1, tt dist $1=1 \cdot 0 e-3$

tt=tboil+theta*derf (dist1/2.0d0/d)

c if (istrea.eq.1000)

c lwrite (*,*)' temp at $x$ into rock', dist1, tt dist $1=1.0 e-2$

tt=tboil+theta*derf (dist1/2.0d0/d)

c if(istrea.eq.1000)

c lwrite (*,*)'temp at $x$ into rock', dist1, tt return

end

C 


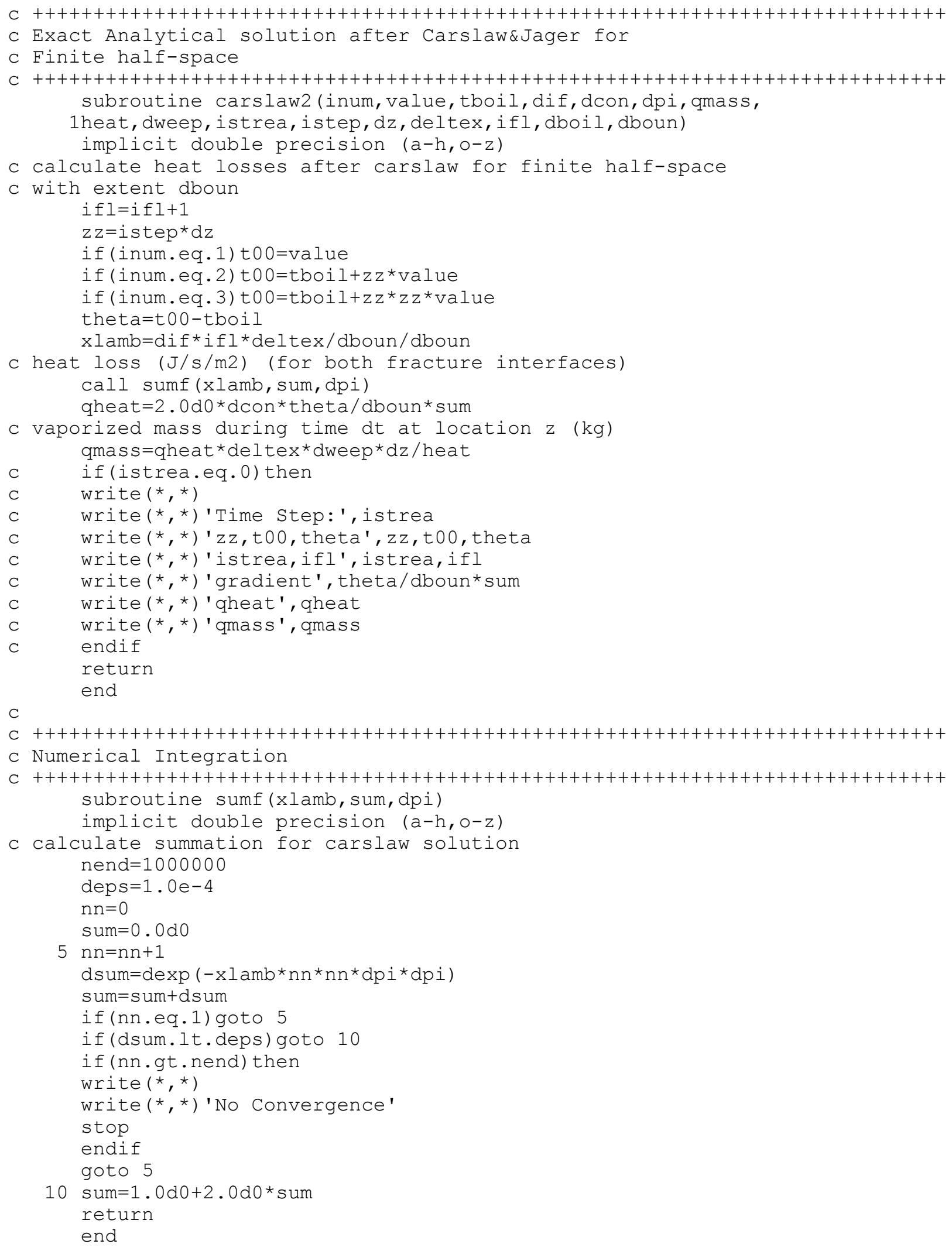

